\title{
RELATIONSHIPS BETWEEN NET PRIMARY PRODUCTION, SOIL MOISTURE AND TOPOGRAPHY IN SEMI-ARID GRASSLAND ENVIRONMENTS
}

\author{
By \\ Steven Robert Miles, B.A. (Hons)
}

A thesis submitted to

the Faculty of Graduate Studies

in partial fulfillment of

the requirements of the degree of

Master of Science

Carleton University

Ottawa, Ontario

(C) 2009 Steven Robert Miles 


\begin{abstract}
This research studies one small basin within Grasslands National Park, Saskatchewan, Canada with a focus on net primary production (NPP), soil moisture and topography. Its purpose is to examine the distribution of soil moisture with respect to topography, and to examine any relationships between NPP and soil moisture or topography. Measures of soil moisture and vegetation biomass were taken along ten transects crossing a test basin during the summer of 2005 and correlated with detailed topographic data. Results showed that the topographic index (TI) and slope were better predictors of soil moisture than upslope area, that NPP and soil moisture do not correlate well, and that TI is a stronger predictor of NPP when the data is segregated by dominant vegetation cover. The strongest predictor of NPP is upslope area, with a threshold of approximately $5.0 \mathrm{~m}^{2}$ resulting in a noticeable increase in the range of NPP.
\end{abstract}




\section{ACKNOWLEDGEMENTS}

This thesis could not have been completed without the encouragement and support of many people who deserve to be recognized.

I would like to start out by thanking Carleton University for providing me with the necessary tools and resources to complete my degree. Also, I need to express my gratitude towards my supervisor, Scott Mitchell, whose guidance, expertise, and endless patience while I finished writing, were invaluable towards the successful completion of this thesis. Thanks so much, Scott. Additional thanks to Sean Carey for providing extra input, comments and guidance on certain aspects of my research and thesis. Funding for the field season was provided by Carleton University through a grant to Scott Mitchell.

I would like to thank the staff of GNP in Val Marie, Saskatchewan for allowing me to conduct my research in the park during the summer of 2005, and for providing me with a place to hang my hat during my time there. I have to thank my classmate, Robert Martin, for visiting Val Marie and GNP in July 2005 to conduct some of my field work so I could attend my wedding and honeymoon! Thanks for covering for me, Robert. A big thanks to Pat Fargey and Rob Sissons for making me feel welcome in Val Marie and for being important sources of guidance and information regarding GNP. Thank you as well to all the residents of Val Marie, Saskatchewan, especially my "neighbour" Lise Perrault and all the staff at the Val Marie hotel bar for making my stay enjoyable.

And lastly, I want to thank my wife, Emily, for her continued emotional support during my degree and for instilling in me the value of education. Thank you so much for flying out to visit me during my field season; it truly made my time away from you much more bearable. 


\section{TABLE OF CONTENTS}

Abstract. ii

Acknowledgements.................................................................................

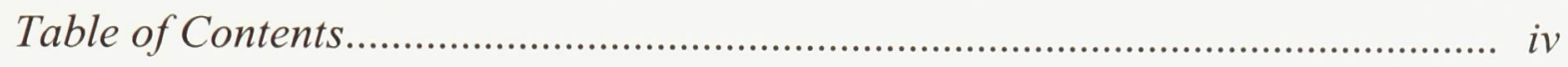

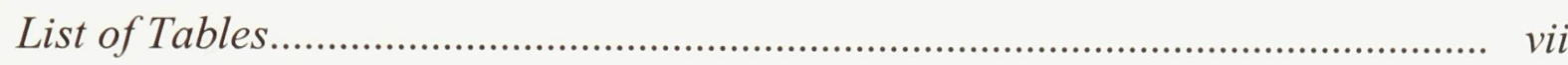

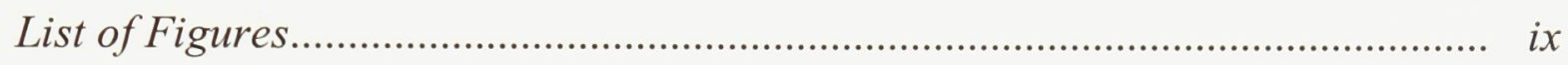

List of Appendices ........................................................................................

List of Acronyms ................................................... $x v$

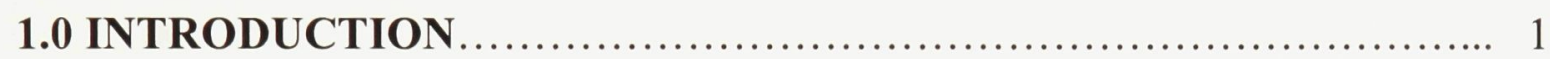

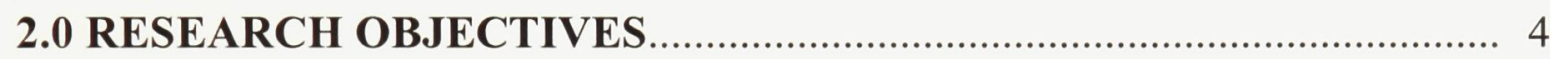

3.0 BACKGROUND

3.1 Modelling...................................................................... 6

3.2 Moisture as a Limit to Plant Growth..................................................... 7

3.3 Soil Moisture Movement (Water Energy)......................... 8

3.4 Soil-Based Factors Affecting Plant Available Moisture.............. 8

3.5 Topography as an Influence on Moisture Movement................. 11

3.6 Soil Moisture Distribution and its Measurement.................. 13

3.7 The Topographic Index.................................. 13

3.8 The Use of Topographic Indices.............................. 16

3.9 The Study of NPP ......................................... 19

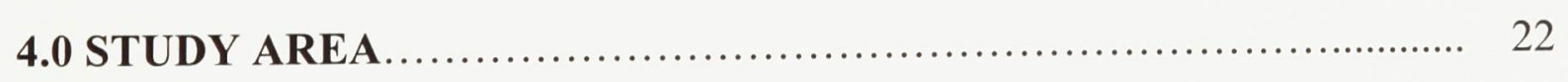

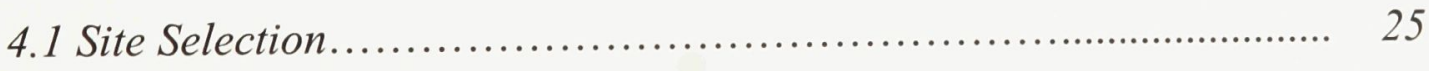

4.2 Test Basin ................................................... 25 
5.1 Measurement Tools............................................. 29

5.2 Instrument Calibration .......................................... 36

5.3 Data Preparation .............................................. 38

5.3.1 DEM and Other Raster Maps ........................... 38

5.3.2 Soil Moisture and NPP Data ........................... 40

5.3.3 Data Segregation ..................................... 41

6.0 BASIN-WIDE CHARACTERISTICS .............................. 43

6.12005 Growing Season.......................................... 43

6.2 Soil Moisture and NPP Trends in the Basin........................ 45

6.3 Basin-Wide Relationships ........................................ 51

7.0 TOPOGRAPHIC AND VEGETATION SEGREGATION.............. 56

7.1 Segregation by Landscape Position ................................... 56

7.1.1 Segregation by Hillslopes.............................. 58

7.1.1.1 West-Facing Hillslope............................. 60

7.1.1.2 East-Facing Hillslope ........................... 65

7.1.2 Segregation by Drainage Zone.......................... 68

7.2 Segregation by Vegetation Type................................ 73

7.2.1 General Moisture and NPP Patterns..................... 75

7.2.2 Grass Dominated Areas................................. $\quad 77$

7.2.3 Selaginella/Lichen Dominated Areas..................... 80

7.2.4 Other Vegetation Covers............................... 84 
8.0 SYNTHESIS

8.1 Hypotheses Summary... 88

8.2 Additional Research Findings and Explanations of Results. 93

8.3 Research Limitations. 99

9.0 CONCLUSION 103

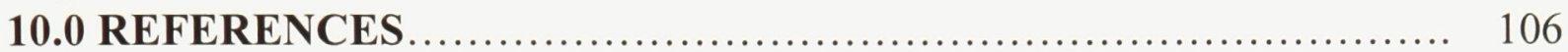

\section{APPENDICES}

A - Soil Survey Class Attributes 115 


\section{LIST OF TABLES}

Table 3.1 - Topographic indices and their effect on hydrological process (source:

Klinkenberg, 2005)

Table 4.1 - Vegetation found in various landscape types in GNP (source: Parks Canada, 2002)

Table 5.1 - Transect specifications (length in metres and the number of flags/sample sites along each transect)

Table 5.2 - HOBO weather station ECH2O probe specifications (Onset Computer Corporation, 2007)

Table 5.3 - Specifications of the CS-620 HydroSense handheld moisture probe (Campbell Scientific, Inc., 2001).

Table 6.1 - Mean, variance, and range of TI values along odd numbered transects of the test basin

Table 6.2 - Comparison of deep $(\sim 25 \mathrm{~cm})$ and shallow $(\sim 12 \mathrm{~cm})$ integrated soil moisture readings taken throughout the 2005 growing season at the top of the test basin by the weather station

Table 6.3 - Correlation strength $\left(\mathrm{R}^{2}\right)$ and significance $\mathrm{P}$ (in parentheses) between variable pairs across the entire test basin. Selections in bold are statistically significant at the $95 \%$ confidence level. Selections in green show trends that are expected, while selections in red show trends that are opposite to what is expected. Legend: NPP = net primary production, $\mathrm{SM}=$ seasonal average soil moisture $(20 \mathrm{~cm}$; 5-point moving average $)$ $(\mathrm{GWC}), \mathrm{TI}=$ topographic index, SLP $=$ slope $($ degrees $), \mathrm{UA}=$ upslope $\operatorname{area}\left(\mathrm{m}^{2}\right)$

Table 7.1 - Correlation strength $\left(\mathrm{R}^{2}\right)$ and significance $\mathrm{P}$ (in parentheses) between variable pairs within each landscape unit. Selections in bold are statistically significant at the 95\% confidence level. Selections in green show trends that are expected, while selections in red show trends that are opposite to what is expected. Underlined selections show correlations that strengthen compared to its basin-wide equivalent. Legend: NPP = net primary production, $\mathrm{SM}=$ seasonal average soil moisture $(20 \mathrm{~cm} ; 5$ point moving average) $(\mathrm{GWC}), \mathrm{TI}=$ topographic index, $\mathrm{SLP}=$ slope (degrees), $\mathrm{UA}=$ upslope area $\left(\mathrm{m}^{2}\right)$.....

Table 7.2 - Distribution of vegetation cover at the sample points in the test basin

Table 7.3 - Correlation strength $\left(\mathrm{R}^{2}\right)$ and significance $\mathrm{P}$ (in parentheses) between variable pairs within each vegetation community. Selections in bold are statistically significant at 
the $95 \%$ confidence level. Selections in green show trends that are expected, while selections in red show trends that are opposite to what is expected. Underlined selections show correlations that strengthen compared to its basin-wide equivalent. Legend: NPP $=$ net primary production, $\mathrm{SM}=$ seasonal average soil moisture $(20 \mathrm{~cm}$; 5-point moving average) $(\mathrm{GWC}), \mathrm{TI}=$ topographic index, $\mathrm{SLP}=$ slope $($ degrees $), \mathrm{UA}=$ upslope area $\left(\mathrm{m}^{2}\right)$ 76 


\section{LIST OF FIGURES}

Figure 3.1 - Relationship between aboveground net primary production and annual precipitation for a regional (spatial) model for the Central Grassland region of the U.S., and for the long-term (temporal) model developed by Lauenroth and Sala (figure source: Lauenroth and Sala, 1992) 7

Figure 3.2 - The effects of organic matter on the field capacity of soil. The field capacity is the soil water content resulting after the free water has been allowed to drain from a saturated soil for 1-2 days; expressed as a percentage on a dry-weight basis (Rose, 2001). The difference between the two lines is available soil moisture (figure source: Brady and Weil, 2002). 10

Figure 4.1 - Regional setting; GNP of Canada (source: Parks Canada, 2002).... 23

Figure 4.2 - Geographical extent of the Great Plains region of North America and showing the location of GNP (source: Parks Canada, 2002) 23

Figure 4.3 - Contour map of the test basin (contour labels in m ASL) (park map source: Parks Canada 2005b) 26

Figure 4.4 - Test basin, showing the location of GNP soil survey classes (inset; separated by the black line). One class (soil ID 254) dominates the basin, and the other class (soil ID 251) occupies a small portion of the northeast corner of the basin (See Appendix A on page 115 for soil survey class attributes) (park road map source: Parks Canada, 2005c) (University of Saskatchewan, 1991) 28

Figure 5.1 - Portion of the test basin showing sections of three transects running eastwest perpendicular to the basin orientation (highlighted in red) 30

Figure 5.2 - HOBO weather station installed at the top of the test basin 32

Figure 5.3 - CS-620 Handheld HydroSense probe used to measure soil moisture. 34

Figure 5.4 - Using the Cropscan Radiometer to measure reflected irradiation.......

Figure 5.5 - Calibration curves for converting field-measured volumetric water content (VWC \%) to gravimetric water content (GWC) (A), and for converting field-measured NDVI to areal biomass $\left(\mathrm{g} \mathrm{m}^{-2}\right)$ (B) 37

Figure 5.6 - Final DEM of the test basin, showing the 10 sample transects. Vertical exaggeration $=3.0$

Figure 6.1 - GNP average daily growing season air temperature (1994 - 2004 from archival records [Parks Canada, 2003; Meteorological Service of Canada, 1997; Meteorological Service of Canada, 2004], plus measurements from the 2005 growing 
season). Y-error bars show 1 standard deviation from the growing season mean.. 44

Figure 6.2 - Total precipitation during growing season (1994- 2004 from archival records [Parks Canada, 2003, Meteorological Service of Canada, 1997, Meteorological Service of Canada, 2004], plus 2005 growing season) 44

Figure 6.3 - Test basin DEM, showing draped TI map. Vertical exaggeration $=3.0$ 46

Figure 6.4 - Line graph showing the distribution of TI values along the odd numbered transects (even numbered transects excluded for simplicity). Special flag/drainage zone marker is true for transects that have a single low point (T5 - T9) and denotes an approximate center point for $\mathrm{T} 1$ and $\mathrm{T} 3$ for comparison purposes

Figure 6.5 - Distribution of seasonal average soil moisture readings $(20 \mathrm{~cm}$; 5-point moving average) (GWC) across the entire basin 48

Figure 6.6 - Deep and shallow integrated soil moisture readings (GWC), and precipitation events $(\mathrm{mm})$, measured continually throughout the 2005 growing season; measured at the top of the basin by the weather station. Shallow probe $(\sim 5 \mathrm{~cm})$ excluded as it showed similar patterns............................................... 50

Figure 6.7 - Distribution of NPP measurements across the entire basin $\left(\mathrm{g} \mathrm{m}^{-2}\right) \ldots 51$

Figure 6.8 - Bivariate correlation of seasonal average soil moisture $(20 \mathrm{~cm}$; 5-point moving average) (GWC) and TI (A) and slope (degrees) (B) across the entire basin

Figure 6.9 - Bivariate correlation of NPP $\left(\mathrm{g} \mathrm{m}^{-2}\right)$ and soil moisture $(20 \mathrm{~cm} ; 5$-point moving average) (GWC) (A), slope (degrees) (B) and upslope area $\left(\mathrm{m}^{2}\right)(\mathbf{C})$ across the entire basin .......................................................... 54

Figure 6.10 - Areas in the test basin with upslope areas $>5.0 \mathrm{~m}^{2}$ (in red). Vertical

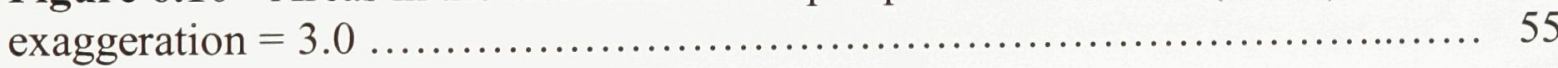

Figure 7.1 - West (on the left) and east (on the right) facing hillslopes of the basin (in red), as defined by those portions of the basin where TI values were less than 5.5 and the elevation was less than $852 \mathrm{~m}$ ASL $(<852 \mathrm{~m})$. Vertical exaggeration $=3.0 \ldots \ldots \ldots 58$

Figure 7.2 - Bivariate correlation of seasonal average soil moisture $(20 \mathrm{~cm}$; 5 -point moving average) (GWC) and TI (A) and slope (degrees) (B) on the basin hillslopes

Figure 7.3 - Bivariate correlation of NPP $\left(\mathrm{g} \mathrm{m}^{-2}\right)$ and upslope area $\left(\mathrm{m}^{2}\right)$ on the basin hillslopes 
Figure 7.4 - Bivariate correlation of seasonal average soil moisture $(20 \mathrm{~cm}$; 5-point moving average) (GWC) and TI (A), slope (degrees) (B) and upslope area $\left(\mathrm{m}^{2}\right)(\mathbf{C})$ on the west-facing hillslope of the test basin

Figure 7.5 - Bivariate correlation of NPP $\left(\mathrm{g} \mathrm{m}^{-2}\right)$ and seasonal average soil moisture (20 $\mathrm{cm}$; 5-point moving average) (GWC) on the west-facing hillslope of the test basin

Figure 7.6 - Distribution of NPP measurements on the west-facing hillslope of the test basin $\left(\mathrm{g} \mathrm{m}^{-2}\right)$ 63

Figure 7.7 - Bivariate correlation of NPP $\left(\mathrm{g} \mathrm{m}^{-2}\right)$ and upslope area $\left(\mathrm{m}^{2}\right)$ on the westfacing hillslope of the test basin 65

Figure 7.8 - Bivariate correlation of seasonal average soil moisture $(20 \mathrm{~cm}$; 5-point moving average) (GWC) and slope (degrees) (A) and upslope area $\left(\mathrm{m}^{2}\right)(\mathbf{B})$ on the eastfacing hillslope of the test basin 66

Figure 7.9 - Bivariate correlation of NPP $\left(\mathrm{g} \mathrm{m}^{-2}\right)$ and seasonal average soil moisture (20 $\mathrm{cm}$; 5-point moving average) (GWC) on the east-facing hillslope of the test basin

Figure 7.10 - Distribution of NPP measurements on the east-facing hillslope of the test basin $\left(\mathrm{g} \mathrm{m}^{-2}\right)$ 67

Figure 7.11 - Bivariate correlation of NPP $\left(\mathrm{g} \mathrm{m}^{-2}\right)$ and upslope area $\left(\mathrm{m}^{2}\right)$ on the eastfacing hillslope of the test basin 68

Figure 7.12 - Drainage zone of the basin (in red), as defined by those portions of the basin where TI values were greater than 5.5 and the elevation was less than $851 \mathrm{~m} \mathrm{ASL}$ $(<851 \mathrm{~m})$. Vertical exaggeration $=3.0$ 69

Figure 7.13 - Bivariate correlation of seasonal average soil moisture $(20 \mathrm{~cm}$; 5-point moving average) (GWC) and TI (A), slope (degrees) (B) and upslope area $\left(\mathrm{m}^{2}\right)(\mathbf{C})$ in the drainage zone of the test basin 70

Figure 7.14 - Distributions of TI values and seasonal average soil moisture $(20 \mathrm{~cm}$; 5point moving average) (GWC) in the drainage zone of the test basin ............ 71

Figure 7.15 - Bivariate correlation of NPP $\left(\mathrm{g} \mathrm{m}^{-2}\right)$ and seasonal average soil moisture (20 $\mathrm{cm}$; 5-point moving average) (GWC) in the drainage zone of the test basin....... 72

Figure 7.16 - Bivariate correlation of NPP $\left(\mathrm{g} \mathrm{m}^{-2}\right)$ and slope (degrees) (A) and upslope area $\left(\mathrm{m}^{2}\right)(\mathbf{B})$ in the drainage zone of the test basin 
Figure 7.17 - Photograph of the test basin, taken from the north (outlet) end, illustrating the diversity of vegetation cover in the basin. Lighter areas are mainly grass and/or selaginella/lichen, while the blue coloured plants are considered forbs/shrubs. The dark patch at bottom-center (and the smaller patch halfway up the basin above it) is mainly juniper

Figure 7.18 - Bivariate correlation of seasonal average soil moisture $(20 \mathrm{~cm}$; 5-point moving average) (GWC) and TI (A), slope (degrees) (B) and upslope area $\left(\mathrm{m}^{2}\right)$ (C) in grass dominated areas of the test basin 78

Figure 7.19 - Distribution of seasonal average soil moisture readings $(20 \mathrm{~cm} ; 5$-point moving average) (GWC) in grass dominated areas of the basin................. 79

Figure 7.20 - Bivariate correlation of NPP $\left(\mathrm{g} \mathrm{m}^{-2}\right)$ and seasonal average soil moisture (20 $\mathrm{cm}$; 5-point moving average) (GWC) (A) and upslope area $\left(\mathrm{m}^{2}\right)(\mathbf{B})$ in grass dominated areas of the test basin 80

Figure 7.21 - Bivariate correlation of seasonal average soil moisture $(20 \mathrm{~cm}$; 5-point moving average) (GWC) and TI (A), slope (degrees) (B) and upslope area $\left(\mathrm{m}^{2}\right)(\mathbf{C})$ in selaginella/lichen dominated areas of the test basin 82

Figure 7.22 - Bivariate correlation of NPP $\left(\mathrm{g} \mathrm{m}^{-2}\right)$ and seasonal average soil moisture (20 $\mathrm{cm}$; 5-point moving average) (GWC) (A), TI (B), and slope (degrees) (C) in selaginella/lichen dominated areas of the test basin..........................

Figure 7.23 - Distribution of seasonal average soil moisture readings $(20 \mathrm{~cm}$; 5 -point moving average) (GWC) in selaginella/lichen dominated areas of the basin..... 84

Figure 7.24 - Bivariate correlation of seasonal average soil moisture $(20 \mathrm{~cm}$; 5-point moving average) (GWC) and TI in forb/shrub dominated areas (A) and in eroded areas

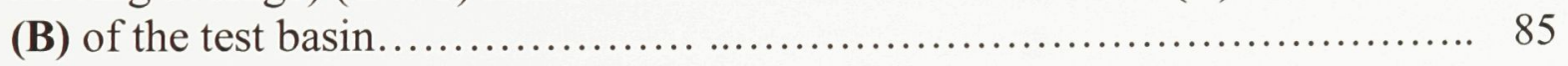

Figure 7.25 - Bivariate correlation of seasonal average soil moisture $(20 \mathrm{~cm}$; 5-point moving average) (GWC) and slope (degrees) in forb/shrub dominated areas of the test basin 86

Figure 7.26 - Bivariate correlation of NPP $\left(\mathrm{g} \mathrm{m}^{-2}\right)$ and upslope area $\left(\mathrm{m}^{2}\right)$ in forb/shrub dominated areas (A) and eroded areas (B) of the test basin................... 87

Figure 8.1 - Areas in the test basin with upslope areas $>5.0 \mathrm{~m}^{2}$ (in red). The range and variability of NPP increased in the red areas, which corresponded to an increase in

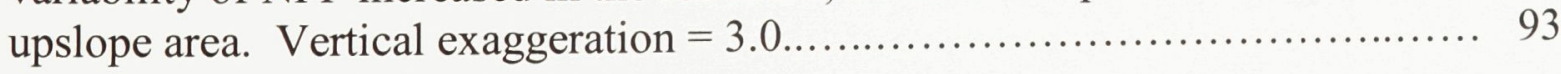

Figure 8.2 - Soil moisture content (GWC) at varying depths, and precipitation events $(\mathrm{mm})$ for a sample pasture in GNP, measured continually from June 28, 2008 to August 21, 2008 (R. Virk, unpublished data, 2008) 
Figure 8.3 - Schematic two-dimensional diagram of Park's pedogeomorphological unit classification system (figure source: Park et al., 2001) 100 


\section{LIST OF APPENDICES}

APPENDIX A - Soil Survey Class Attributes ............................... 115 


\section{LIST OF ACRONYMS}

DEM - Digital Elevation Model

GNP - Grasslands National Park

GWC - Gravimetric Water Content

NDVI - Normalized Difference Vegetation Index

NPP - Net Primary Production

PAR - Photosynthetically Active Radiation

RHESSys - Regional Hydro-Ecologic Simulation System

TDR - Time-Domain Reflectometry

TI - Topographic Index

VWC - Volumetric Water Content 


\subsection{INTRODUCTION}

In numerous environments worldwide, soil moisture is one of the most influential variables controlling various hydrologic processes, such as flooding, erosion, solute transport, land-atmosphere interactions and plant growth (Western and Bloschl, 1999). Globally, grasslands are one of the most important ecosystems. They make up the largest terrestrial biome, comprising approximately $20 \%$ of all terrestrial land cover, and play an important role in the global carbon cycle, containing about $30 \%$ of global carbon stocks (Ojima et al., 1996; Parton et al., 1996). In addition, grasslands are important economically, containing the majority of the grain growing capacity of the world (Burke et al., 1989). Therefore, it is beneficial to understand and be able to predict the role of soil moisture distribution in grassland environments, and its impact on vegetation.

Topography has a major influence on the distribution of soil moisture (Wigmosta et al., 1994), especially in uneven, rolling regions. It is the most important factor controlling not only soil water distribution, but also organic matter, nutrients, soil textural composition and other soil properties that affect plant growth (Si and Farrell, 2004). Topography influences the spatial distribution of soil moisture by affecting its lateral flow (Wilson et al., 2005), thus playing a role in where soil moisture accumulates and becomes available to be taken up by plants. However, the dominance of this influence differs greatly between environments. It influences soil moisture more consistently in humid environments, because in drier environments, soil moisture distribution and availability is affected more by vertical fluxes, evapotranspiration (Grayson et al., 1997; Western et al., 1999) and soil characteristics (Freer at al., 1997). 
The distribution of soil moisture across a hillslope is highly variable in space and time, making it important that methods are in place that accurately measure soil moisture and estimate its areal distribution. Current methods to estimate soil moisture include i) field measurements, ii) measurements via remotely sensed data, and iii) estimation through the application of simulation models (Grayson and Western, 1998). While all three methods are somewhat interdependent (i.e. methods ii) and iii) rely on ground measurements of some sort), a mismatch in scale often exists between the field (point) measurements and the areal estimates obtained from remotely sensed data and simulation modelling (Grayson and Western, 1998). While remotely sensed data potentially give spatial patterns, interpretation of the signal is often difficult (Western and Bloschl, 1999). The alternative is to use field data alone, or use the two in conjunction with each other.

It has been suggested that there is a lack of reliable methods for measuring the spatial distribution of soil moisture. Grayson and Western (1998) note that sampling strategies that use present (point) techniques and are able to provide accurate and precise estimates of areal soil moisture should be attracting the most attention, because the limited availability of detailed spatial measurements has impeded the progress in understanding the spatial dynamics of soil moisture. Extending from that, Wilson et al. (2005) claim that no method of reliably measuring the spatial distribution of soil moisture content in the root zone yet exists, so a method of interpreting point measurements in a spatial context is required. This stresses the importance of developing a strong sampling method for measuring soil moisture, of having modelling techniques that accurately predict soil moisture, and suggests that soil moisture is often difficult to predict and that 
measurements usually characterize small areas. Due to the importance of soil moisture to plants, especially in dry grasslands regions, the demand for predictions over larger areas is significant, so any tests on the reliability and feasibility on potential modelling strategies is important. The topographic index (TI), a derivative of digital elevation models (DEMs), is a commonly used parameter in many hydrological models that predict areas of soil moisture accumulation and moisture distribution across hillslopes. Despite its demonstrated predictive power in numerous environments (i.e. Burt and Butcher, 1985; Ladson and Moore, 1992; Moore and Thompson, 1996; Nyberg 1996; Moore et al. 1988; Zavlasky and Sinai, 1981), its suitability for drier environments is not well tested. Therefore, testing is required to judge its potential to help predict soil moisture in semiarid grasslands.

Due to the effects of available soil moisture on plant growth in drier regions, understanding the influence of topography on soil moisture distribution is important, and tools should be in place that facilitate the prediction of soil moisture. Secondly, if we are to successfully manage the Grasslands National Park (GNP) environment, it is important to understand the dependence of soil moisture on topography, and the impacts of this relationship on net primary production (NPP) because it is also highly constrained by minimally available soil moisture in these climates (Fuhlendorf and Smeins, 1996). 


\subsection{RESEARCH OBJECTIVES}

This research will test the relationships among three important variables in grasslands: NPP, soil moisture, and topography (as expressed by the TI and its two main components, slope and upslope area) in the Grasslands National Park (GNP), Saskatchewan, Canada.

The hypotheses of this thesis are:

i) that soil moisture will be positively correlated to TI (and, by extension, slope will be negatively correlated and upslope areas positively correlated),

ii) that above-ground NPP will be positively related to soil moisture and TI (and, by extension, slope will be negatively correlated and upslope areas positively correlated), and

iii) that the reduced heterogeneity within specific landscape positions and vegetation communities will strengthen the relationships among NPP, soil moisture and topography.

Because TI, slope and upslope area (referred to as the topographic variables in this study) are among the commonly used methods to characterize topography, this thesis will contribute by testing how well the TI applies to predict soil moisture in drier environments. Extending from that logic, testing to see whether the individual components of TI are correlated with soil moisture in such a way that contributes to the predictive power of TI for soil moisture will help further understand its applicability. The applicability of TI to predict NPP will also be tested in drier environments and 
whether any thresholds of NPP with respect to soil moisture and TI exist. Due to time restrictions, this research will focus on within season variations (i.e. only during one summer growing season), measurements of soil moisture and estimates of above-ground NPP. 


\subsection{BACKGROUND}

\subsection{Modelling}

An environmental system is a set of logical operations acting upon, and acted upon by, one or more inputs (Bennett and Chorley, 1978) and the elements within a system are linked by flows of mass and/or energy. In science, we are always attempting to better understand system properties, and one method of achieving this is through the use of models. Models are idealized and structured representations of these systems (Johnston et al., 1994, p.385) and contain their essential elements. The elements contained within a model are those that are critical in the context of the problem one is attempting to solve or describe. Models are based on a defined relation between elements (variables), usually implying that they are causally related to each other.

In environmental modelling, models are not strictly theoretical (created from theory) but tend to be both empirically-based (based on experience or observational information) and based on well known physical laws that relate the elements of a system to each other. Thus, models are invaluable in science, offering an alternative to field experimentation in that they can be used repeatedly, at various resolutions and extents without any disturbance to the study area. Models are not only valuable tools for predicting how an environmental system behaves, but they can also provide an indication as to the level of our knowledge of a system. If a model does not predict or behave as planned, this may suggest that there is a component of the system that is not well understood by the researcher. 


\subsection{Moisture as a Limit to Plant Growth}

Moisture availability is one of the single most important factors governing the structure and functioning of ecosystems in dry environments (Singh et al., 1998).

Specifically, NPP has shown to be positively related to mean annual precipitation in grassland environments (Lauenroth and Sala, 1992; Paruelo et al., 1999), suggesting that if precipitation (and therefore soil moisture availability) is low, grassland growth will be negatively affected (Figure 3.1). Precipitation in GNP is relatively low and variable, resulting in limited available soil moisture. This puts a strong constraint on grassland NPP. In order to understand the dependence of soil moisture on topography, and the impacts of this relationship on NPP, we require models that accurately characterize the distribution of soil moisture as well as measurement techniques that capture the full array of characteristics of the environment being studied.

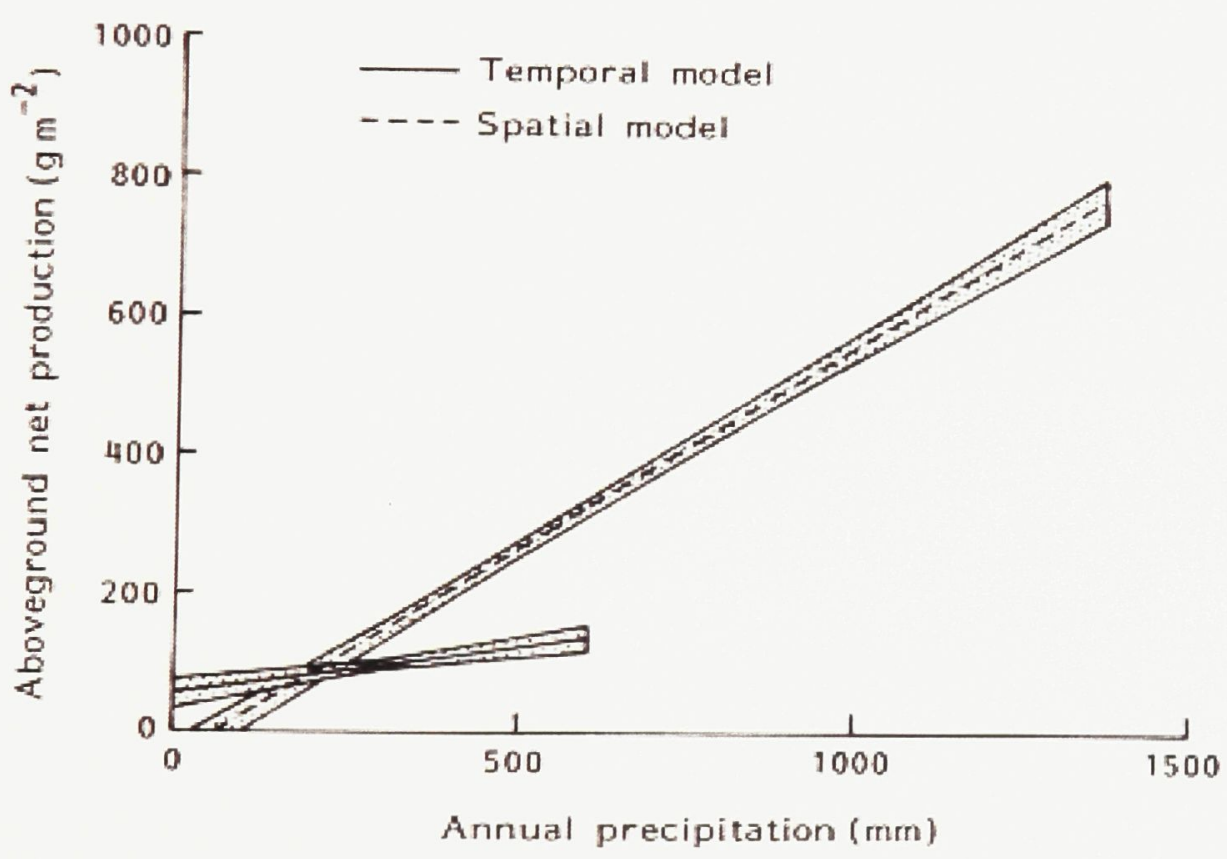

Figure 3.1 - Relationship between aboveground net primary production and annual precipitation for a regional (spatial) model for the Central Grassland region of the U.S., and for the long-term (temporal) model developed by Lauenroth and Sala (figure source: Lauenroth and Sala, 1992). 


\subsection{Soil Moisture Movement (Water Energy)}

The movement of moisture through soil, its uptake and translocation in plants, as well as its loss to the atmosphere are all energy related, with the potential energy of soil moisture acting as the most important factor in determining the status and movement of the moisture (Brady and Weil, 2002). This energy is controlled by three major factors. The attraction of water molecules to solids and ions are two factors, both of which reduce the energy state of water near particle surfaces as well as in the soil solution (called matric and osmotic forces respectively). As a result, moisture will move from wetter soil (higher energy) to drier soil (lower energy), or pure water (higher energy) will move towards a solution (lower energy) across a semi-permeable membrane, for example. Gravity is the third major force affecting the movement of soil moisture by pulling water downward due to differences in energy levels between moisture at a higher elevation and moisture at a lower elevation in the profile (Brady and Weil, 2002). These differences in energy determine the direction and rate of moisture movement in soils (Brady and Weil, 2002). In drier environments such as GNP, moisture in the soil tends to be located in small pores and thin water films, therefore being held tightly by the soil solids (Brady and Weil, 2002). This causes moisture movement to be limited in drier soils because of the reduced energy level.

\subsection{Soil-Based Factors Affecting Plant Available Moisture}

Numerous factors combine to affect the amount of soil moisture available for plant uptake, including soil texture, organic composition and osmotic potential (solute levels), soil compaction, and soil depth and layering (Brady and Weil, 2002). Soil texture 
has been shown to be an important limiting factor in a study by Singh et al. (1998) in north-central Colorado, USA. Their study underlined the importance of the variability in soil texture as a governing factor for soil water storage, with precipitation inputs being stored according to the distribution of soil particles; the moisture holding capacity of soils is predominantly determined by soil texture and depth. Soil water throughout a sample profile was highest in a clay/loam site and the site was also characterized by the greatest vegetation cover. The clay/loam soils also showed the expected gradient of increased soil moisture storage in the lowland landscape positions. The least amount of soil moisture was stored in a sandy/loam site.

The organic composition of the soil affects plant available moisture by increasing its moisture holding capacity (Figure 3.2). A higher percentage of soil organic matter by weight helps to stabilize soil structure, increase total soil volume and the size of soil pores (Brady and Weil, 2002). This raises the moisture holding capacity of the soil. Related to this is the osmotic potential (solute levels) of soil. The presence of soluble salts, such as fertilizers or naturally occurring compounds reduces available moisture, and this becomes more important in dry regions, where an already limited amount of moisture is further affected by the presence of soluble salts (Brady and Weil, 2002).

The third factor is soil compaction. A more compact soil can hold less moisture than one that is less compact. A decrease in bulk density due to crushed soil pores and a decrease in total pore space are the major factors leading to this negative effect. In addition to a lower moisture holding capacity, the ability for roots to penetrate a highly 
compacted soil is decreased (Brady and Weil, 2002). Several studies have examined the effects of soil compaction on plant growth, and all have shown that soil compaction affects plant growth, mainly through restricting root expansion and extension (Nadian et al., 1997; Grzesiak et al., 2002; Rhoades et al., 2003; Kristoffersen and Riley, 2005).

Lastly, soil depth and layering affect the amount of available soil moisture through impervious layers which can slow down the rate of water movement and also restrict root penetration to certain depths (Brady and Weil, 2002).

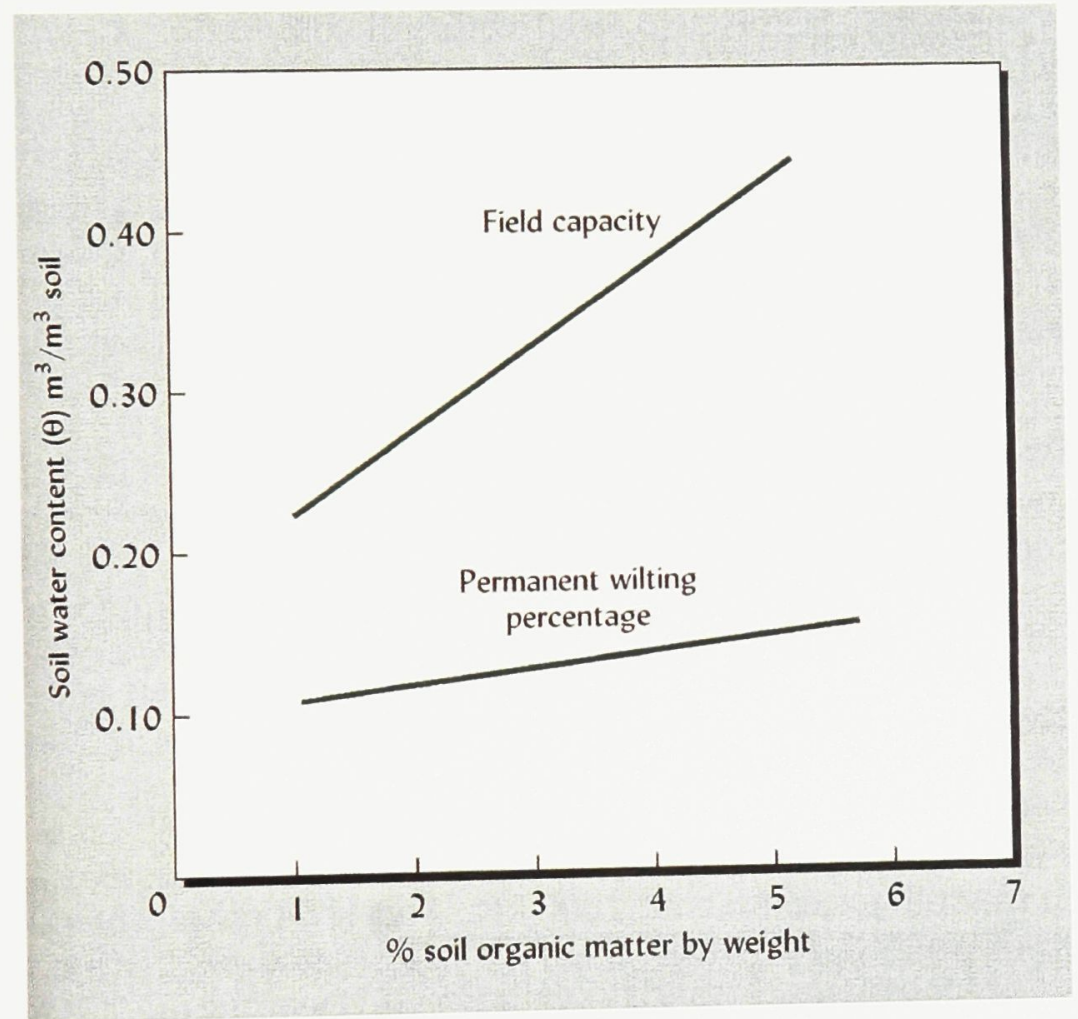

Figure 3.2 - The effects of organic matter on the field capacity of soil. The field capacity is the soil water content resulting after the free water has been allowed to drain from a saturated soil for 1-2 days; expressed as a percentage on a dry-weight basis (Rose, 2001). The difference between the two lines is available soil moisture (figure source: Brady and Weil, 2002). 


\subsection{Topography as an Influence on Moisture Movement}

Rolling terrain is an important influence on soil moisture because the effect of gravity becomes more variable than on flatter terrain. Slope influences water flow rates, absorption of surface water, and seepage of sub-surface flow in such a way that steeper slopes have a greater ability to drain water more quickly, meaning they tend to have a lower soil water content than flatter terrain (Sulebak et al., 2000), and this has been shown in several studies (Hills and Reynolds, 1969; Moore et al., 1988; Nyberg, 1996). Furthermore, lowland areas are expected to be wetter than upland areas, and this effect has been shown by Knapp et al. (1993) in their study of a subhumid tallgrass prairie in eastern Kansas. Topography further affects moisture movement through the concept of a catena. A catena is a grouping of soils and vegetation that occurs on the landscape, with each grouping differing from others because of the effects of topography on horizontal and vertical water movement (Milne, 1935). The thickness of the A horizon, solum depth and proportion of fine particles should increase from the convex positions (upland) of a basin to the concave (lowland) positions as a function of moisture movement (Milne, 1936).

In these environments, snowfall comprises only one-third of the annual precipitation, but over $80 \%$ of the annual runoff is derived from snowmelt (Gray et al., 1989), making snow accumulation a primary factor controlling prairie runoff generation. Numerous topographic effects have been shown to affect snow accumulation (Pomeroy et al., 1993). Snow accumulation has been shown to increase with rising vegetation height (Pomeroy and Gray, 1994, 1995), and snow depth has been shown to increase with the 
degree of topographic sheltering in the immediate vicinity of a site (i.e. accumulation in topographically sheltered sites) mainly due to minimized effects of prevailing winds (Lapen and Martz, 1996). This pattern of accumulation can lead to the retention of snowmelt runoff, soil moisture replenishment and shallow groundwater recharge in these small depressions (i.e. more sheltered sites) and concave areas (Hayashi et al., 2003). Consequently, there is a definite link between topography and soil moisture availability. A firm understanding of the relationship between topography and soil moisture availability/distribution, can lead to a more complete understanding of the relationship between soil moisture and NPP.

In addition to topographic factors, another important variable affecting plant available moisture is the rate at which moisture is evaporated from the plant leaves (Brady and Weil, 2002). This information is commonly obtained from estimating evapotranspiration; the combined loss of moisture directly from the soil and from the leaf surfaces after plant uptake (Brady and Weil, 2002). Evapotranspiration is largely driven by factors such as air temperature, cloud cover (which affects incoming solar radiation), and wind speed and turbulence, all of which influence the vapour pressure gradient between a wet soil or a plant and the atmosphere (Brady and Weil, 2002). Aspect also influences moisture through evapotranspiration, because energy inputs differ depending on the direction a hillslope faces (Wilson et al., 2005). 


\subsection{Soil Moisture Distribution and its Measurement}

Field measurements of soil moisture often measure a surrogate (e.g. soil moisture probes that measure the soil's dielectric constant) and must therefore be calibrated against gravimetric samples (Wilson et al., 2003). Gravimetric samples are currently the only way to obtain a direct measurement of soil moisture and are therefore a standard means for calibration. Gravimetric sampling is a method whereby soil cores are removed from the environment and weighed, followed by drying in an oven. Once dried, samples are re-weighed, with the weight loss representing the amount of soil water that was present in the soil.

Field measurements of the spatial distribution of soil moisture are typically carried out using time-domain reflectometry (TDR) techniques using moisture probes, and by making many point measurements within an area (Wilson et al., 2003). A major limitation to this, however, is that only relatively small areas can be sampled and the data are always point samples, making the transition from point measurements to areal distribution of soil moisture difficult. Western and Bloschl (1999) point out that field data are often collected in small catchments, while soil moisture predictions are needed in large catchments. They also note that samples are often spaced too widely, suggesting that there is a need for improved methods to measure the distribution of soil moisture.

\subsection{The Topographic Index}

A primary focus of this research was to test the feasibility of modelling the horizontal distribution of soil moisture across a hillslope with respect to topography. 
Hillslopes are normally the half-basins generated by the same delineation as watershed/basin mapping, and they are defined as areas that drain to a single point or stream reach (Tague et al., 2001). The topographic index (TI) can be used to describe and model the topographic controls on soil water. The upslope contributing area and the slope of the terrain are the two most important characteristics of a hillslope that influence the likelihood of areas of saturation developing (Hornberger et al., 1998), therefore, TI is calculated using the following equation:

$$
T I=\ln (a / \tan \beta)
$$

where $a$ is the upslope contributing area per unit contour length $(A / c)$ (the area above a contour segment divided by the length of that segment; a measure of the potential area that can contribute lateral flow through a unit contour length [Western et al., 1999]) and $\tan \beta$ is the local slope (Hornberger et al., 1998). Hydrological models that use the TI (e.g. RHESSys [Tague and Band, 2004]) to predict water distribution assume that subsurface groundwater flow dominates soil water distribution and that any given point in the catchment is connected to its upslope area ( $\mathrm{Si}$ and Farrell, 2004). They aim to represent the key hydrological processes controlling the spatial distribution of soil moisture in a simplified but realistic way, and assume that topography is dominant in controlling and modifying the hydrologic processes operating in the landscape (Western et al., 1999). Original developments of topographic indices were used to predict zones of surface saturation, but they have also been used to predict patterns of soil moisture and saturation deficit (Western et al., 1999). One commonly used tool for predicting soil 
moisture distribution is the hydrological model TOPMODEL (TOPography MODEL) (Beven and Kirkby, 1979). It is based on the idea that topography exerts a dominant control on flow routing through upland catchments, and it has long been used to explore how precipitation can be routed through a catchment (the area contributing flow to a point on a drainage system) to calculate streamflow (Hornberger et al., 1998). While streamflow is an important part of the hydrologic cycle, its effect on plant productivity is minimal (Hornberger et al., 1998). The present study concentrates on soil moisture in the plant rooting zone.

In the early 1990s, the development and increased availability of digital elevation models (DEM) that provide highly accurate and increasingly important topographic information made the use of topographic indices more appealing as a readily available data source (Zeleke and Si, 2004). Mapping the distribution function back into space to predict the soil moisture (or saturation deficit) pattern is possible from topographic indices, although this is generally only true where gravity dominates drainage (Western et al., 1999). High values of the TI reveal areas with large contributing areas and relatively flat slopes. These areas are typically found at the foot of the hillslope and near the stream draining the basin. Lower values of the TI are found at the tops of hills, in regions with little upslope contributing areas and steeper slopes (Hornberger et al., 1998). The spatial nature of topographic indices makes them particularly attractive for use with remotely sensed data (i.e. digital elevation models [DEMs]) (Western et al., 1999). Topographic indices are often regarded as composite parameters, summarizing the collective interactions of various yield-affecting factors and their interactions (Si and Farrell, 2004). 


\subsection{The Use of Topographic Indices}

While topographic indices are considered very useful tools in hydrological modelling, their value ultimately stems from their predictive ability (i.e. how well they explain the spatial variability of soil moisture) (Western et al., 1999). Topographic indices have been found to be good predictors of soil moisture on numerous sites throughout the world. Studies by Burt and Butcher (1985) in the United Kingdom, Ladson and Moore (1992) in Kansas, USA, Moore and Thompson (1996) in British Colombia, Canada, and Nyberg (1996) in Sweden all concluded that topographic indices are good predictors of soil moisture, although it is worth noting that these environments are much wetter than the present study.

The predictive power of other topographic parameters, such as slope convexity and concavity, slope curvature, and slope aspect (Table 3.1), has also been examined. Moore et al. (1988) found that TI along with slope aspect was the best predictor of soil moisture in the Australian temperate climates, whereas Zavlasky and Sinai (1981) found that slope curvature was the best predictor of soil moisture in the Israeli climate, an environment similar to the one in the present study. Gómez-Plaza et al. (2001) concluded that upslope contributing area, aspect, soil profile curvature and soil depth best explained the spatial variability of soil moisture in a semi-arid vegetated region of Spain, whereas slope and soil texture were the stronger predictors in burnt areas with little vegetation.

Sorensen et al. (2005) looked at different methods for calculating TI and sought to examine how TI correlated with a number of hydrological variables (species richness, 
soil $\mathrm{pH}$, groundwater level and soil moisture) when it was computed differently. The calculation of TI was varied by changing six parameters affecting the distribution of accumulated area among downslope cells and by varying the way that slope was calculated. They found that no single calculation method of TI performed best, but that using the Beven and Kirkby method for calculating slope $(\tan \beta)$ was superior for estimating the hydrological variables than the $\tan \beta_{\mathrm{d}}$ method introduced by Hjerdt et al. (2004), which is defined as the slope to the closest point that is $d$ metres below the cell of interest. Despite the considerable history of the use of topographic indices to help predict moisture availability, their application is not well tested in grassland environments. 


\begin{tabular}{|c|c|c|c|}
\hline$\frac{\text { TOPOGRAPHIC }}{\text { VARIABLE }}$ & DEFINITION & UNITS & $\frac{\begin{array}{c}\text { EFFECT ON } \\
\text { HYDROLOGICAL }\end{array}}{\underline{\text { PROCESSES }}}$ \\
\hline SLOPE & $\begin{array}{l}\text { Rate of change in } \\
\text { elevation }\end{array}$ & $\begin{array}{c}\text { Degrees }\left(0^{0} \text { to } 90^{\circ}\right) \text { or } \\
\text { percent }(0 \% \text { to } \\
100 \%)\end{array}$ & $\begin{array}{l}\text { Influences flow rates } \\
\text { of water and sediment } \\
\text { by controlling the rate } \\
\text { of energy expenditure } \\
\text { or stream power } \\
\text { available to drive the } \\
\text { flow }\end{array}$ \\
\hline ASPECT & Slope direction & Degrees $\left(0^{0}\right.$ to $\left.360^{0}\right)$ & $\begin{array}{l}\text { Influences the } \\
\text { direction of flow }\end{array}$ \\
\hline $\begin{array}{c}\text { PROFILE } \\
\text { CURVATURE (i.e. } \\
\text { convexities) }\end{array}$ & $\begin{array}{c}\text { Rate of change of } \\
\text { slope }\end{array}$ & $\begin{array}{c}\text { Degrees/100 } \\
\text { (determined at every } \\
\text { matrix point or DEM } \\
\text { cell) }\end{array}$ & $\begin{array}{c}\text { Affects flow } \\
\text { acceleration and } \\
\text { deceleration thereby } \\
\text { affecting degradation } \\
\text { (the surface of the } \\
\text { Earth is generally } \\
\text { lowered by the action } \\
\text { of wind and water) } \\
\text { and aggradation (a } \\
\text { stream's gradient } \\
\text { becomes steeper due } \\
\text { to increased } \\
\text { deposition of } \\
\text { sediment) }\end{array}$ \\
\hline $\begin{array}{c}\text { PLANFORM } \\
\text { CURVATURE (i.e. } \\
\text { convexities) }\end{array}$ & $\begin{array}{l}\text { Curvature of land } \\
\text { surface across the } \\
\text { slope direction }\end{array}$ & $\begin{array}{l}\text { Degrees } / 100 \\
\text { (determined at every } \\
\text { matrix point or DEM } \\
\text { cell) }\end{array}$ & $\begin{array}{l}\text { Influences flow } \\
\text { convergence or } \\
\text { divergence }\end{array}$ \\
\hline UPAREA & \multicolumn{3}{|c|}{ Drainage area contributing to a point's flow of water and/or sediment } \\
\hline
\end{tabular}

Table 3.1 - Topographic indices and their effect on hydrological processes (source: Klinkenberg, 2005). 


\subsection{The Study of NPP}

NPP is defined as the total photosynthetic gain, less respiratory losses of vegetation per unit ground area, often expressed on an annual basis (Scurlock et al., 2002). It is equal to the change in both above-ground and below-ground plant mass plus any losses over the measurement period due to death and decomposition, herbivory and exudation/volatilization (Long et al., 1989, 1992; Roberts et al., 1993). Understanding NPP distribution provides information on the productivity of croplands, forest and grasslands and thus helps improve management strategies for sustainable development of natural resources. At the national scale, NPP allows the estimation of the contribution of the Canadian landmass to the global carbon budget which is important in global change studies (Canada Centre for Remote Sensing, 2008). If correlations and/or thresholds of grassland growth can be estimated with respect to soil moisture, the sustainability of this ecosystem could be managed and accurate predictions regarding how grasslands react to a changing climate can be made.

Links between NPP and soil moisture, as well as associations between NPP and topographic parameters, have been studied in similar environments to the present study. Studies by Webb et al. $(1978,1983)$ in the central grasslands region of North America have shown that variance in NPP is affected mainly by precipitation and potential evapotranspiration. Si and Farrell (2004) used wavelet analysis to examine the relationship between wheat grain yields and topographic indices at various length scales in the grasslands of Saskatchewan. Wheat yields were found to be significantly correlated with topographic indices and the study indicated that the relationship between 
wheat yield and topographic indices was scale dependent. Upslope length correlated significantly with wheat yield at scales of $<180 \mathrm{~m}$, and the wetness index (i.e. TI) correlated well with wheat yield when the scale was $<140 \mathrm{~m}$. Zeleke and Si (2004) performed a similar study, using a multifractal approach to characterize the scaling properties of four topographic indices (relative elevation, the Beven and Kirkby wetness index [TI], upslope length, and slope curvature) at the same Saskatchewan site, and their relationship to wheat yield. Results suggested that upslope length was the best indicator of wheat yield and biomass at any scale. Elevation, slope and aspect have been shown to exert a significant influence on wheat yield (Yang et al., 1998) and soybean quality (Kravchenko and Bullock, 2002). However, associations between topography and crop yield are often weak in different fields (Si and Farrell, 2004). Miller et al. (1988) found no correlation between slope percentage and wheat yield in their study in the Dunnigan Hills northwest of Sacramento, California.

Studies relating the yields of various crops and topography have also explored the effects of varying precipitation (e.g. Sinai et al., 1981, Timlin et al., 1998, Pennock et al., 2001, and Kravchenko et al., 2000). Years with low to average precipitation were characterized by higher crop yields in concave areas of the landscape (i.e. depressions) compared to convex areas, probably because concave areas could provide more plantavailable water than areas with convex shapes (Kravchenko and Bullock, 2000). Conversely, wet years were characterized by a decrease in crop yields in water logged depressions, although this may have been caused by abnormally high precipitation during the study years resulting in drainage problems in low-sloped areas. 
The limited testing of TI in drier environments was an important consideration for the present study. Furthermore, several studies concluded that other topographic parameters were better predictors of soil moisture than TI, emphasizing the objective to test soil moisture against slope and upslope area. Topographic parameters (including the TI) and soil moisture have been shown to be applicable to drier environments, especially when relating them to predictions of NPP, inciting further examination of their relationships in GNP. 


\subsection{STUDY AREA}

The study was performed in GNP, near Val Marie, Saskatchewan, Canada (Figure 4.1). The park lies close to the Saskatchewan-Montana border and was created to provide for the preservation of Canadian native northern mixed grass prairie (Coupland, 1992). The park is divided into two blocks (east and west) that cover approximately $906.5 \mathrm{~km}^{2}$, and it lies near the northern edge of the Great Plains region of North America, which spans as far south as northern Mexico, and northwards up to central Saskatchewan (Parks Canada, 2002) (Figure 4.2).

The climate of the park is dry-subhumid to semi-arid with occasional severe droughts and clusters of dry years (Coupland, 1992). Summer climate is generally hot, with average summertime temperatures ranging between mid $20^{\prime} \mathrm{s}^{\circ} \mathrm{C}$ to low $30^{\prime} \mathrm{s}^{\circ} \mathrm{C}$. Precipitation averages only $30-33 \mathrm{~cm}$ per year, with about half of it falling during the summer months (Parks Canada, 2005a). Topography is characterized by gently rolling hills, coulees and badlands, and prior to the formation of the park, the majority of the land was used for cattle ranching. While the park's management plan was in formation, all large grazers were excluded from the park. Bison have now been re-introduced into the study area, but at the time of the field work described here, there had been no grazing by large mammals for at least 15 years (Parks Canada, 2002).

Vegetation in the park is described as mixed-grass, as the park contains both short and mid-height grasses. The vegetation varies depending on landscape type. Dominant grass species and their associated landscape types are summarized in Table 4.1. 


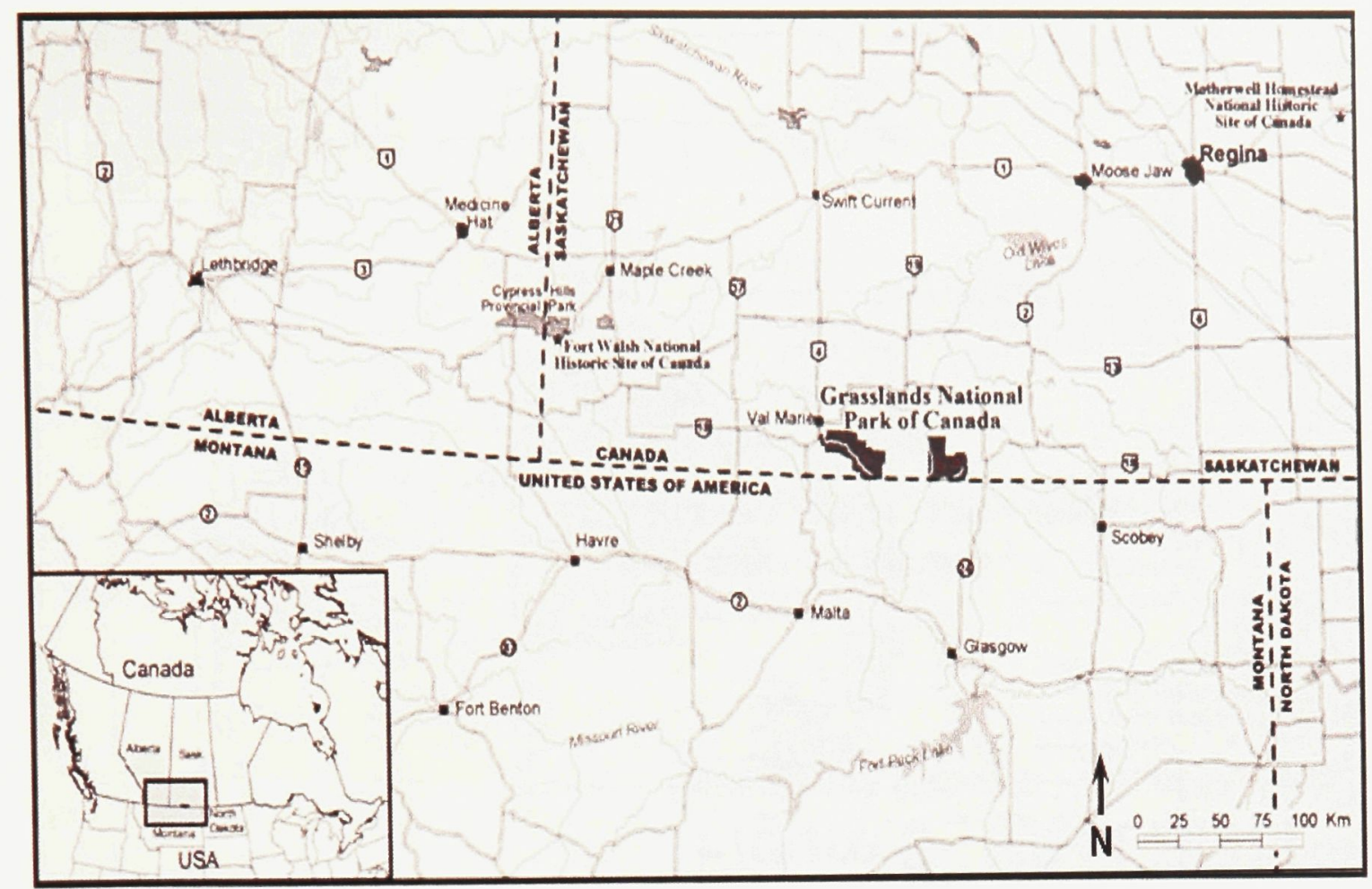

Figure 4.1 - Regional setting; GNP of Canada (source: Parks Canada, 2002).

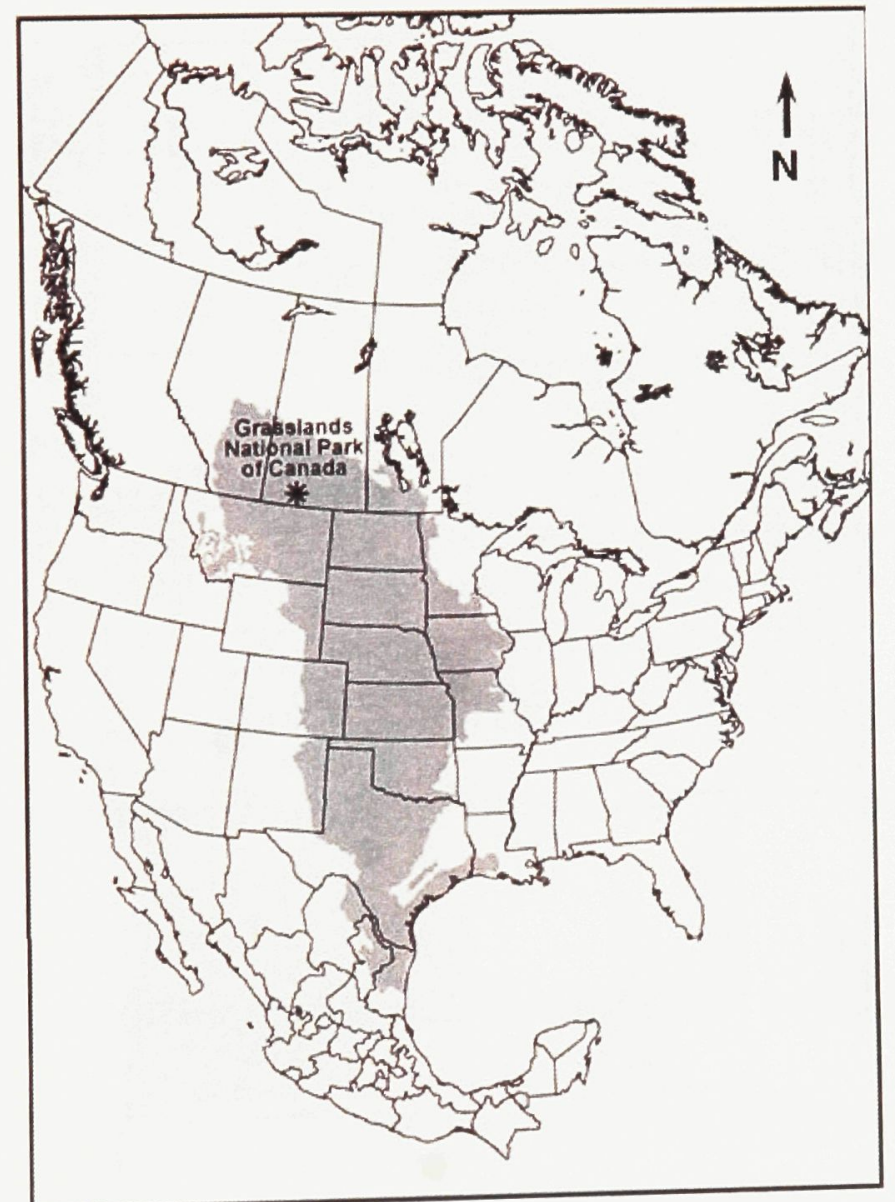

Figure 4.2 - Geographical extent of the Great Plains region of North America and showing the location of GNP (source: Parks Canada, 2002). 


\begin{tabular}{|c|c|}
\hline Landscape Type & $\underline{\text { Vegetation Type }}$ \\
\hline Upland Prairies & $\begin{array}{l}\text { - Wild Needle-and-Thread } \\
\text { Grass (Stipa comata) } \\
\text { - Blue Grama Grass } \\
\text { (Bouteloua gracilis) }\end{array}$ \\
\hline Broad Valleys & $\begin{array}{l}\text { - Sagebush (Artemisia frigida) } \\
\text { - Greasewood (Sacrobatus } \\
\text { vermiculatus) } \\
\text { - Prickly Pear Cactus } \\
\text { (Cactaceae Opuntia) } \\
\text { - Creeping Juniper (Juniperus } \\
\text { horizontalis) } \\
\text { - Western Wheatgrass } \\
\text { (Pascopyrum smithii) }\end{array}$ \\
\hline Badlands & $\begin{array}{l}\text { - Juniper Rose (Juniperus } \\
\text { coahuilensis) } \\
\text { - Various Goosefoot } \\
\text { (Chenopodium) species }\end{array}$ \\
\hline Rivers and Streams & $\begin{array}{l}\text { - Buckbrush (Ceanothus) } \\
\text { species } \\
\text { - Shrubby cinquefoil (Potentilla } \\
\text { fruitcosa) } \\
\text { - Thorny Buffaloberry } \\
\text { (Shepherdia argentea) } \\
\text { - Willow (Salix) species } \\
\text { - Trembling Aspen (Populus } \\
\text { tremuloides) } \\
\text { - Manitoba Maple (Acer } \\
\text { negundo) }\end{array}$ \\
\hline
\end{tabular}

Table 4.1 - Vegetation found in various landscape types in GNP (source: Parks Canada, 2002).

GNP is an attractive location for research on mixed-grass ecosystems because much of the land remains unaltered by human activity, leaving the ecosystem in its natural state. The park represents a dynamic, resilient, and evolving grassland system that maintains its native biodiversity and wilderness character (Parks Canada, 2002). 


\subsection{Site Selection}

The test site was selected within the west block of the park. Site selection was carried out based on the following criteria:

- Basin orientation; a basin oriented in a north-south direction, with east-west facing slopes, was selected in order to standardize as much as possible the exposure to incoming radiation.

- Basin size and shape; the basin needed to represent a typical basin within the park (representative topography and vegetation cover).

- Feasibility to instrument the site with the available equipment.

A list of candidate basins were selected from topographic maps and verified by visiting them by foot.

\subsection{Test Basin}

The selected test basin is situated at $49^{\circ} 8^{\prime} 16^{\prime \prime} \mathrm{N}, 107^{\circ} 37^{\prime} 27.3^{\prime \prime} \mathrm{W}$ within the west block of GNP (Figure 4.3), and covers approximately $8450 \mathrm{~m}^{2}$. It has a north-south facing orientation. Vegetation cover in the basin is primarily mixed-grass, with occasional juniper, spikemoss, June grass, lichens and mixed shrubs. The basin is on the cusp of the prairie uplands and is one of the many coulees that drain into the Frenchman River valley. 


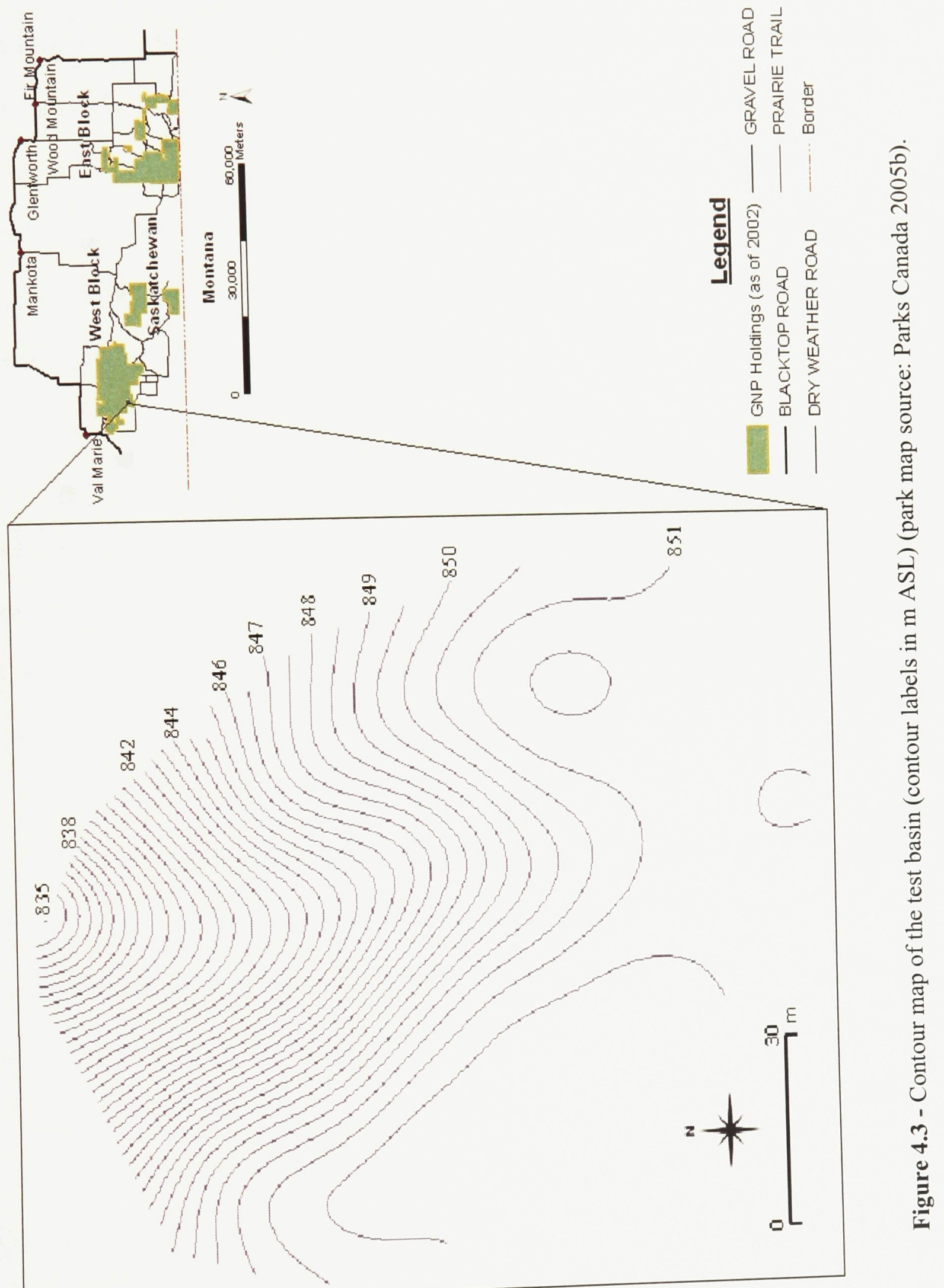


According to a May 1991 soil survey (University of Saskatchewan), the test basin is dominated by a clay/loam soil, with patches of clay and loam. The entire basin falls within one soil class, except for a small portion of the northeast corner of the basin (Figure 4.4). The majority of the basin has a weak degree of salinity (electrical conductivity of $0-60 \mathrm{~cm}$ depth $=2-4 \mathrm{~m} / \mathrm{cm}$ ) with most of the saline soils occurring throughout the bottoms of depressions and sloughs. There are patches where soils in the bottoms of depressions are leached and nonsaline.

The northeast portion of the basin is moderately to exceedingly stony, while the rest of the basin is moderately to very stony. $80 \%$ of the soil surface $\mathrm{pH}$ in the northeast portion of the basin is circumneutral ( $\mathrm{pH} 6.7$ to 7.5 ) with the other $20 \%$ being slightly acid ( $\mathrm{pH} 5.5$ to 6.0 ). The rest of the basin is $50 \%$ slightly acid to neutral soil ( $\mathrm{pH} 6.1$ to 6.7 ) and $50 \%$ neutral to slightly alkaline soil (pH 6.8 to 7.5$)$.

Soil erosion is more severe in the northeast portion of the basin. Lower slopes do not exhibit a thickening of the surface horizon due to accumulation of upper slope material. Soils are moderately susceptible to erosion and there is evidence of rill erosion (small channels a few centimetres deep, occurring after substantial rain or snowmelt). The rest of the basin is only slightly susceptible to erosion, with knolls having a slightly thinner surface horizon, with no noticeable thickening of the surface horizons on mid to lower slopes (University of Saskatchewan, 1991). 


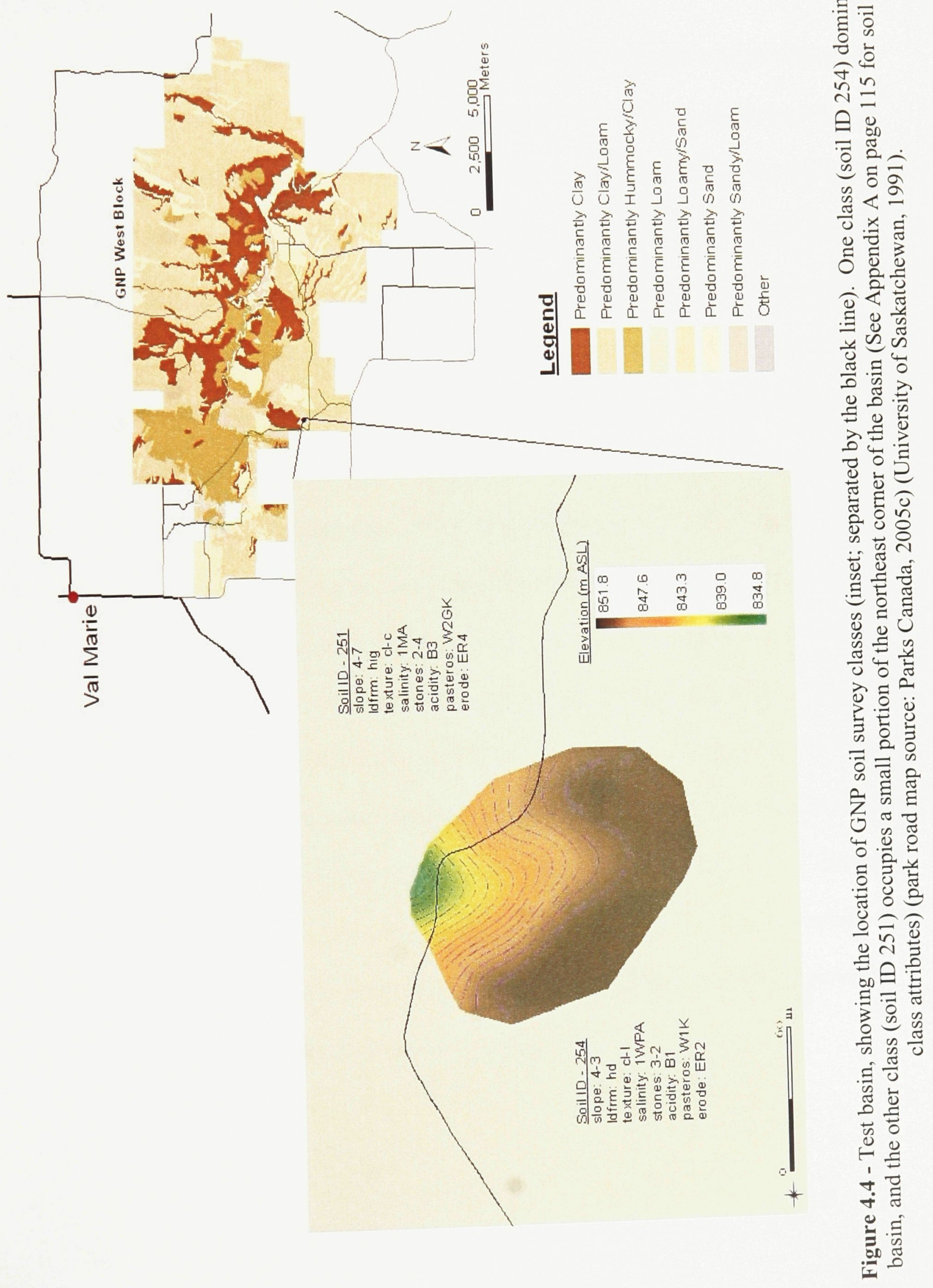




\subsection{METHODS}

\subsection{Measurement Tools}

A sampling grid that would adequately capture the full range of basin dynamics was set up in the test basin. The grid layout aimed to cover all topographic landscapes (flat areas, sloped areas, drainage zones and the basin outlet). Sample points needed to be spaced closely enough to capture the local variability of both soil moisture and aboveground plant dynamics. Equally important, however, the grid needed to be of reasonable size to be able to feasibly sample the basin during the time frame of the study. A perimeter line was established to define the area within which water would be drained by the test basin. It was mapped using a GPS to obtain baseline elevation information and coordinates from which the transects and DEM could be measured and mapped. Within this perimeter, 10 transects running east-west were set up, with flags (sample points) placed at 1 metre intervals along each transect (Figure 5.1). All transects had starting points on the western side of the basin $(0 \mathrm{~m})$ and ending points on the eastern ridge. Each transect, with the exception of transect 1 (T1), had a designated "special flag" used to identify the perceived lowest point along the transect (i.e. the point along the transect that would potentially have the greatest moisture, as it is a point of collection). T1 did not have a special flag, as it was deemed to be essentially flat. Transect lengths varied, and were generally longer closer to the bottom/outlet of the basin as the width of the basin increased. Table 5.1 displays the transect specifications. 


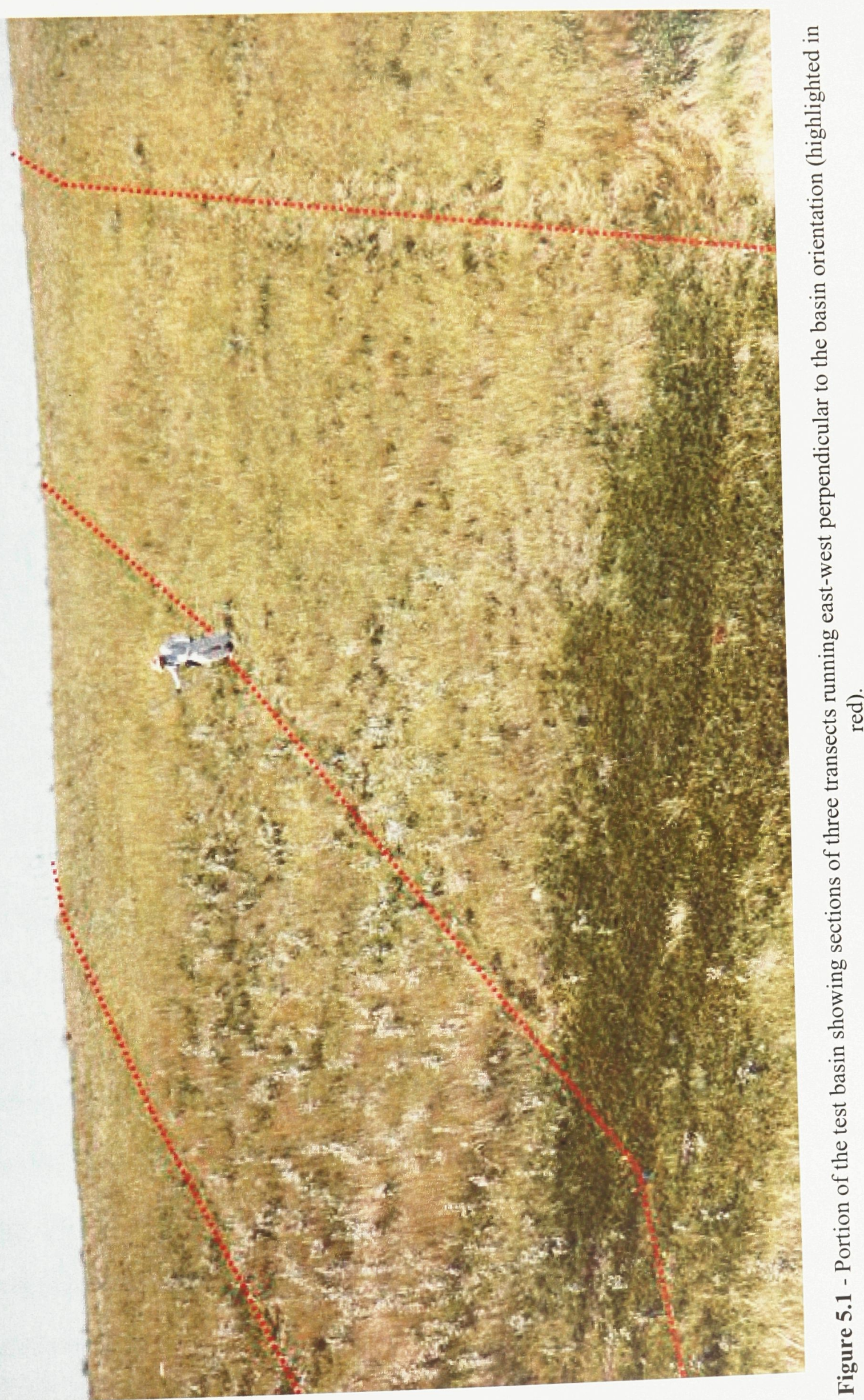




\begin{tabular}{|c|c|c|}
\hline Transect Number & Length $(\mathrm{m})$ & \# of Flags (Sample Sites) \\
\hline $\mathbf{1}$ & 28 & 29 \\
\hline $\mathbf{2}$ & 36 & 38 \\
\hline $\mathbf{3}$ & 50 & 53 \\
\hline $\mathbf{4}$ & 48 & 51 \\
\hline $\mathbf{5}$ & 47 & 49 \\
\hline $\mathbf{6}$ & 50 & 52 \\
\hline $\mathbf{7}$ & 65 & 67 \\
\hline $\mathbf{8}$ & 64 & 68 \\
\hline $\mathbf{9}$ & 65 & 66 \\
\hline $\mathbf{1 0}$ & 45 & 47 \\
\hline
\end{tabular}

Table 5.1 - Transect specifications (length in metres and the number of flags/sample sites along each transect).

A HOBO weather station (Onset Computer Corporation) was installed at the top of the basin and recorded weather data from May 25, 2005 to August 28, 2005 (referred to as the "growing season" in this study) (Figure 5.2). Data was recorded to the onboard computer every 5 minutes. The station measured 5 weather and above-ground variables, including rainfall $(\mathrm{mm})$, wind speed $(\mathrm{km} / \mathrm{h}) \&$ direction $(\varnothing)$, photosynthetically active radiation $(\mathrm{PAR})\left(\mathrm{uE} / \mathrm{m}^{2} / \mathrm{s}\right)$, and air temperature $\left({ }^{\circ} \mathrm{C}\right)$. Three $20 \mathrm{~cm} \mathrm{ECH} 2 \mathrm{O}$ soil moisture probes (Onset Computer Corporation) were inserted into the ground surrounding the station and recorded the soil moisture integrated across varying depths. One probe was inserted vertically into the soil to a depth of $\sim 25.4 \mathrm{~cm}$ (10"), while two others were inserted at angles to depths of $\sim 12 \mathrm{~cm}$ and $\sim 5 \mathrm{~cm}$. A soil temperature probe was inserted 
into the soil at a depth of $2 \mathrm{~cm}$. The probes measured soil moisture continually throughout the 2005 growing season. The $\mathrm{HOBO}$ weather station $\mathrm{ECH} 2 \mathrm{O}$ probe specifications are shown in Table 5.2.

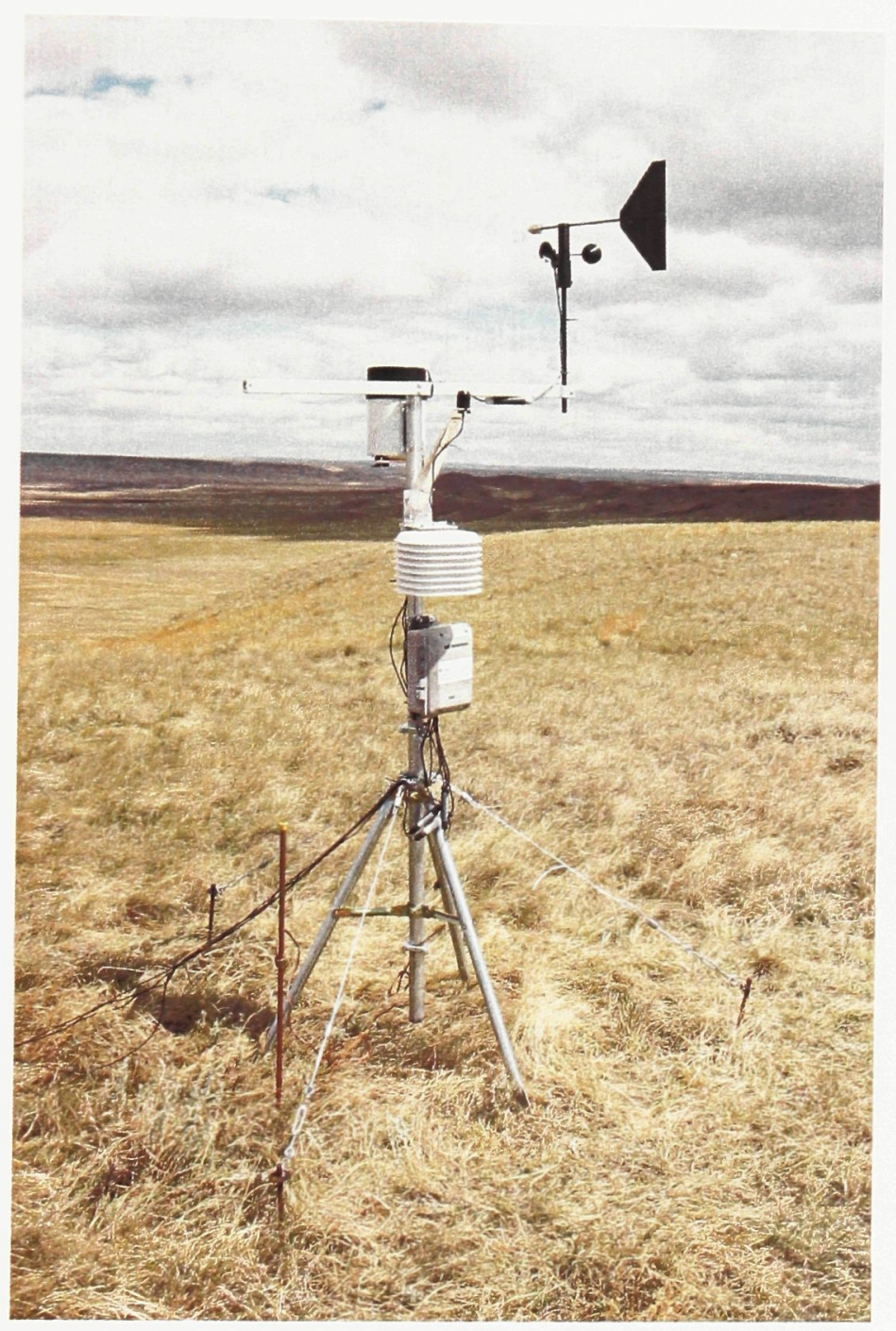

Figure 5.2 - HOBO weather station installed at the top of the test basin. 


\section{Manufacturer:}

- Decagon Devices, Inc. (Pullman, WA, USA)

\section{Measurement Range:}

- In Soil: 0 to $0.405 \mathrm{~m}^{3} / \mathrm{m}^{3}$ ( 0 to saturated volumetric water content)

- Extended Range: -0.29 to $1.4475 \mathrm{~m}^{3} / \mathrm{m}^{3}$ (full scale)

\section{Accuracy:}

- $+/-0.041 \mathrm{~m}^{3} / \mathrm{m}^{3}(+/-4 \%)$, typical 0 to $50^{\circ} \mathrm{C}\left(+32^{\circ} \mathrm{F}\right.$ to $\left.+122^{\circ} \mathrm{F}\right)$

- $+/-0.020 \mathrm{~m}^{3} / \mathrm{m}^{3}(+/-2 \%)$, with soil specific calibration

\section{Resolution:}

- $+/-0.0004 \mathrm{~m}^{3} / \mathrm{m}^{3}(+/-0.04 \%)$

\section{Sensor Operating Temperature:}

- 0 to $50^{\circ} \mathrm{C}\left(+32^{\circ} \mathrm{F}\right.$ to $\left.+122^{\circ} \mathrm{F}\right)$. While the sensor probe and cable can safely operate at below freezing temperatures (to $-40^{\circ} \mathrm{C} / \mathrm{F}$ ) and up to $+75^{\circ} \mathrm{C}\left(167^{\circ} \mathrm{F}\right)$, the soil moisture data collected at these extreme temperatures is outside of the sensor's accurate measurement range.

\section{Soil Probe Dimensions:}

- $254 \times 32 \times 1.0 \mathrm{~mm}(10 \times 1.25 \times 0.04$ in $)$

\section{Weight:}

- 200 grams $(7 \mathrm{oz}$.

\section{Bits Per Sample:}

- 12

Table 5.2 - HOBO weather station ECH2O probe specifications (Onset Computer Corporation, 2007).

In addition to the main weather station at the top of the basin, a smaller $\mathrm{HOBO}$ data logger was installed approximately halfway down the basin drainage zone and another at the bottom of the basin, both measuring soil moisture. The station located halfway down the basin drainage zone also recorded PAR $\left(\mathrm{uE} / \mathrm{m}^{2} / \mathrm{s}\right)$ and air temperature $\left({ }^{\circ} \mathrm{C}\right)$. 
Soil moisture was measured using $12 \mathrm{~cm}$ and $20 \mathrm{~cm}$ HydroSense handheld moisture probes (Campbell Scientific CS-620) (Figure 5.3). Sample sites where rocky soil prevented proper insertion of the probes were excluded from the analysis.

Specifications of the handheld moisture probe are shown in Table 5.3. Measurements of reflected irradiation in Landsat-TM bands 4 (NIR: 0.76-0.90 $\mu \mathrm{m}$ ) and 3 (RED: 0.63-0.69 $\mu \mathrm{m})$ were taken using a Cropscan Model MSR5 Multispectral Radiometer (Cropscan Inc., Rochester, MN, USA) (Figure 5.4). Soil moisture and measurements of reflected irradiation were taken at every sample site throughout the 2005 summer growing season, from late May to late August. For reflected irradiation, three measurements were taken at each sample point along the transects, then averaged off site. These final, averaged measurements were used to calculate NDVI, which in turn were used to estimate NPP.

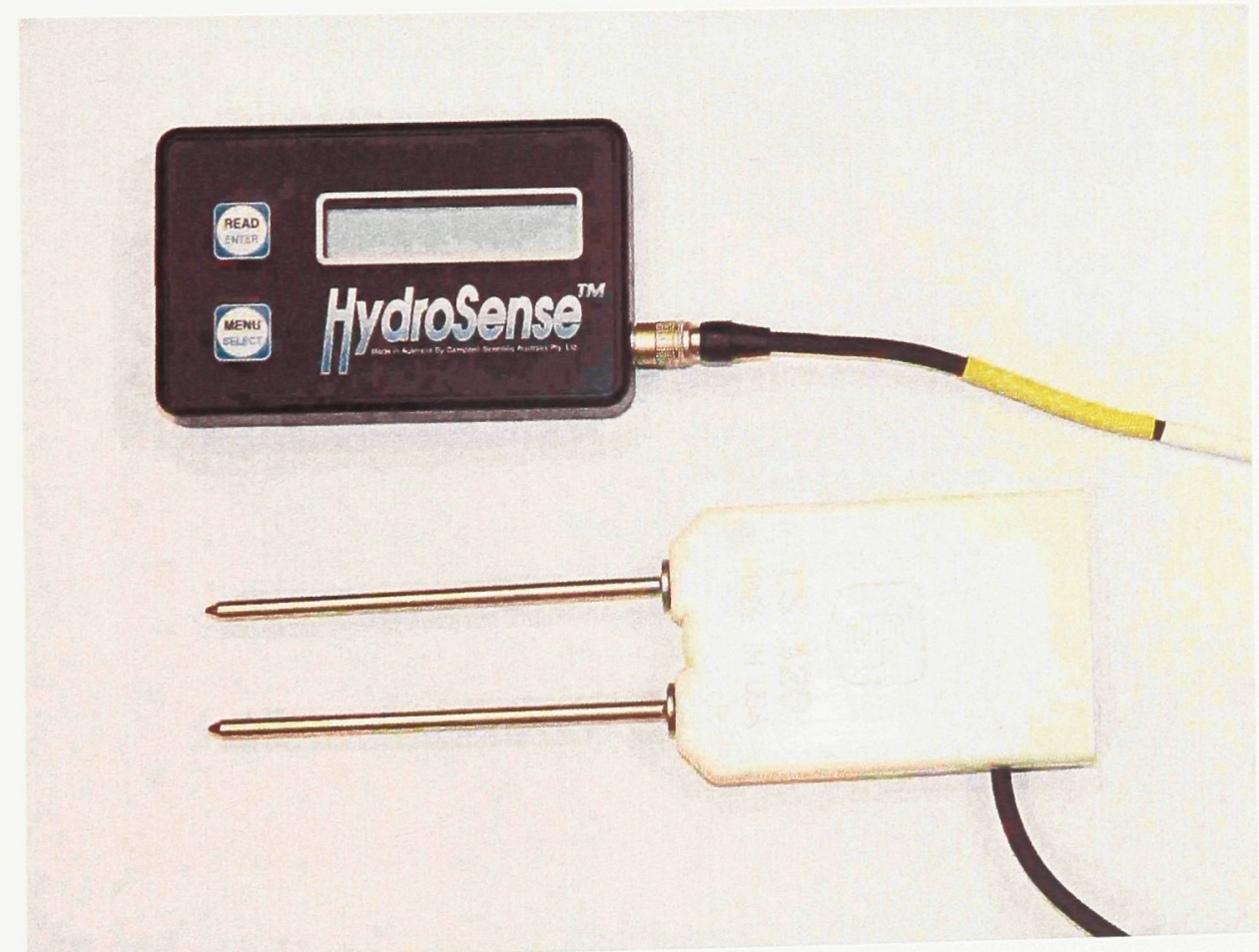

Figure 5.3 - CS-620 Handheld HydroSense probe used to measure soil moisture. 


\section{HydroSense Readout}

- Measurement: \% Volumetric Water Content

- Resolution: $1.0 \%$

- Dimensions: $12 \mathrm{~cm}$ x $7.3 \mathrm{~mm} \times 2.4 \mathrm{~cm}$

- Weight: $166 \mathrm{~g}$

\section{HydroSense Probe}

- Accuracy: $+/-3.0 \%$ volumetric water content with electrical conductivity, $2 \mathrm{dS} \mathrm{m}^{-1}$

- Range: $0 \%$ to saturation (saturation is typically around $50 \%$ volumetric water content)

- Stabilization Time: Instantaneous

- Dimensions:

- $105 \mathrm{~mm} \times 70 \mathrm{~mm} \times 18 \mathrm{~mm}$ (Probe Head)

- 12 or $20 \mathrm{~cm}$ length, $5 \mathrm{~mm}$ diameter, $32 \mathrm{~mm}$ spacing (Probe Rods)

- Weight: $\sim 400 \mathrm{~g}$

Table 5.3 - Specifications of the CS-620 HydroSense handheld moisture probe (Campbell Scientific, Inc., 2001).

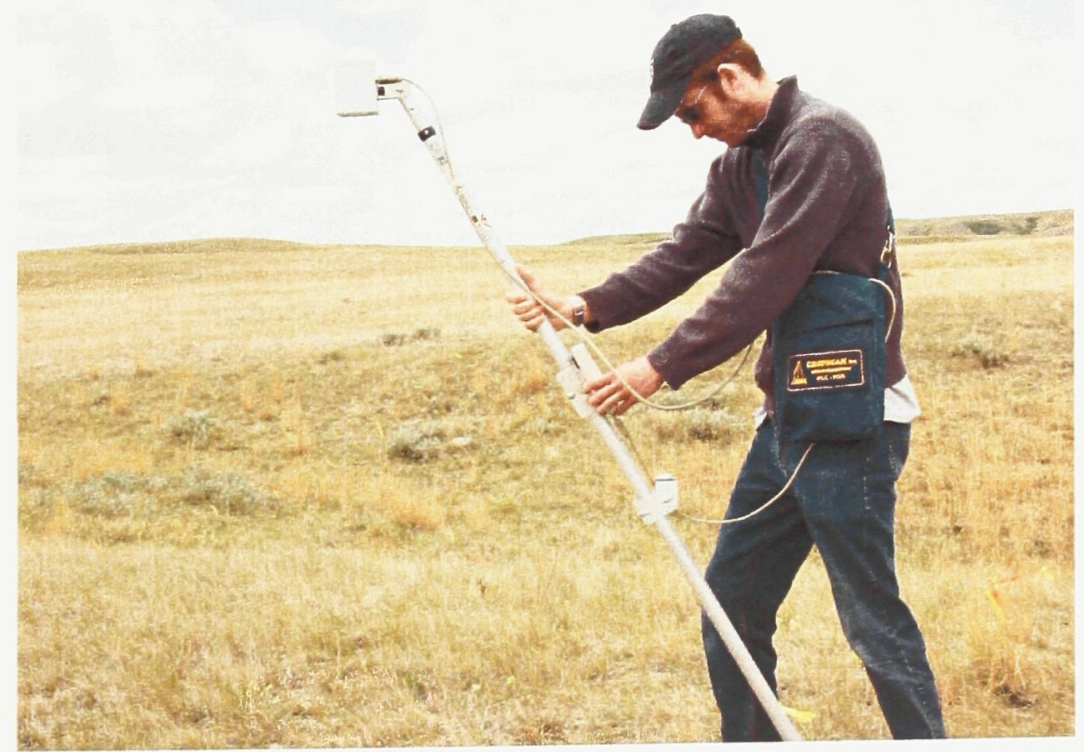

Figure 5.4 - Using the Cropscan Radiometer to measure reflected irradiation. 


\subsection{Instrument Calibration}

Soil moisture probe calibration was accomplished with simultaneous gravimetric and probe samples. Volumetric water content (VWC \%) measurements were taken using the handheld probe at a sample site, and then soil cores were taken from the ground at the same location. A total of 9 different sample locations were used, over 5 different days throughout the growing season (Figure 5.5). Anywhere from 3 to 10 handheld probe measurements were taken at a given sample site, then averaged for each specific location. A total of nine $20 \mathrm{~cm}$ deep soil cores and one $12 \mathrm{~cm}$ deep soil core were sampled.

These cores were put into small cans, weighed, dried in an oven at $105^{\circ} \mathrm{C}$ for $24 \mathrm{~h}$ and then re-weighed, and calibration equations were developed (Figure 5.5(A)) so that handheld measurements could be converted from VWC to gravimetric water content (GWC). Since this research focused on looking for correlations, any consistent estimation of soil moisture was considered sufficient for this study, but this method was chosen because GWC is the only direct measure of soil moisture.

Radiometer calibration was carried out using methods described by Davidson et al. (2006). NDVI was calculated at sample plots (either $50 \mathrm{~cm} \times 10 \mathrm{~cm}$ or $25 \mathrm{~cm} \times 10$ $\mathrm{cm}$ ), which were clipped of all their standing vegetation and sorted immediately after harvest into live biomass and dead biomass components, as well as according to vegetation type (grasses, selaginella/lichen, forb/shrubs, and juniper), then placed into paper bags. The paper bags were stored in a freezer until they could be transported to the GNP research facility to be weighed. After fresh (wet) biomass weights were determined 
for each sample, the clippings were force air-dried at $65^{\circ} \mathrm{C}$ for $48 \mathrm{~h}$. Dry clipping weights were measured at the end of each drying cycle and areal biomass $\left(\mathrm{g} \mathrm{m}^{-2}\right)$ was calculated by dividing the dry weight ( $\mathrm{g}$ ) by sample plot area. This data was combined with similar but more extensive field calibration data collected by Davidson et al. (2006) to derive the calibration equations used in this study (Figure 5.5(B)).

GWC $=-0.268586+0.1201877[\operatorname{Ln}[$ Field Measured Soil Moisture (VWC\%)]

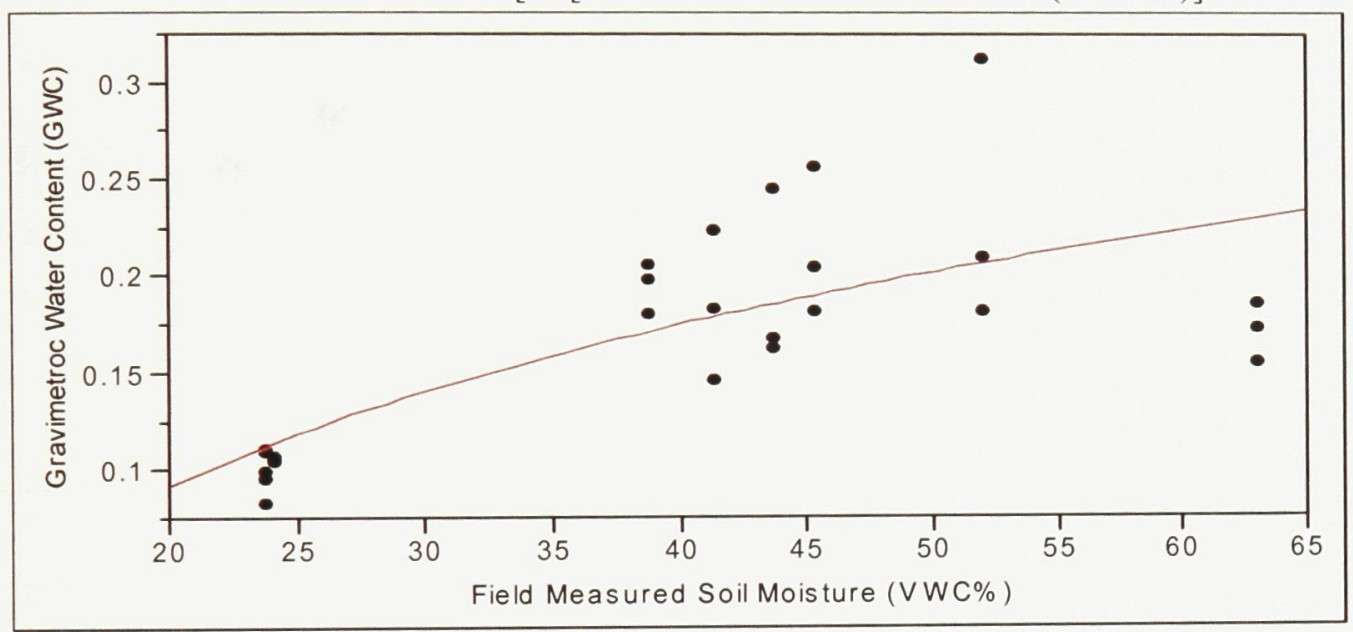

$\mathrm{R}^{2}=0.54$

$\mathrm{R}=0.74$

$\mathrm{P}=<.0001$

$\mathrm{N}=27$

(A)

Biomass $\left(\mathrm{g} \mathrm{m}^{-2}\right)=-84.99583+530.82459[\mathrm{Ln}($ Field Measured NDVI $)]$

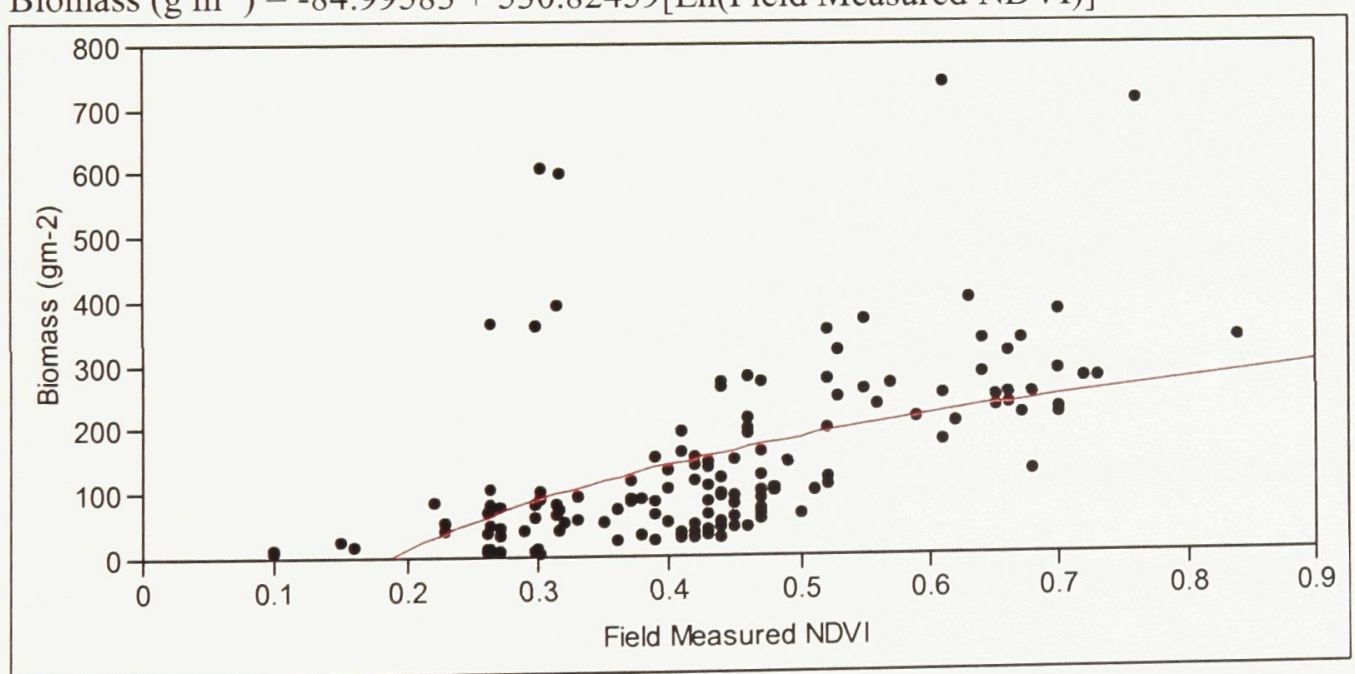

$\mathrm{R}^{2}=0.26$

$\mathrm{R}=0.51$

$\mathrm{P}=<.0001$

$\mathrm{N}=144$

(B)

Figure 5.5 - Calibration curves for converting field measured volumetric water content (VWC \%) to gravimetric water content (GWC) (A), and for converting field measured NDVI to areal biomass $\left(\mathrm{g} \mathrm{m}^{-2}\right) \mathbf{( B )}$. 
The resultant calibrations were deemed sufficient, given the number of samples taken, but a better fit would have been preferred. The implications of this fit on further analysis are discussed in section 8.3. Given the number of points, the only way to improve this relationship would have been to get more field samples, especially in the ranges of VWC not well covered by the data. The radiometer calibration is not especially strong, but is in line with results achieved in previous studies using broadband sensors, including the Davidson et al. (2006) study used as the base for this calibration.

\subsection{Data Preparation}

\subsubsection{DEM and Other Raster Maps}

Topographic information was obtained through a field survey using common surveying techniques. A surveyor's level and measuring staff were used for foresighting and backsighting along the transects, allowing the calculation of elevations from an arbitrary point. The elevation data was used to interpolate a highly detailed DEM ( $0.5 \mathrm{~m}$ resolution) of the test basin using the v.surf.rst regularized spline tension module in GRASS (GRASS Development Team, 2006). This method of interpolation was chosen because of its generality and accuracy for this kind of data (Neteler and Mitasova, 2008). The final DEM was smoothed by applying a 9x9 median filter to produce the final version of the DEM $($ RMSE $=0.711 \mathrm{~m})$ (Figure 5.6). Using the final DEM as an input, raster maps for slope, aspect and the topographic index (TI) were also produced using the r.topidx command in GRASS (GRASS Development Team, 2006). Slope and aspect were calculated as follows: 
$\gamma=\arctan \sqrt{f_{x}^{2}+f_{y}^{2}}$

and

$$
\alpha=\arctan \frac{f_{x}}{f_{y}}
$$

where $\gamma$ is slope and $\alpha$ is aspect, and $f_{x}$ is the rate of change in elevation with respect to the $\mathrm{x}$ coordinate and $\mathrm{f}_{\mathrm{y}}$ is the rate of change in elevation with respect to the $\mathrm{y}$ coordinate (Neteler and Mitasova, 2004).

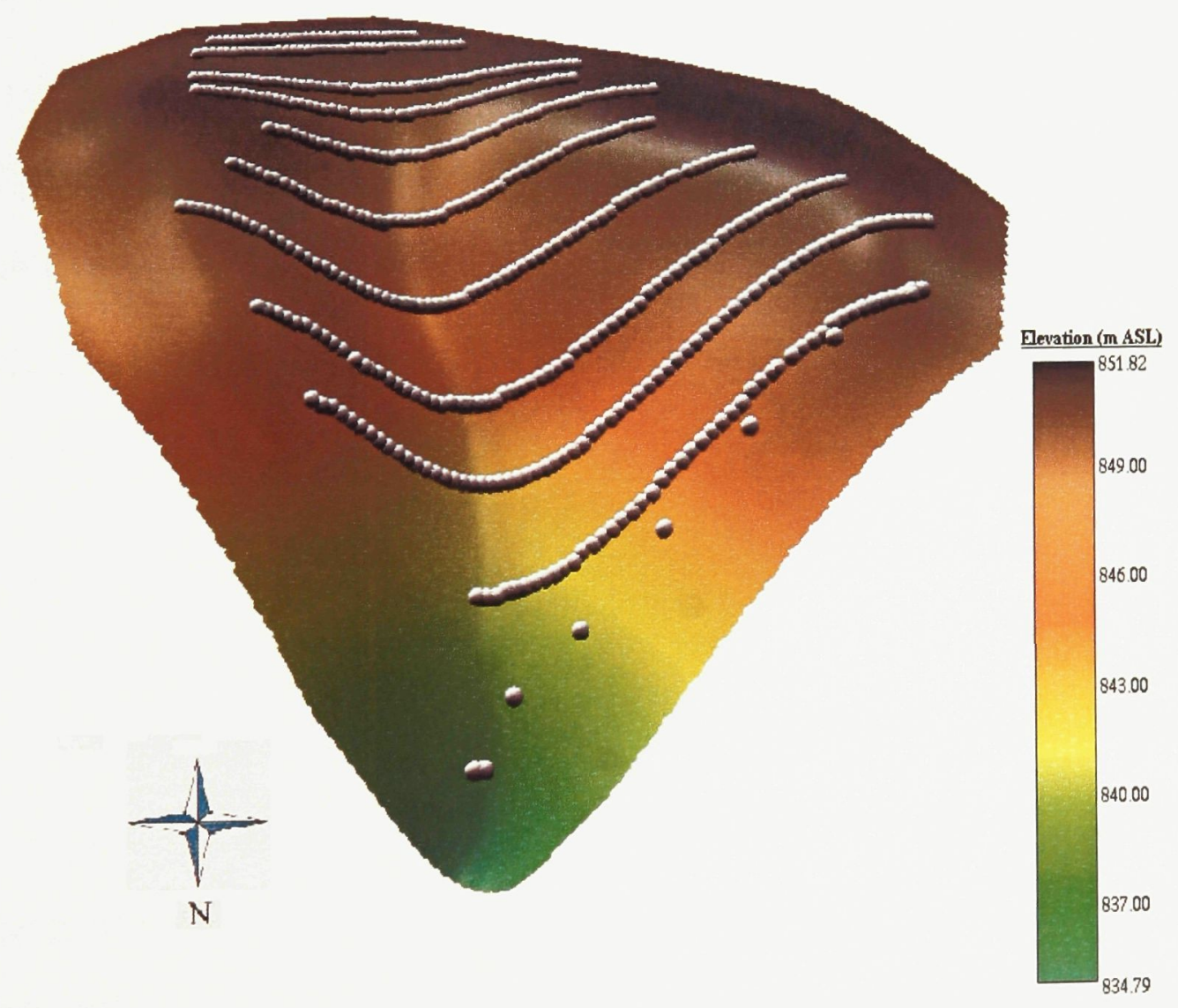

Figure 5.6 - Final DEM of the test basin, showing the 10 sample transects. Vertical exaggeration $=3.0$. 


\subsubsection{Soil Moisture and NPP Data}

Bivariate correlations in the present study were performed using JMP v. 7.0.1 (SAS Institute Inc., Cary, NC, USA), and using a linear regression fit at the $95 \%$ confidence level. The Pearson correlation coefficient (R) was used for all relationships presented. Raw soil moisture values from the handheld probe were compiled by transect, by day the measurements were taken, and by probe length $(12 \mathrm{~cm}$ or $20 \mathrm{~cm})$. Values were converted from VWC to GWC using the equation obtained through probe calibration (Figure 5.5(A) on page 37). An arbitrarily selected 5-point moving average of GWC was calculated for each transect and each day, to check for patterns across broader spatial scales. This was because individual point measurements varied greatly along certain transects and initial correlations using raw measured values were insignificant or lacked consistent pattern. Initial correlations using $12 \mathrm{~cm}$ values produced inconsistent results, but results with $20 \mathrm{~cm}$ probes were more consistent. Therefore, only values of soil moisture integrated over a greater depth $(20 \mathrm{~cm}, 5$-point moving average, averaged across the growing season to give growing season average soil moisture) were used for all the correlations and analyses presented in this paper (henceforth referred to as "soil moisture").

NPP values were estimated from the Cropscan radiometer readings taken throughout the growing season. Three measurements of reflected irradiation were taken at each sample site and the average for that sample, on each given sample day, was calculated. After downloading the spectral data from the radiometer to a computer, NDVI was calculated using Equation 2 (Lillesand and Kiefer, 1994). 
$N D V I=\frac{N I R-R}{N I R+R}$

where NIR is the reflected energy in the near-infrared wavelength $(0.76-0.90 \mu \mathrm{m})$ and $R$ is the reflected energy in the red wavelength $(0.63-0.69 \mu \mathrm{m})$.

Next, NDVI was converted to a measure of areal biomass $\left(\mathrm{g} \mathrm{m}^{-2}\right)$ using the equation obtained through the radiometer calibration (Figure 5.5(B) on page 37). NPP was calculated for the growing season by subtracting peak seasonal biomass from start of season biomass. The result was an above-ground NPP value for each sample site using one of the commonly used methods ("Method 3" as defined in Scurlock et al., 2002).

\subsubsection{Data Segregation}

To test for the presence of contrasting relationships in different topographic positions or vegetation communities, the data were segregated into distinct groups. Areas were chosen based on numerous factors including aspect, topographic position, and dominant vegetation cover. East and west facing hillslopes of the basin were qualitatively different. For the purpose of this study, the drainage zone was defined as an area of potential increased moisture accumulation, where moisture and potentially soil gathers and is transported out of the basin, and was defined based on slope and aspect values.

The east and west facing hillslopes were calculated based on those portions of the basin where TI values were less than 5.5 and the elevation was less than $852 \mathrm{~m} \mathrm{ASL}$. 
The drainage zone was the area in the middle of the test basin not covered by the parameters used to define the basin hillslopes. Vegetation was categorized using the same classes used in the Cropscan radiometer calibration; correlations were calculated for sample points in areas dominated by grasses, selaginella/lichen, forbs/shrubs, juniper, and with the addition of mainly eroded areas. At each sample point, the dominant vegetation cover was determined from photos taken along each transect and the sample points were separated into groups. The soil moisture measurements for each landscape position and dominant vegetation cover were tested against the topographic variables, while NPP estimates for each landscape position and dominant vegetation cover were correlated against soil moisture and the topographic variables. 


\subsection{BASIN-WIDE CHARACTERISTICS}

\subsection{Growing Season}

Weather station data were used to characterize the growing season environment. Data for 2005 were compared to Parks Canada data from 1994 to 2004 as well as 30 year (1967 to 1996) monthly maximum and minimum values for temperature and precipitation from Meteorological Services Canada.

Park weather conditions for the 2005 growing season were within average conditions when compared to archival data (Parks Canada, 2003; Meteorological Service Canada, 1997; Meteorological Service Canada, 2004). Between 1994 and 2004, average daily growing season air temperature had a range of $4.4^{\circ} \mathrm{C}\left(\max : 19.1^{\circ} \mathrm{C}\right.$ in 2003 and $\min$ : $14.6^{\circ} \mathrm{C}$ in 2004) (Figure 6.1). The average air temperature in 2005 was $18.0^{\circ} \mathrm{C}$ (Figure 6.1). A total of $137 \mathrm{~mm}$ of rain fell, making the 2005 growing season relatively dry, despite total precipitation falling within the average for the previous 11 years (Figure 6.2). This followed an 11 year high of $310 \mathrm{~mm}$ in 2002 and a low of $62 \mathrm{~mm}$ in 2003. The majority of the 2005 growing season precipitation fell in June (95 mm). 


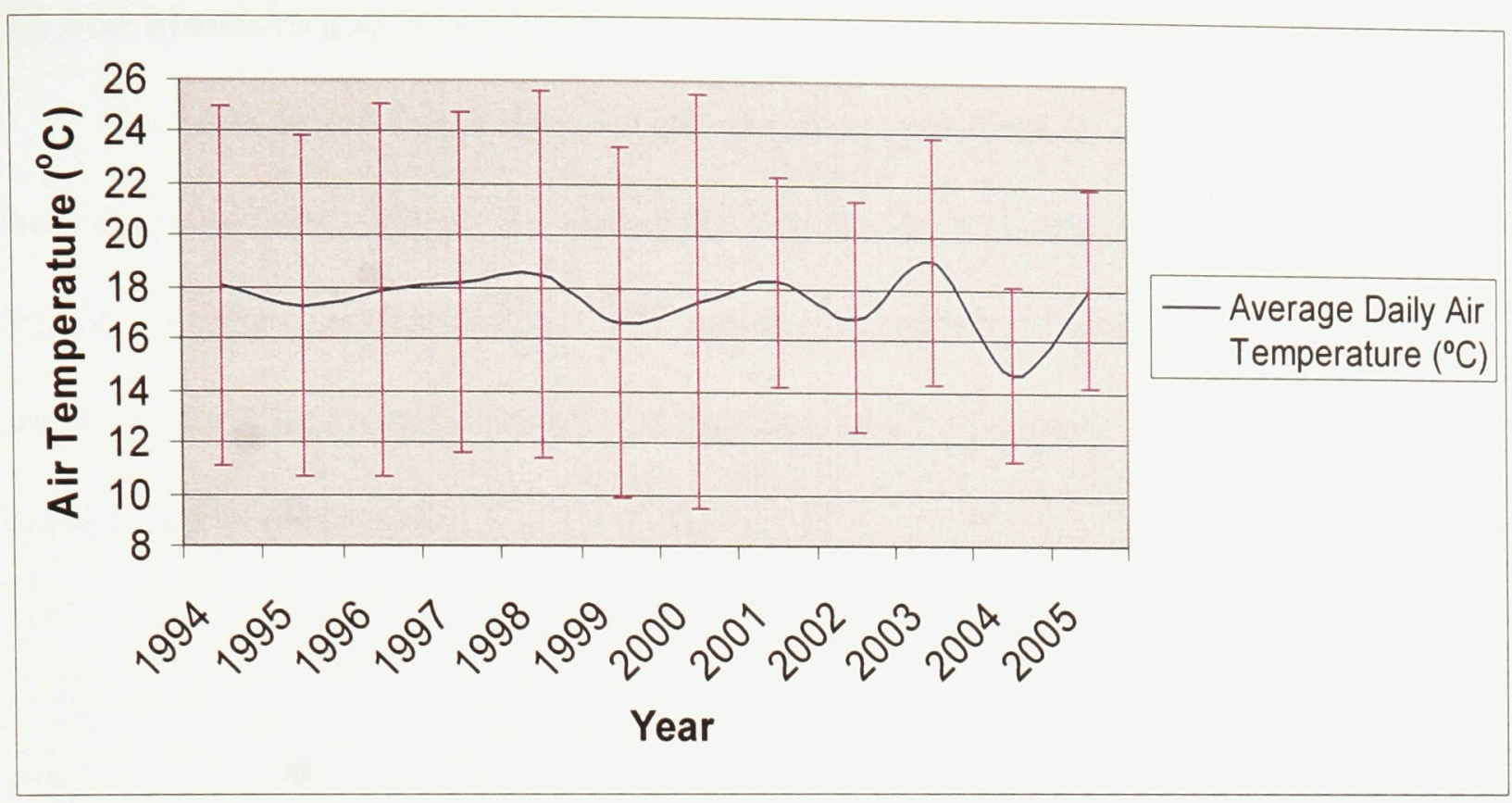

Figure 6.1 - GNP average daily growing season air temperature (1994 - 2004 from archival records [Parks Canada, 2003; Meteorological Service of Canada, 1997; Meteorological Service of Canada, 2004], plus measurements from the 2005 growing season). Y-error bars show 1 standard deviation from the growing season mean.

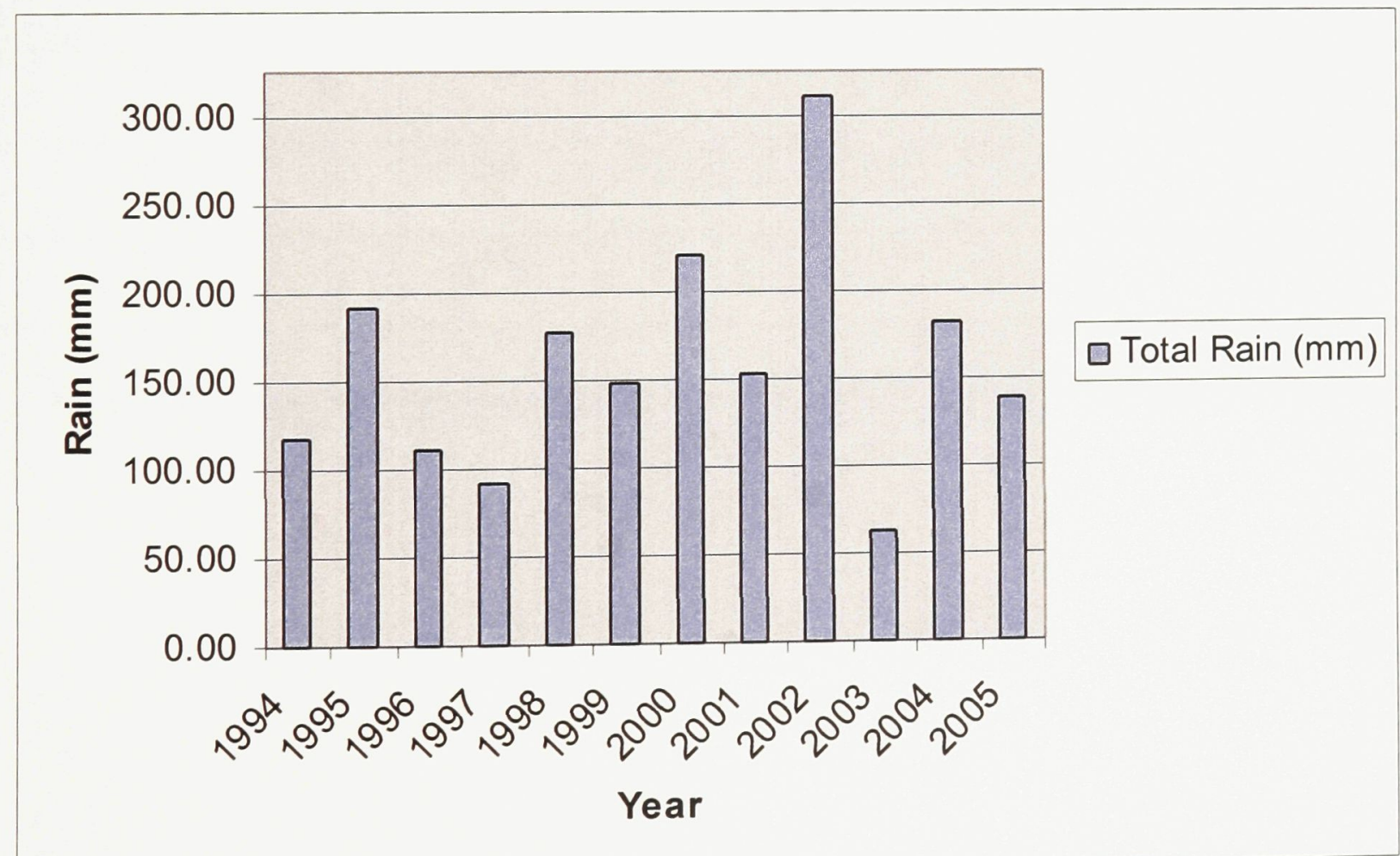

Figure 6.2 - Total precipitation during growing season (1994-2004 from archival records [Parks Canada, 2003, Meteorological Service of Canada, 1997, Meteorological Service of Canada, 2004], plus 2005 growing season). 


\subsection{Soil Moisture and NPP Trends in the Basin}

In order to test the study's hypotheses, the general trends across the entire basin were examined first. Figure 6.3 shows the distribution of TI across the test basin and Figure 6.4 shows the distribution of TI values along select transects. Variability and range in TI values increased nearer the bottom/outlet of the basin (Table 6.1), but the mean TI value decreased.

\begin{tabular}{|c|c|c|c|}
\hline TRANSECT & MEAN (TI) & VARIANCE $\left(\mathbf{T I}^{2}\right)$ & RANGE (TI) \\
\hline T1 & 6.4 & 0.15 & 1.24 \\
\hline T3 & 6.0 & 0.78 & 2.79 \\
\hline T5 & 5.4 & 0.89 & 4.01 \\
\hline T7 & 5.0 & 1.31 & 4.82 \\
\hline T9 & 4.8 & 1.61 & 5.61 \\
\hline
\end{tabular}

Table 6.1 - Mean, variance, and range of TI values along odd numbered transects of the test basin. 


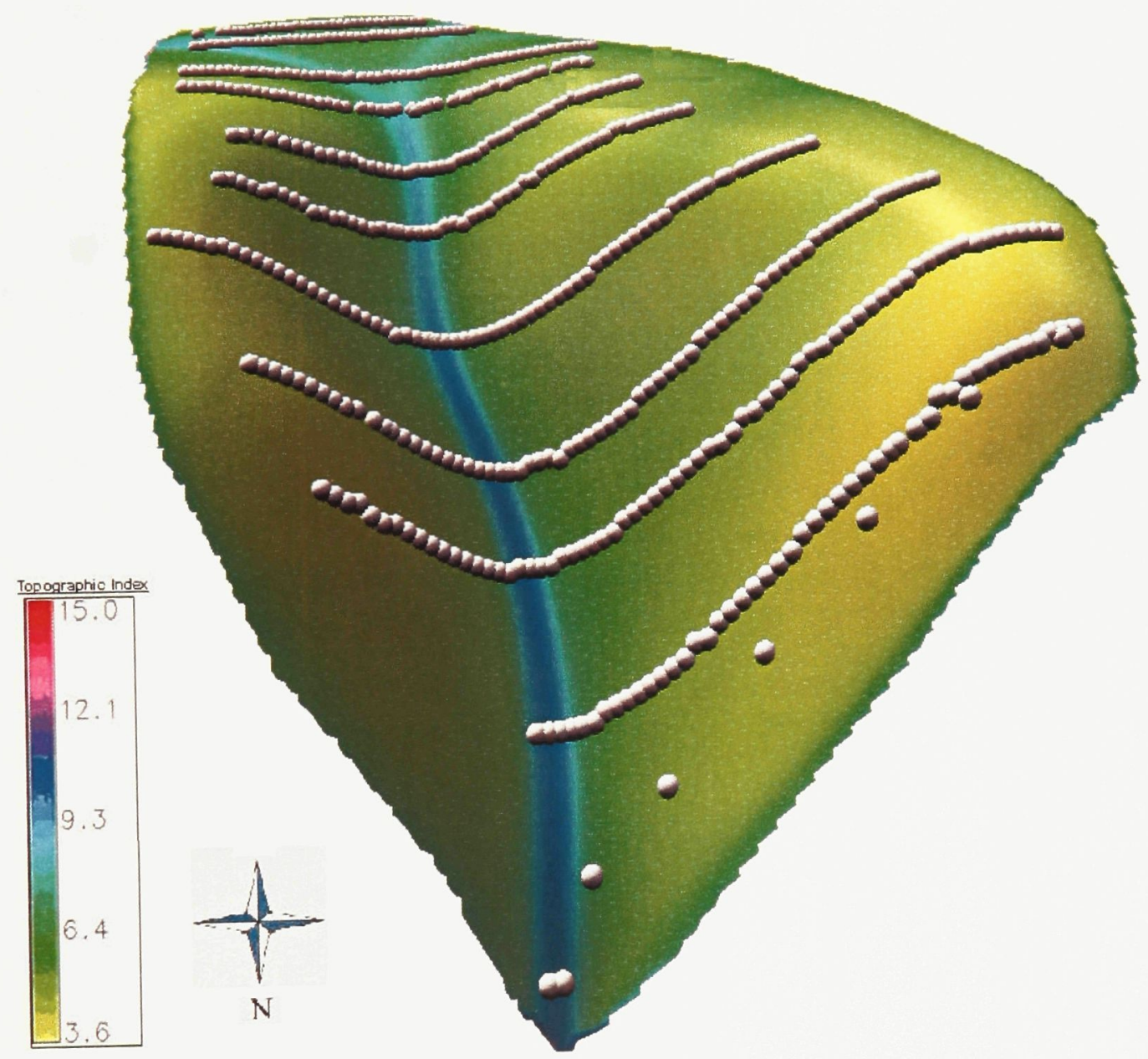

Figure 6.3 - Test basin DEM, showing draped TI map. Vertical exaggeration = 3.0. 


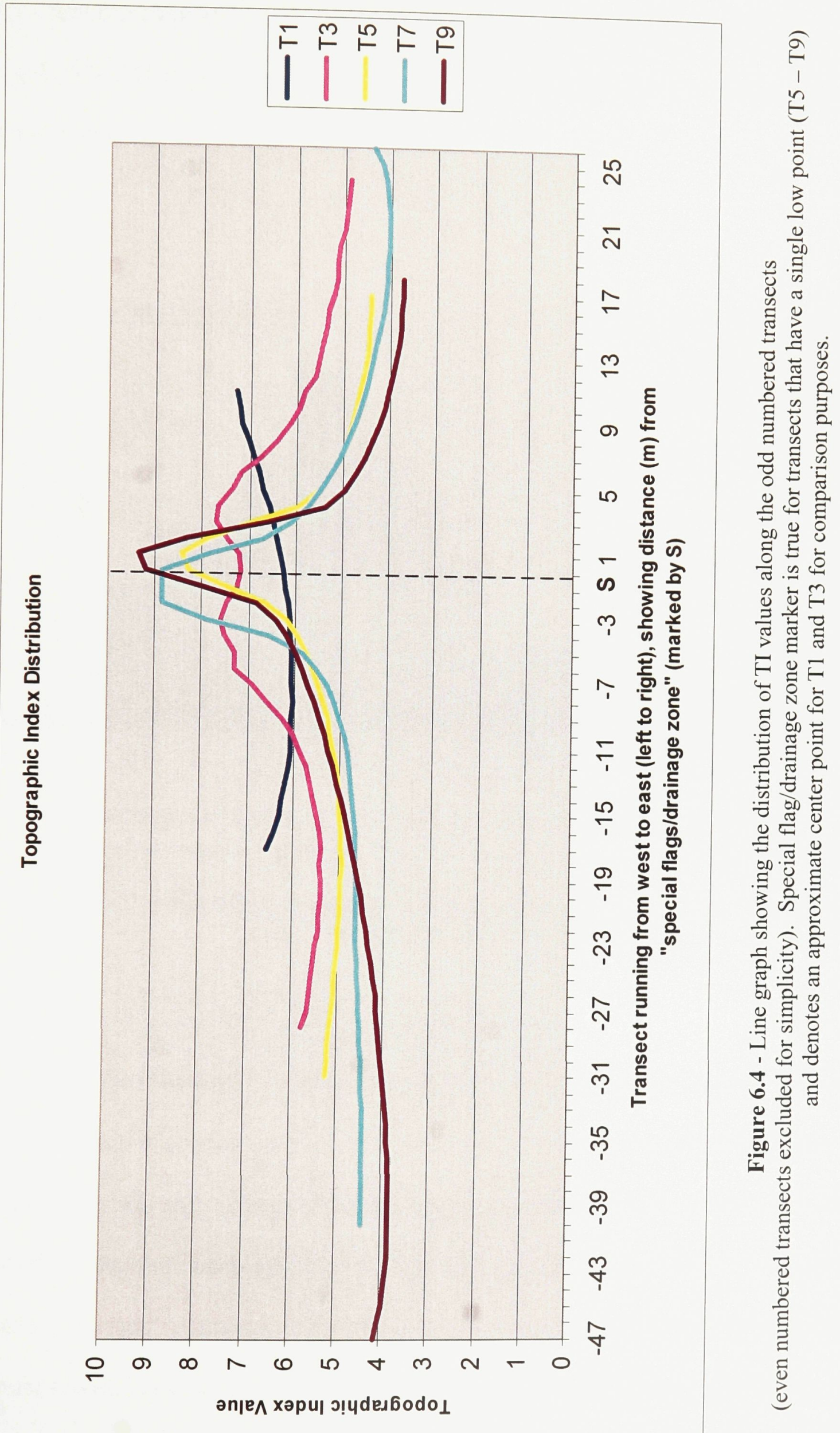


Soil moisture distribution across the entire basin is shown in Figure 6.5. There was a $42.5 \%(\mathrm{GWC})$ range in values across the entire basin, with a few anomalous values that were removed from further analysis.

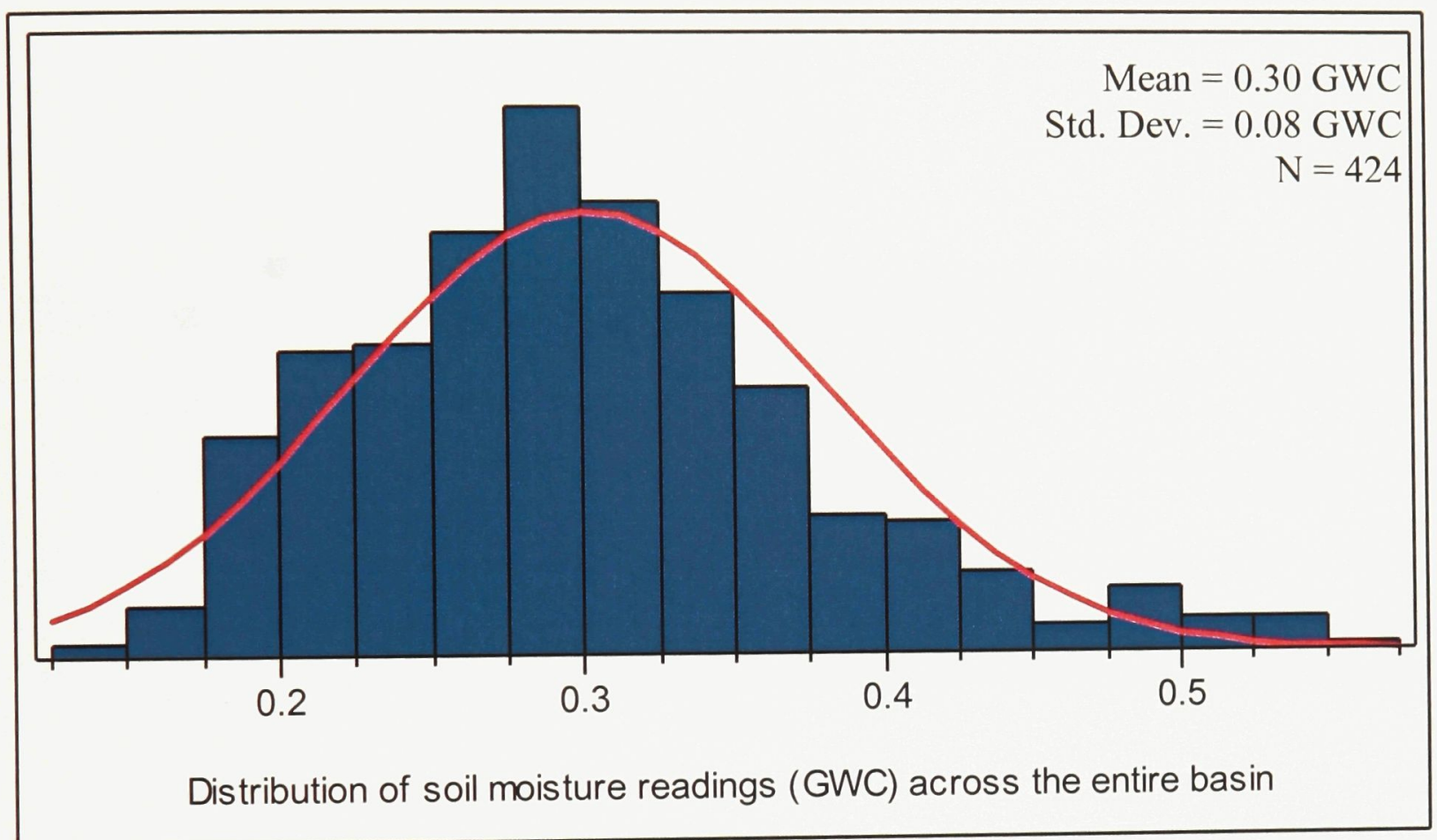

Figure 6.5 - Distribution of seasonal average soil moisture readings $(20 \mathrm{~cm}$; 5-point moving average) (GWC) across the entire basin.

Data from the three soil moisture probes placed in the ground near the weather station at the top of the test basin were examined. There was little difference in the season-long means and variance of the soil moisture across different depths, while the range of soil moisture integrated across a greater depth was slightly higher (Table 6.2). Short-term variability was the most noticeable difference, with deeper integrated soil moisture increasing more after precipitation events, yet exhibiting less variability 
between them. The greater increase in soil moisture at depth after precipitation can be attributed to shallower soil moisture being lost more quickly to evapotranspiration and instantaneous plant uptake (Figure 6.6).

\begin{tabular}{|c|c|c|c|}
\hline PROBE DEPTH & MEAN (GWC) & VARIANCE (GWC (G) $^{\mathbf{R}}$ & RANGE (GWC) \\
\hline$\sim \mathbf{1 2} \mathbf{~ c m}$ & 0.077 & 0.00015 & 0.047 \\
\hline$\sim \mathbf{2 0} \mathbf{~ c m}$ & 0.071 & 0.00017 & 0.068 \\
\hline
\end{tabular}

Table 6.2 - Comparison of deep $(\sim 25 \mathrm{~cm})$ and shallow $(\sim 12 \mathrm{~cm})$ integrated soil moisture readings taken throughout the 2005 growing season at the top of the test basin by the weather station. 


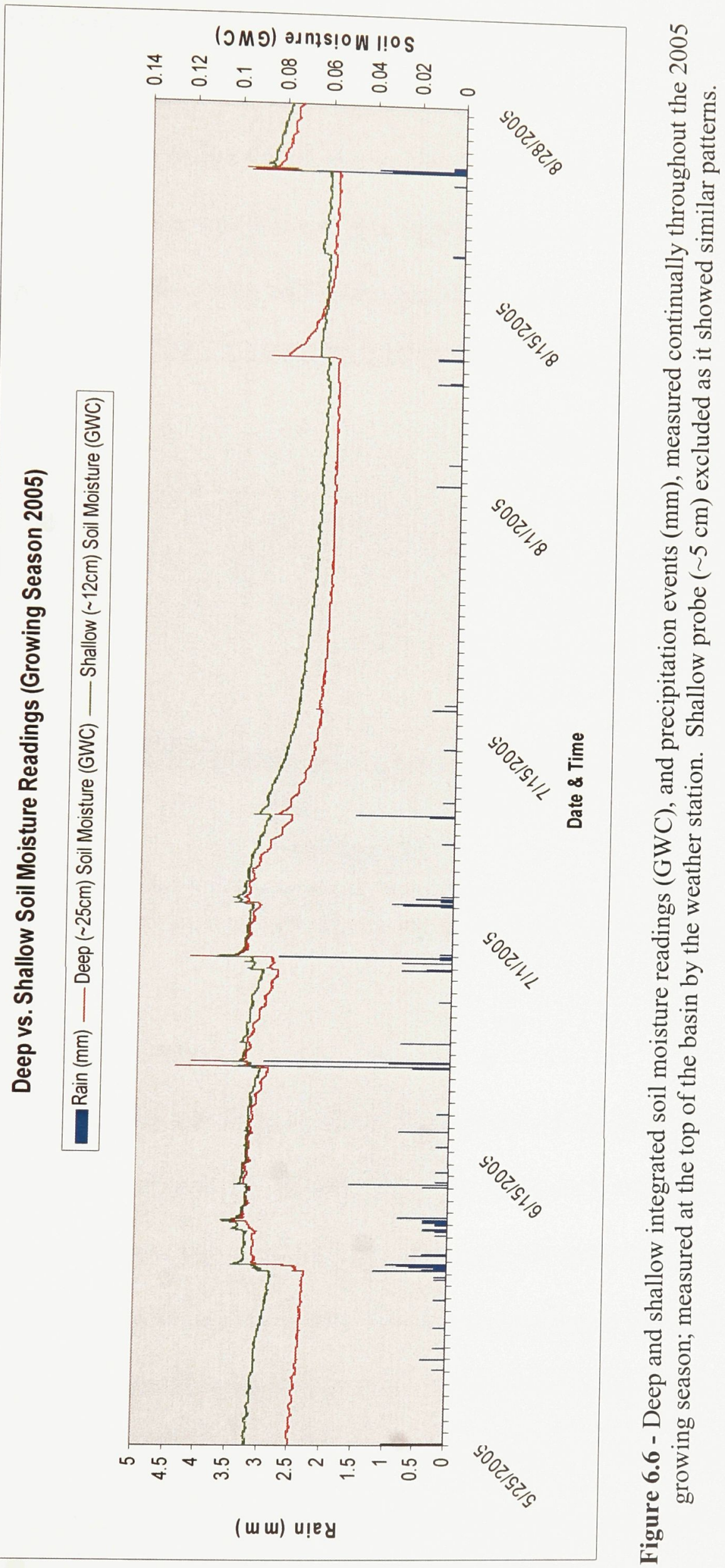


NPP across the entire basin ranged from $0 \mathrm{~g} \mathrm{~m}^{-2}$ to $454.9 \mathrm{~g} \mathrm{~m}^{-2}$ as shown in Figure 6.7. Measurements of $0 \mathrm{~g} \mathrm{~m}^{-2}$ occurred at four sample points across the basin, and can be attributed to eroded areas within the basin (especially along the eastern portion transect 8) where little to no vegetation was present. The vast majority of the values fell within the first third of this range. The mean NPP value was $81.7 \mathrm{~g} \mathrm{~m}^{-2}$.

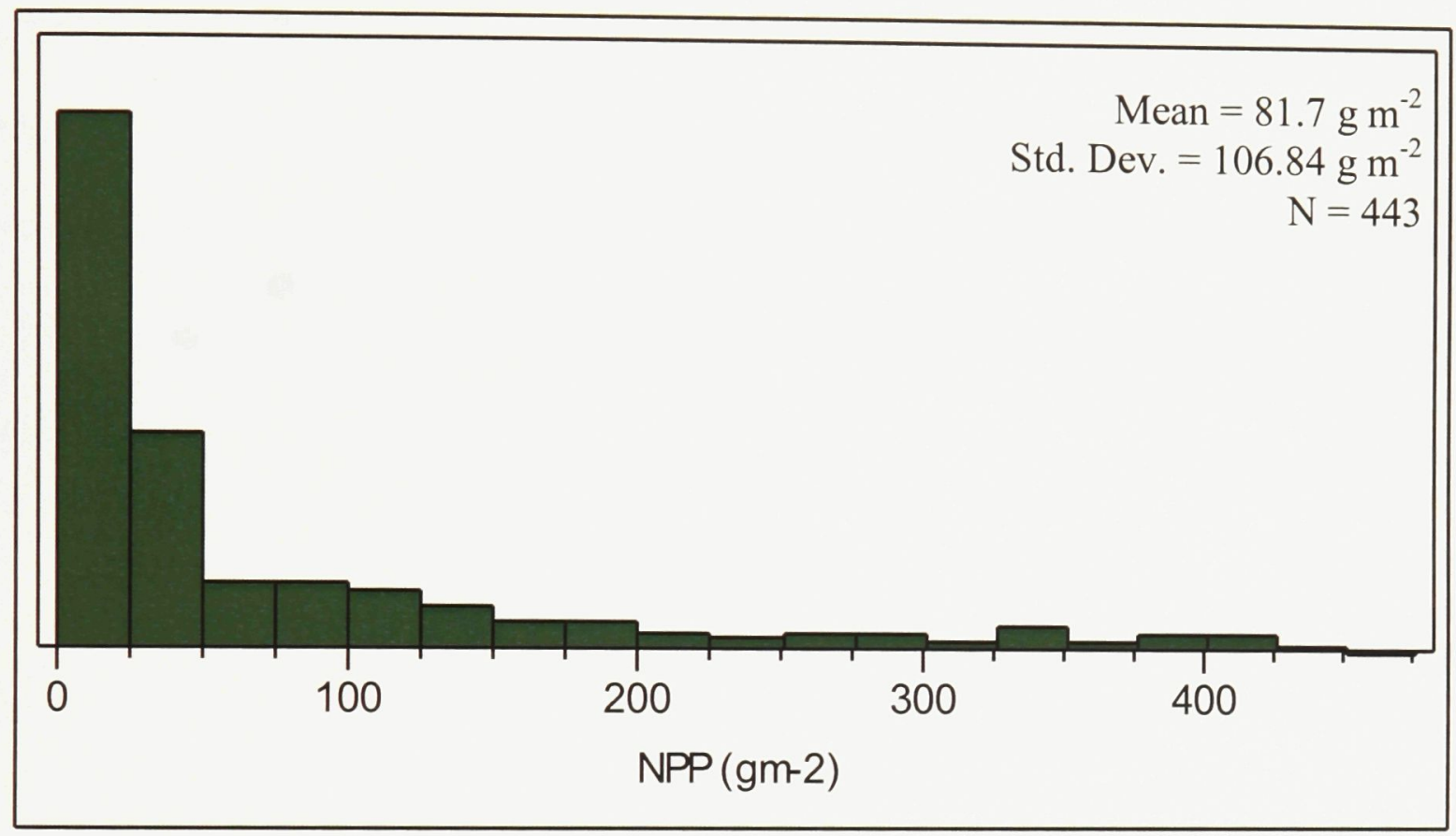

Figure 6.7 - Distribution of NPP measurements across the entire basin $\left(\mathrm{g} \mathrm{m}^{-2}\right)$.

\subsection{Basin-Wide Relationships}

It was hypothesized that there would be a positive correlation between the distribution of soil moisture and TI. By extension, soil moisture's relationships with slope and upslope area were also examined to see whether the individual components of TI were correlated with soil moisture in such a way that contributes to the predictive power of TI for soil moisture (i.e. slope was expected to correlate negatively, and upslope area was expected to correlate positively, with soil moisture). It was also hypothesized that NPP would be positively related with soil moisture and the topographic variables. 
The actual basin-wide correlations are presented in Table 6.3. There was a positive relationship between soil moisture and TI, but TI accounted for only $17 \%$ of the variance in soil moisture $\left(\mathrm{R}=0.41, \mathrm{R}^{2}=0.17, \mathrm{P}=<.0001, \mathrm{~N}=424\right)$ (Figure 6.8(A)), suggesting that higher TI values are not strong predictors of soil moisture accumulation. Soil moisture correlated with slope as hypothesized, but slope only accounted for $17 \%$ of the variance in soil moisture $\left(\mathrm{R}=-0.41, \mathrm{R}^{2}=0.17, \mathrm{P}=<.0001, \mathrm{~N}=424\right)$ (Figure 6.8(B)). The relationship shown suggests that more moisture is found near the headlands/shoulders and toe slopes of the basin where it is flatter rather than in steeper mid-slope areas. Upslope area was weakly correlated with soil moisture $\left(\mathrm{R}=-0.28, \mathrm{R}^{2}=\right.$ $0.08, \mathrm{P}=<.0001, \mathrm{~N}=424)$.

\begin{tabular}{c|c}
\hline & Basin-Wide \\
\hline NPP v. SM & $0.01(0.2489)$ \\
\hline SM v. TI & $\mathbf{0 . 1 7 ( < . 0 0 0 1 )}$ \\
SM v. SLP & $\mathbf{0 . 1 7}(<.0001)$ \\
SM v. UA & $\mathbf{0 . 0 8}(<.0001)$ \\
\hline NPP v. TI & $\mathbf{0 . 0 3 ( 0 . 0 0 0 3 )}$ \\
NPP v. SLP & $\mathbf{0 . 0 8}(<.0001)$ \\
NPP v. UA & $\mathbf{0 . 2 5 ( < . 0 0 0 1 )}$ \\
\hline
\end{tabular}

Table 6.3 - Correlation strength $\left(\mathrm{R}^{2}\right)$ and significance $\mathrm{P}$ (in parentheses) between variable pairs across the entire test basin. Selections in bold are statistically significant at the $95 \%$ confidence level. Selections in green show trends that are expected, while selections in red show trends that are opposite to what is expected. Legend: NPP = net primary production, $\mathrm{SM}=$ seasonal average soil moisture ( $20 \mathrm{~cm}$; 5 -point moving average) $(\mathrm{GWC}), \mathrm{TI}=$ topographic index, $\mathrm{SLP}=$ slope (degrees), $\mathrm{UA}=$ upslope $\operatorname{area}\left(\mathrm{m}^{2}\right)$. 


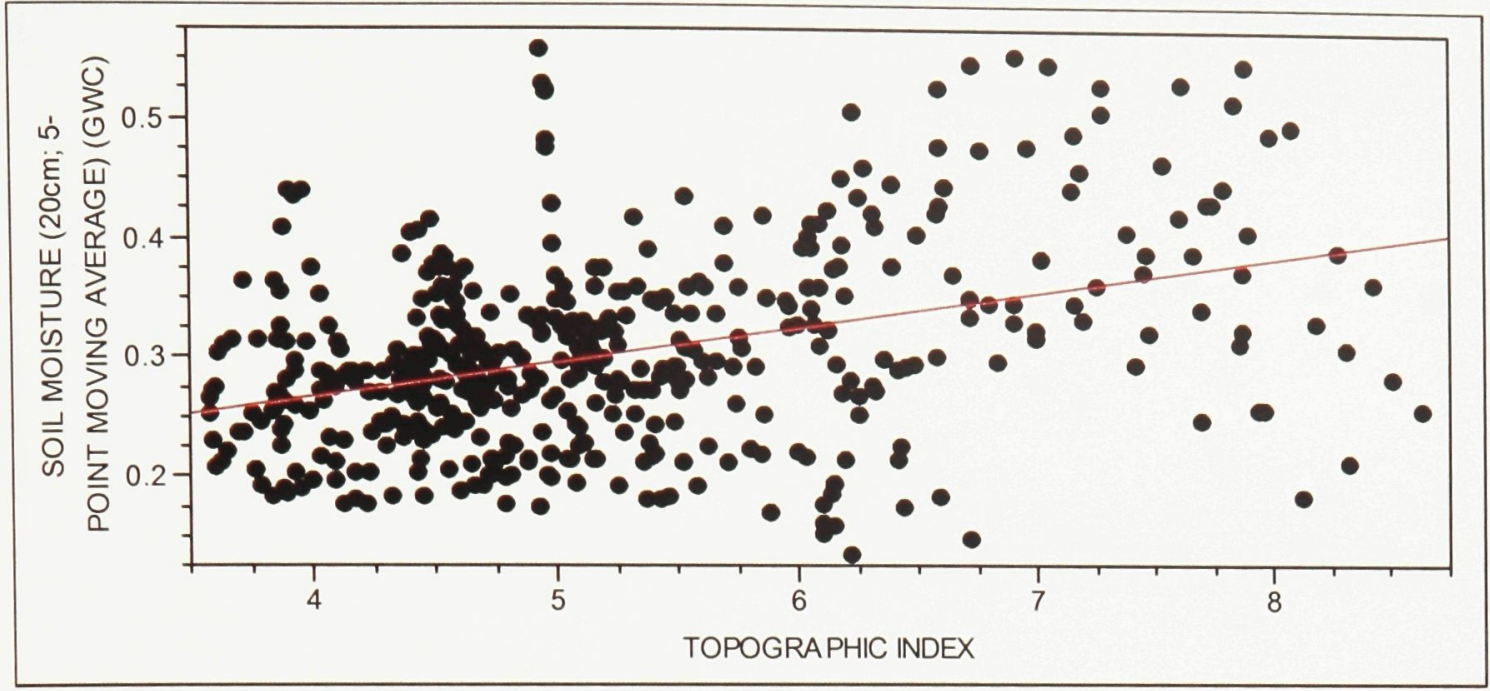

$\mathrm{R}^{2}=0.17$

$\mathrm{R}=0.41$

$\mathrm{P}=$

$<.0001$

$\mathrm{N}=424$

(A)

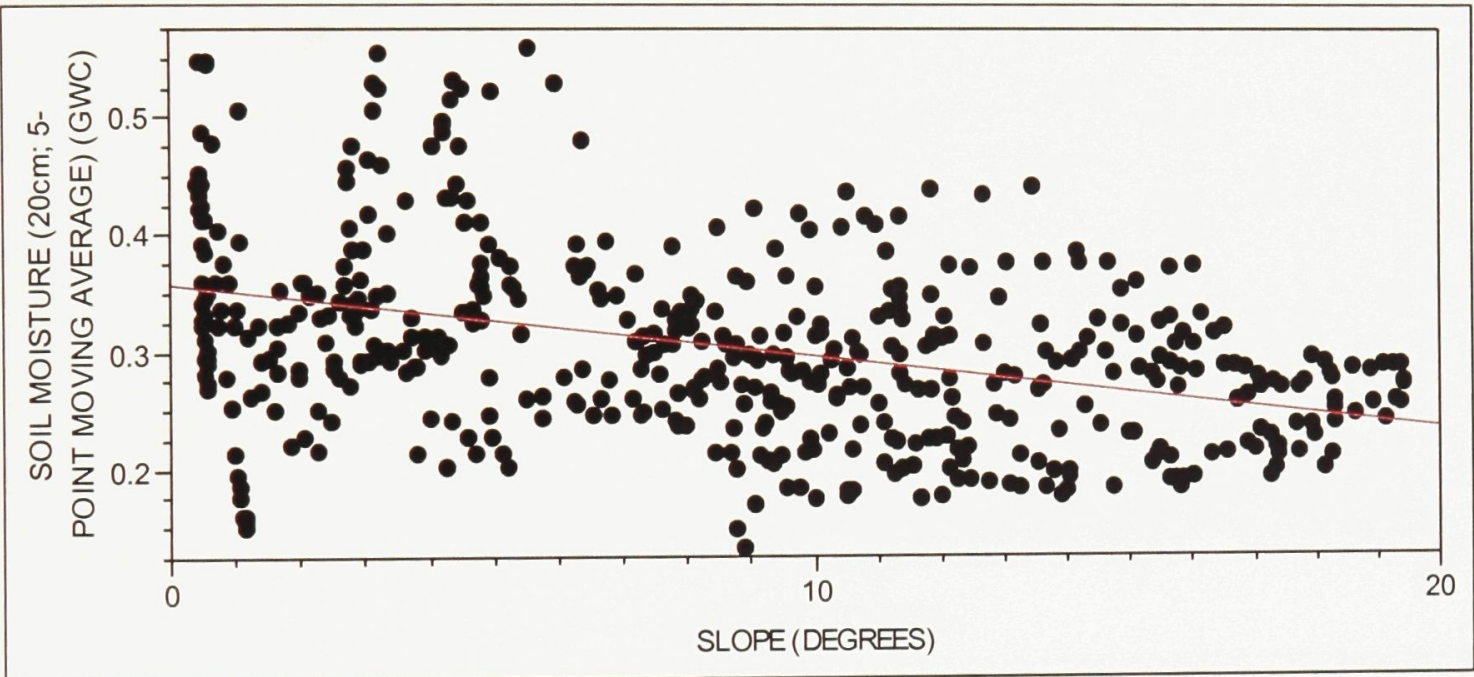

$\mathrm{R}^{2}=0.17$

$\mathrm{R}=-0.41$

$\mathrm{P}=$

$<.0001$

$\mathrm{N}=$

424

(B)

Figure 6.8 - Bivariate correlation of seasonal average soil moisture $(20 \mathrm{~cm}$; 5-point moving average) (GWC) and TI (A) and slope (degrees) (B) across the entire basin.

NPP had no relationship with soil moisture $\left(R=0.17, R^{2}=0.01, P=0.2489, N\right.$ =424) (Figure 6.9(A)). This is against the hypothesis that NPP and soil moisture would be positively correlated. The second element of that hypothesis was that NPP would be positively related to TI. Extending from that, steeper slopes would result in less productive vegetation, while a larger upslope area would result in increased productivity. TI and slope explained very little of the variance in NPP across the whole basin. TI accounted for only $3 \%$ of the variance $\left(R=0.17, R^{2}=0.03, P=0.0003, N=443\right)$, while 


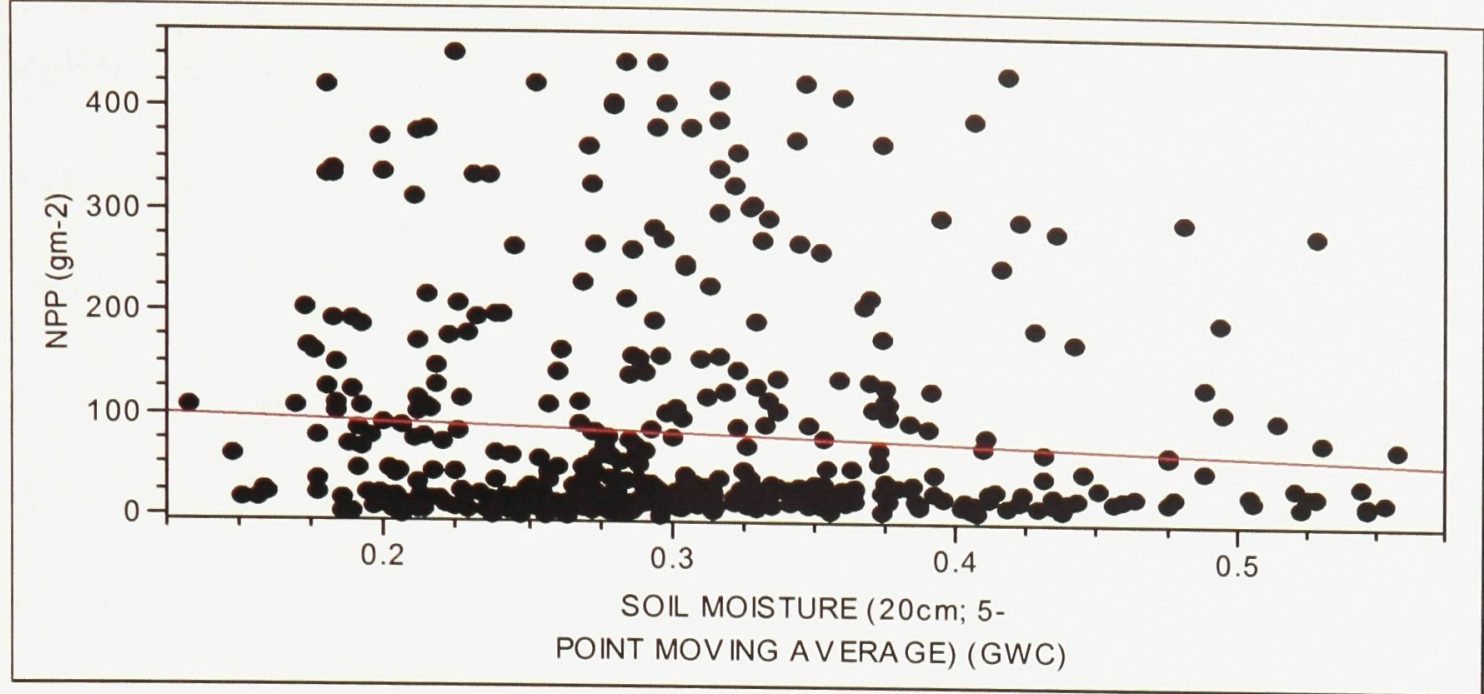

$\mathrm{R}^{2}=$

0.01

$\mathrm{R}=$ -

0.10

$\mathrm{P}=$

0.2489

$\mathrm{N}=$

424

(A)

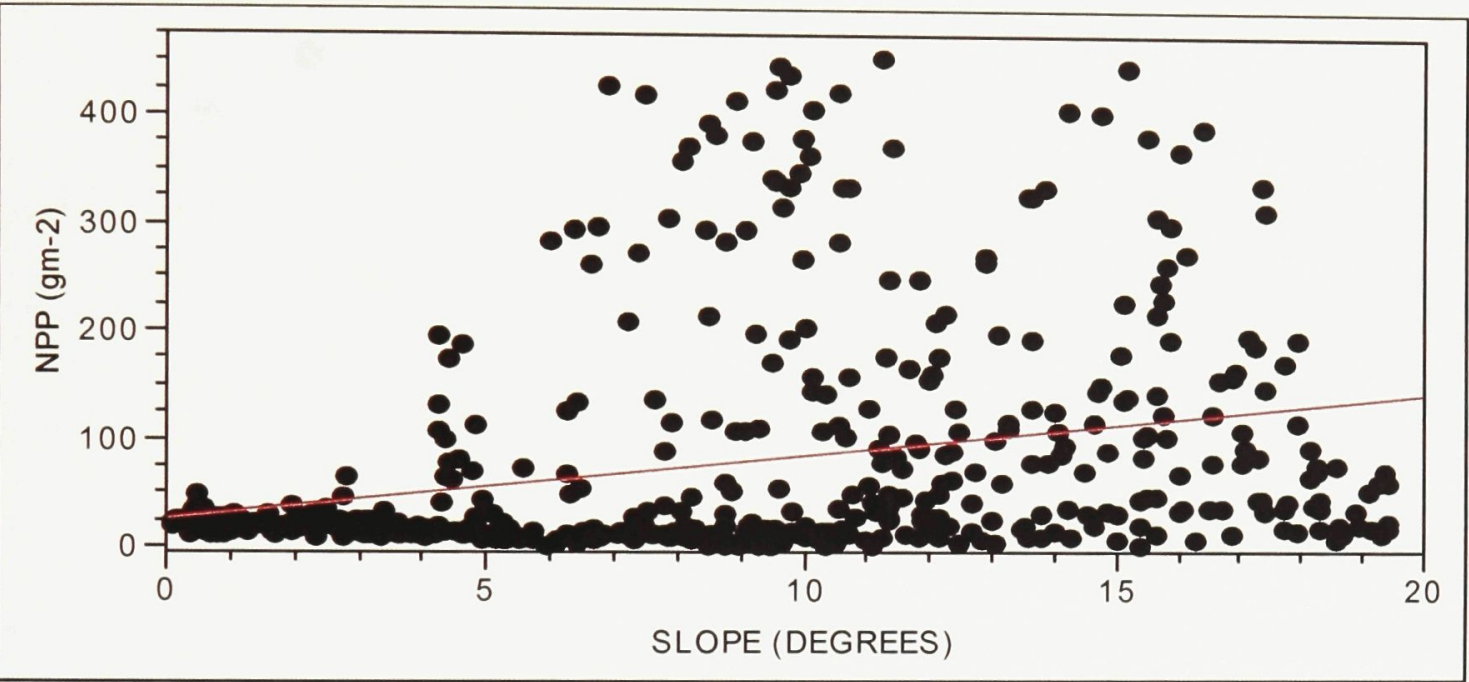

$\mathrm{R}^{2}=$

0.09

$\mathrm{R}=$

0.29

$\mathrm{P}=$

$<.0001$

$\mathrm{N}=$

443

(B)

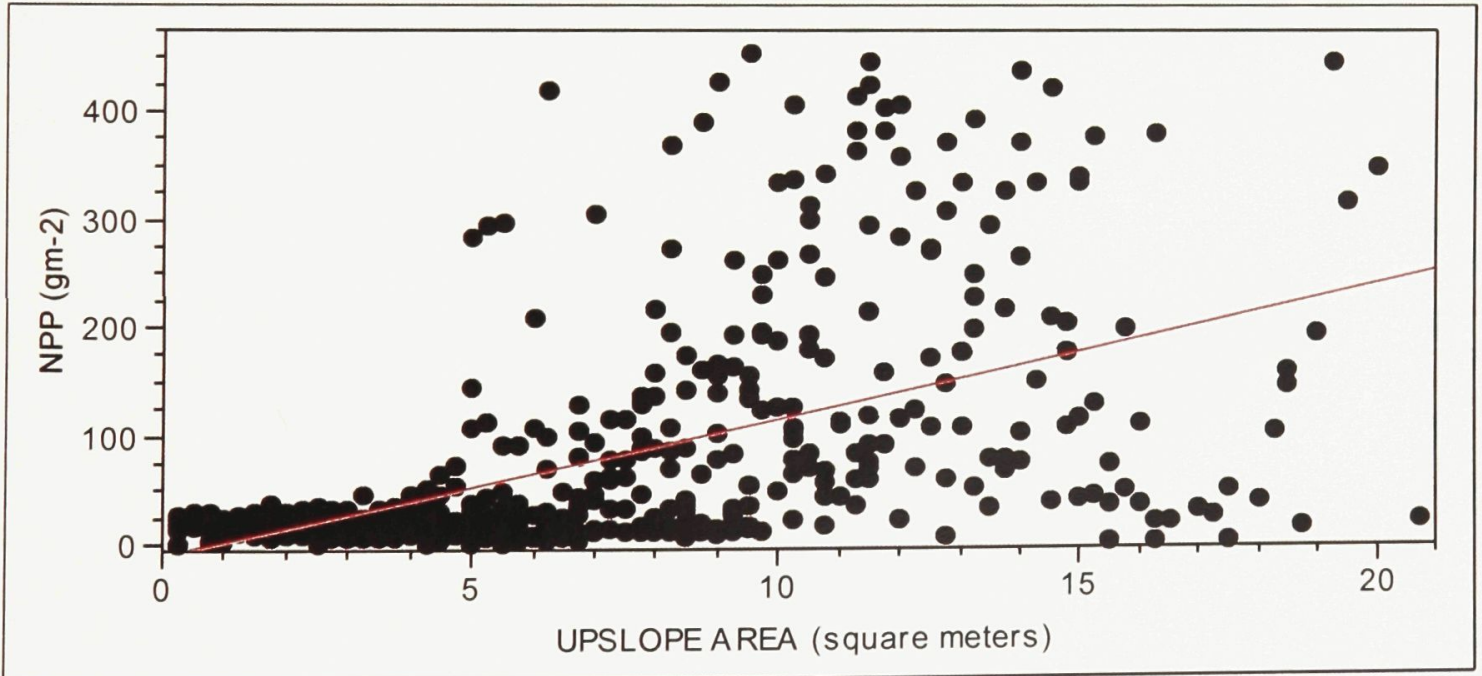

$\mathrm{R}^{2}=$

0.25

$\mathrm{R}=$

0.49

$\mathrm{P}=$

$<.0001$

$\mathrm{N}=$

Figure 6.9 - Bivariate correlation of NPP $\left(\mathrm{g} \mathrm{m}^{-2}\right)$ and seasonal average soil moisture $(20 \mathrm{~cm}$; 5point moving average) (GWC) (A), slope (degrees) (B) and upslope area $\left(\mathrm{m}^{2}\right)(\mathbf{C})$ across the entire basin. 
its relationship with slope was not in the hypothesized direction $\left(\mathrm{R}=0.29, \mathrm{R}^{2}=0.09, \mathrm{P}=\right.$ $<.0001, \mathrm{~N}=443$ ) (Figure 6.9(B)). The average and variability of NPP increased on midranged slopes (at a value of approx. $4^{\circ}$ ) and lower values were spread across the flattest and steepest parts of the basin, which was against the hypothesis that steeper slopes would predict a decrease in productivity. Of the topographic variables, upslope area was the best predictor of NPP, accounting for $25 \%$ of its variance $\left(\mathrm{R}=0.49, \mathrm{R}^{2}=0.25, \mathrm{P}=\right.$ $<.0001, \mathrm{~N}=443)($ Figure 6.9(C)).

The latter relationship is worth more detailed examination. The average and variability in NPP increased when the upslope area reached a size of approximately 5.0 $\mathrm{m}^{2}$, and this corresponded to values that occurred within the concave portion of the test basin and up to the transition between the backslope and the shoulders of the basin, as shown by the red areas in Figure 6.10. A possible threshold existed here, where at certain points on the landscape, once the upslope area reached a specific size, vegetation was seen to flourish. This suggests that upslope area is not the only factor affecting the growth of the vegetation in the basin, but appears to be an important one predicting NPP.

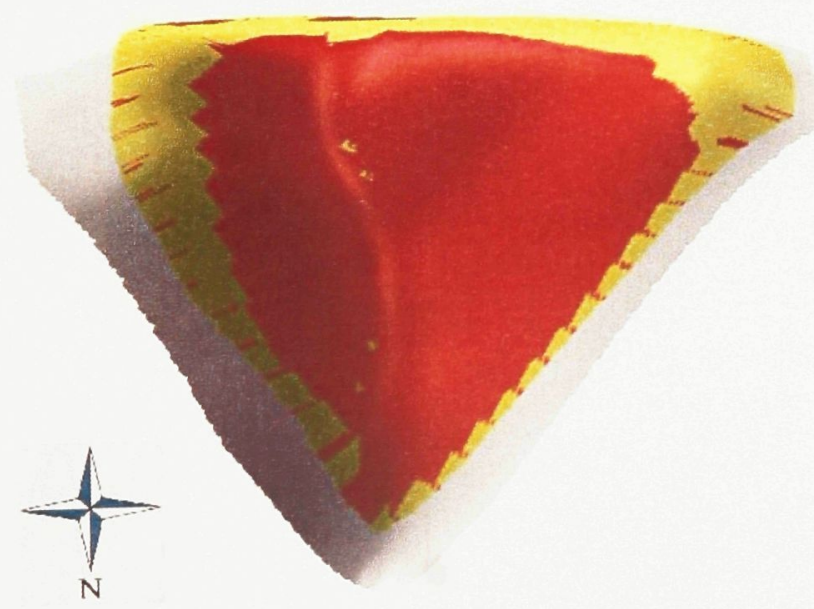

Figure 6.10 - Areas in the test basin with upslope areas $>5.0 \mathrm{~m}^{2}$ (in red). Vertical exaggeration $=3.0$. 


\subsection{TOPOGRAPHIC AND VEGETATION SEGREGATION}

The third hypothesis of this thesis was that the reduced heterogeneity within specific landscape positions and vegetation communities would strengthen the relationships among NPP, soil moisture and the topographic variables.

\subsection{Segregation by Landscape Position}

The data were first segregated by landscape position within the basin, including aspect (east and west facing hillslopes), as well as delineation between drainage zone and upslope areas. Table 7.1 summarizes the relationships among the variables of interest within the different landscape position segregations. 


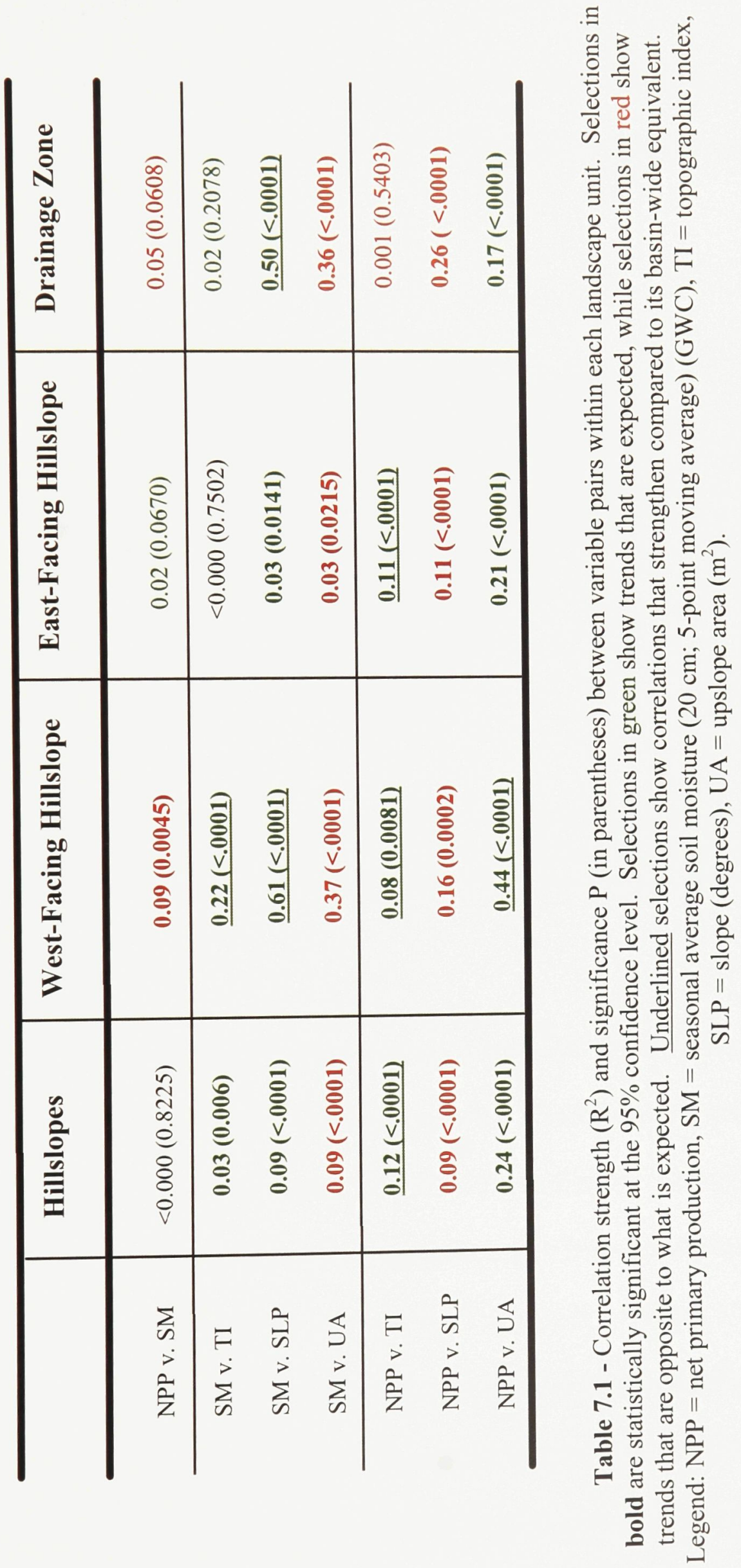




\subsubsection{Segregation by Hillslopes}

The calculated east and west facing hillslopes are shown in Figure 7.1. This delineated those areas occupying the inner bowl of the basin, inside the outer ridges, but excluding the drainage zone.

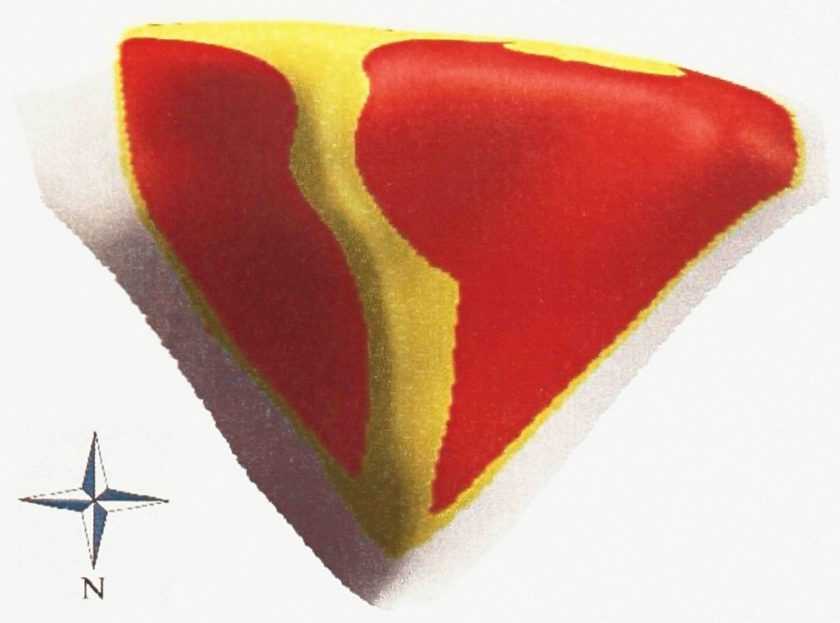

Figure 7.1 - West (on the left) and east (on the right) facing hillslopes of the basin (in red), as defined by those portions of the basin where TI values were less than 5.5 and the elevation was less than $852 \mathrm{~m}$ ASL $(<852 \mathrm{~m})$. Vertical exaggeration $=3.0$.

None of the hypothesized relationships involving soil moisture was strengthened by restricting analysis to the within-hillslope samples. There was no relationship between soil moisture and TI $\left(R=0.16, R^{2}=0.03, P=0.006, N=285\right)$ (Figure 7.2(A)). Slope's account of the variance in soil moisture decreased from a basin-wide value of $17 \%$ to a hillslope correlation of $9 \%\left(\mathrm{R}=-0.29, \mathrm{R}^{2}=0.09, \mathrm{P}=<.0001, \mathrm{~N}=285\right)$ (Figure 7.2(B)) and upslope area was again negatively correlated with soil moisture $(\mathrm{R}=-0.30$, $\mathrm{R}^{2}=0.09, \mathrm{P}=<.0001, \mathrm{~N}=285$ ). The hillslopes still encompassed a wide range of basin dynamics when analyzed as a single unit, and the lack of any noted change in relationship 
direction or strength may be attributed to this, as conditions remained similar to the entire basin. Within the hillslopes, there is a decreased range of slope, but still a high variability in soil moisture.

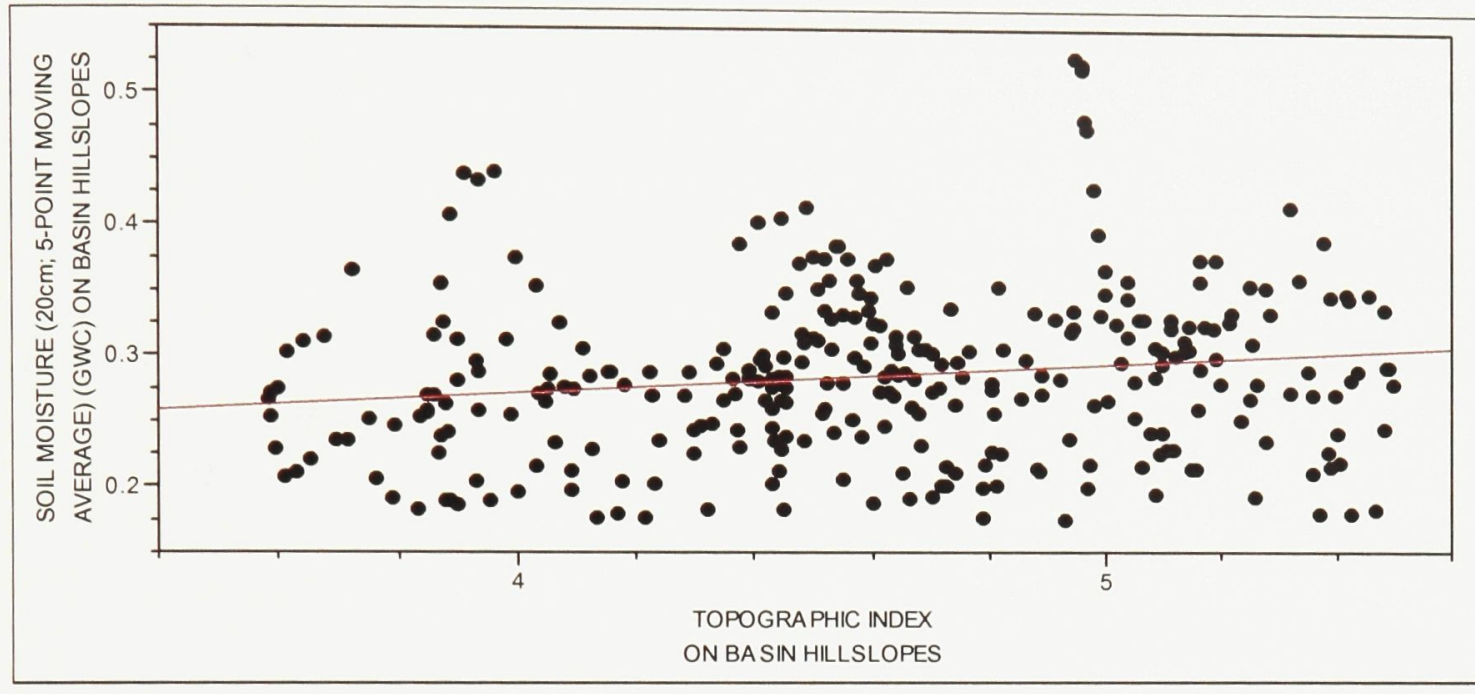

$\mathrm{R}^{2}=$

0.03

$\mathrm{R}=$

0.16

$\mathrm{P}=$

0.006

$\mathrm{N}=$

285

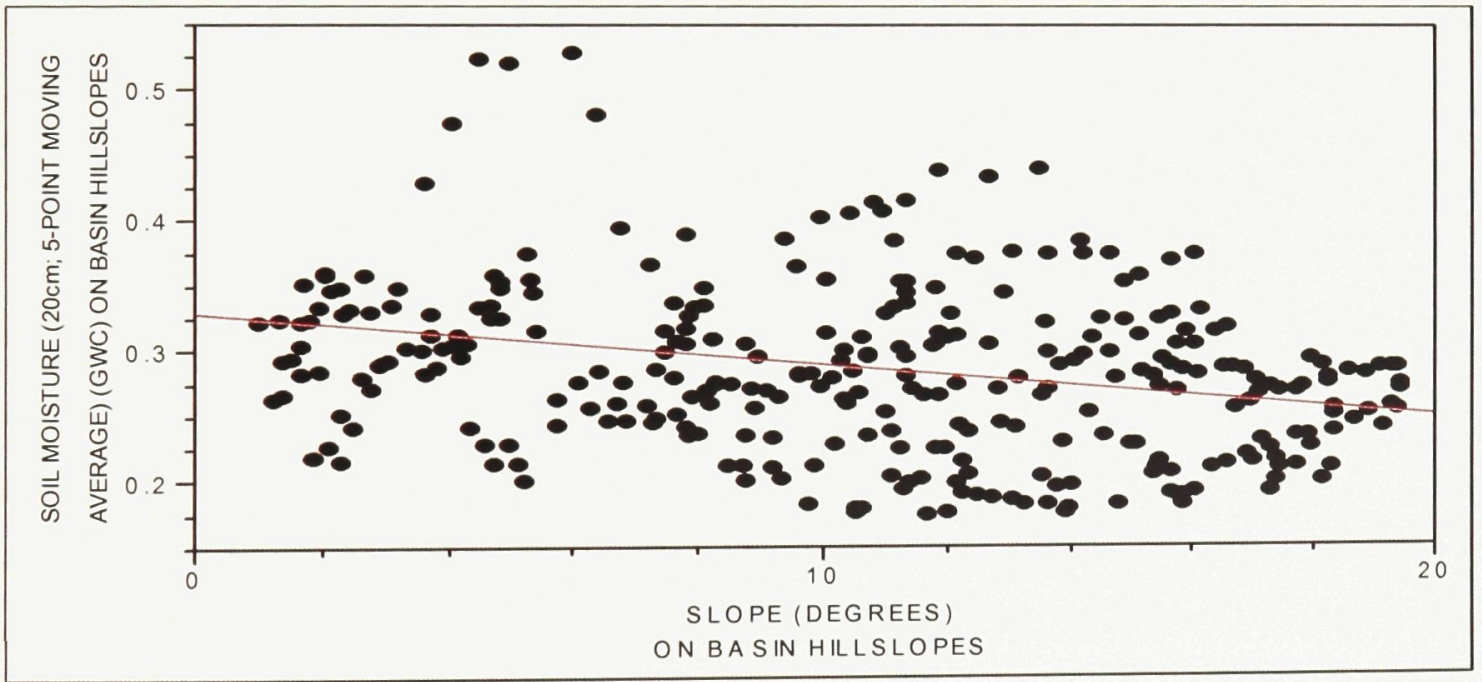

$\mathrm{R}^{2}=$

0.09

$\mathrm{R}=$

$-0.29$

$\mathrm{P}=$

$<.0001$

$\mathrm{N}=$

285

Figure 7.2 - Bivariate correlation of seasonal average soil moisture $(20 \mathrm{~cm}$; 5-point moving average) (GWC) and TI (A) and slope (degrees) (B) on the basin hillslopes.

There was no relationship between NPP and soil moisture when restricting analysis to the within-hillslope samples $\left(R=-0.01, R^{2}=<0.000, P=0.8225, N=285\right)$. TI's account of the variance in NPP on the hillslopes increased to $12 \%$, up from a $3 \%$ 
basin-wide correlation $\left(\mathrm{R}=0.35, \mathrm{R}^{2}=0.12, \mathrm{P}=<.0001, \mathrm{~N}=285\right)$. Slope remained positively correlated with NPP, with a weak explanation of variance $\left(R=0.29, R^{2}=0.09\right.$, $\mathrm{P}=<.0001, \mathrm{~N}=285$ ), while upslope area continued to be positively correlated with NPP $\left(\mathrm{R}=0.49, \mathrm{R}^{2}=0.24, \mathrm{P}=<.0001, \mathrm{~N}=285\right)$. The same increase in the average and variability of NPP in relation to upslope area was observed in this landscape position (Figure 7.3), occurring when the upslope area reached a size of approximately $5.0 \mathrm{~m}^{2}$. This corresponded still to regions within the concave portion of the test basin and up to the transition between the backslope and the shoulders, just as the basin sides began to increase in slope towards the drainage zone.

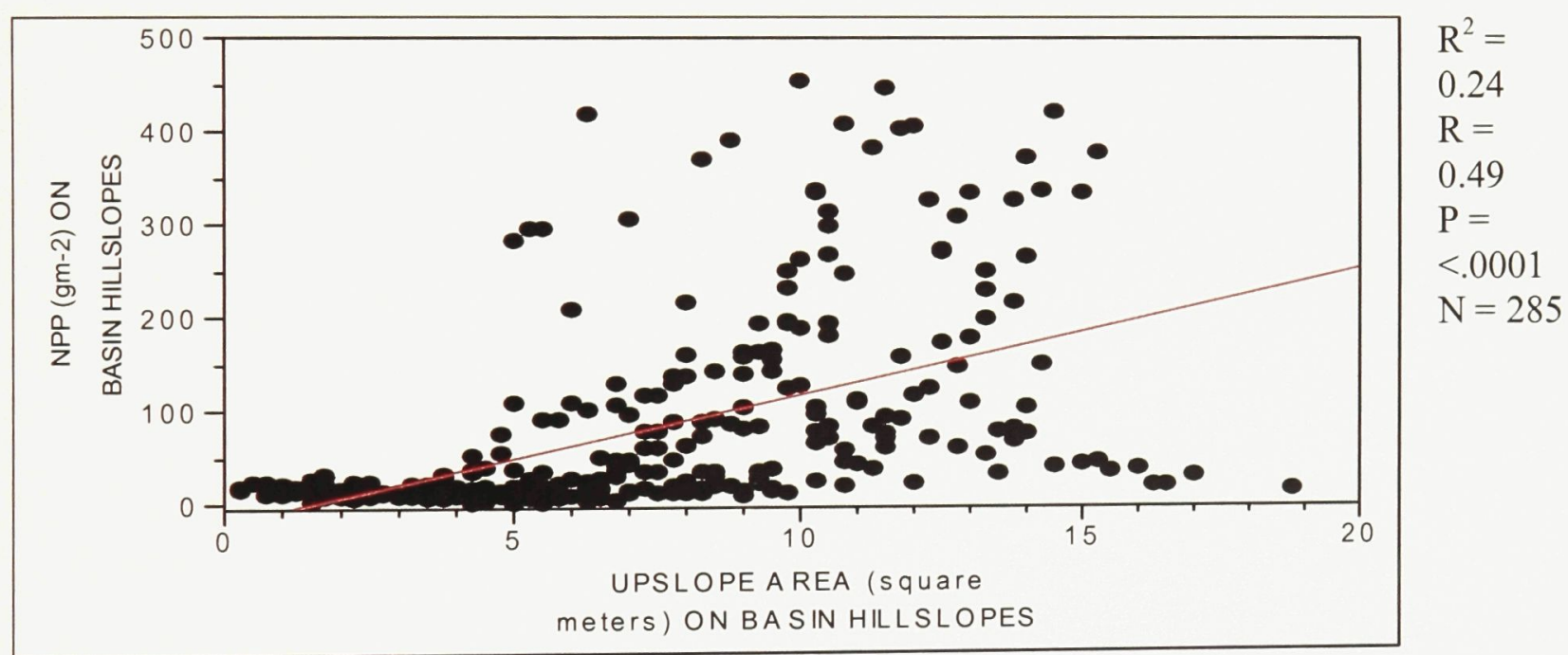

Figure 7.3 - Bivariate correlation of NPP $\left(\mathrm{g} \mathrm{m}^{-2}\right)$ and upslope area $\left(\mathrm{m}^{2}\right)$ on the basin hillslopes.

\subsubsection{1 - West-Facing Hillslope}

Further testing of the third hypothesis was carried out by examining the hillslopes defined as separate units, based on aspect. On the west-facing hillslope, the relationship between soil moisture and TI remained in the hypothesized direction, with TI accounting 
for $22 \%$ of the variance in soil moisture $\left(R=0.47, R^{2}=0.22, P=<0.0001, N=85\right)$ (Figure 7.4(A)), compared to a 17\% basin-wide correlation. Slope's account of the variance in soil moisture increased to $61 \%\left(R=-0.78, R^{2}=0.61, P=<.0001, N=85\right)$ (Figure 7.4(B)), up from a 17\% basin-wide correlation. This hillslope is noticeably more eroded than other parts of the basin, suggesting that its moisture holding capability is lower, which would lead to the expected slope effect. Upslope area continued to correlate negatively with soil moisture $\left(\mathrm{R}=-0.56, \mathrm{R}^{2}=0.37, \mathrm{P}=<.0001, \mathrm{~N}=85\right.$ ) (Figure 7.4(C)) 


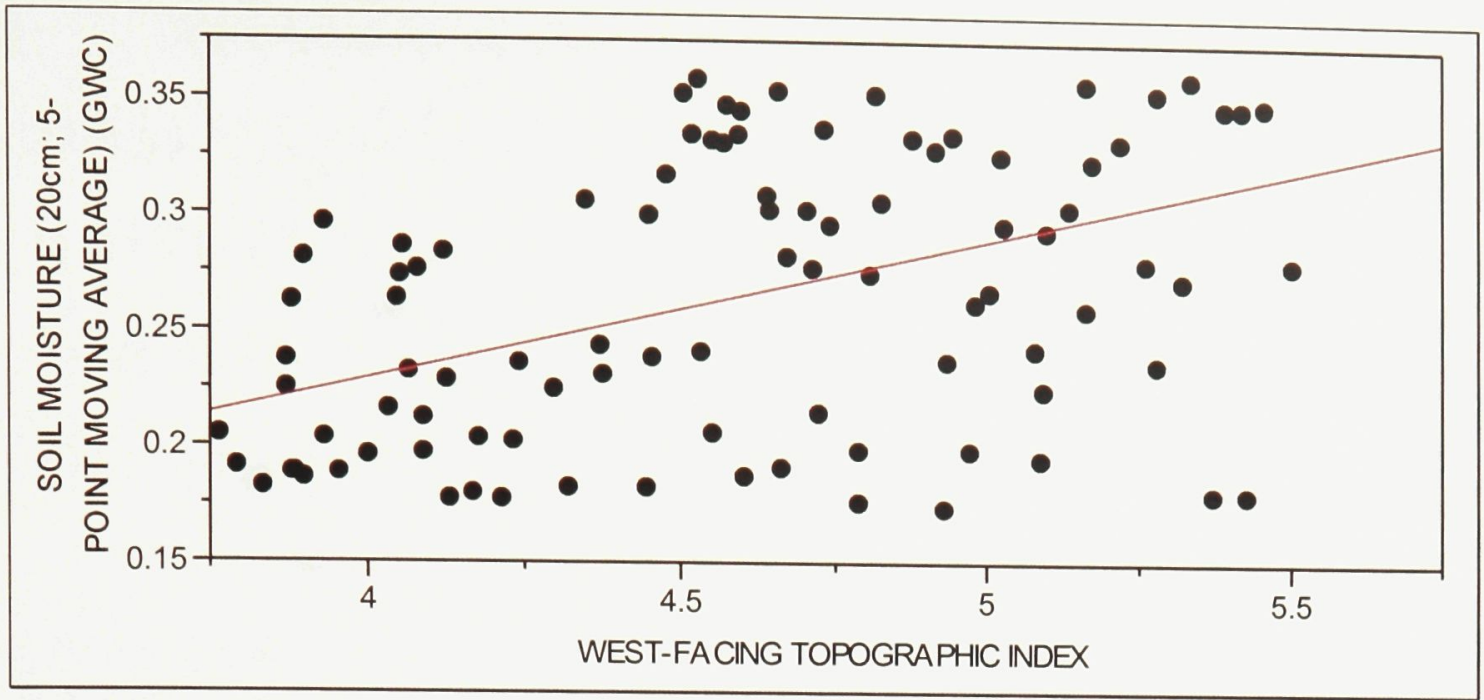

$\mathrm{R}^{2}=$

0.22

$\mathrm{R}=$

0.47

$\mathrm{P}=$

$<.0001$

$\mathrm{N}=85$

(A)

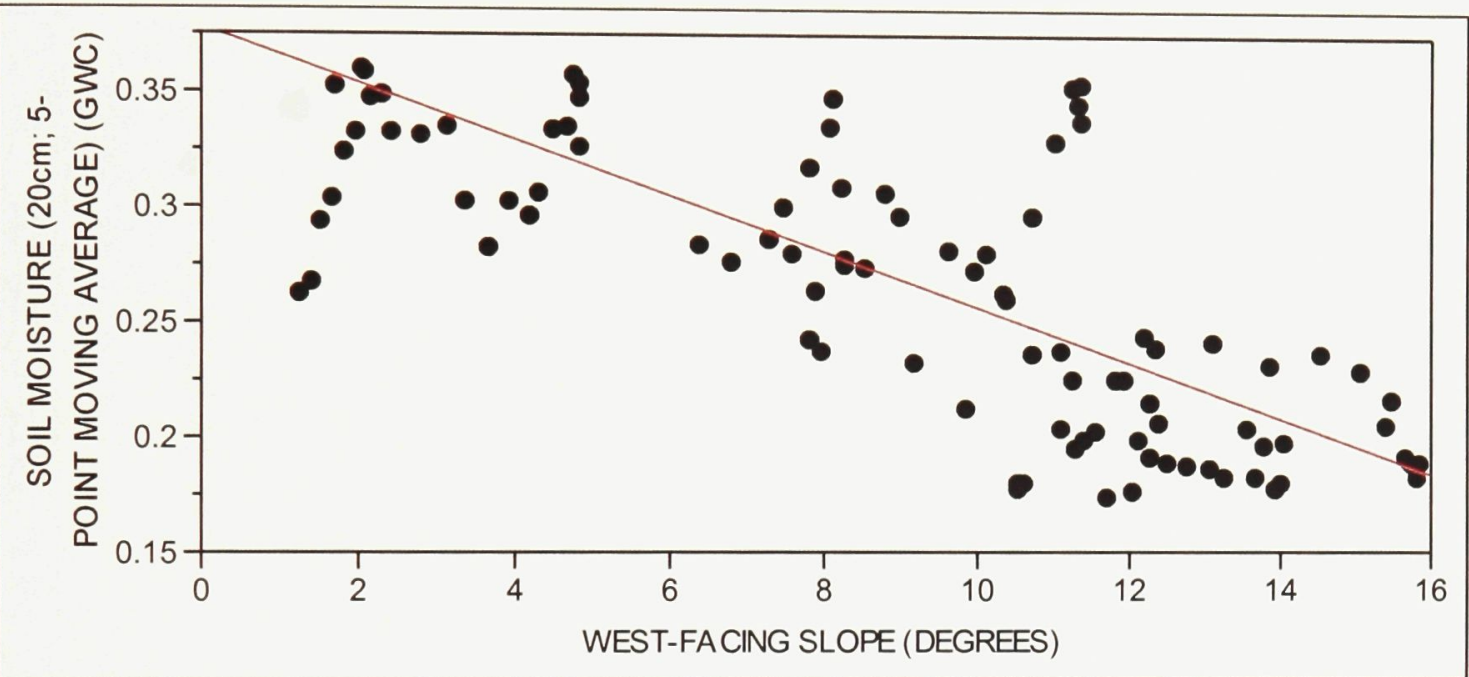

$\mathrm{R}^{2}=$

0.61

$\mathrm{R}=$

$-0.78$

$\mathrm{P}=$

$<.0001$

$\mathrm{N}=85$

(B)

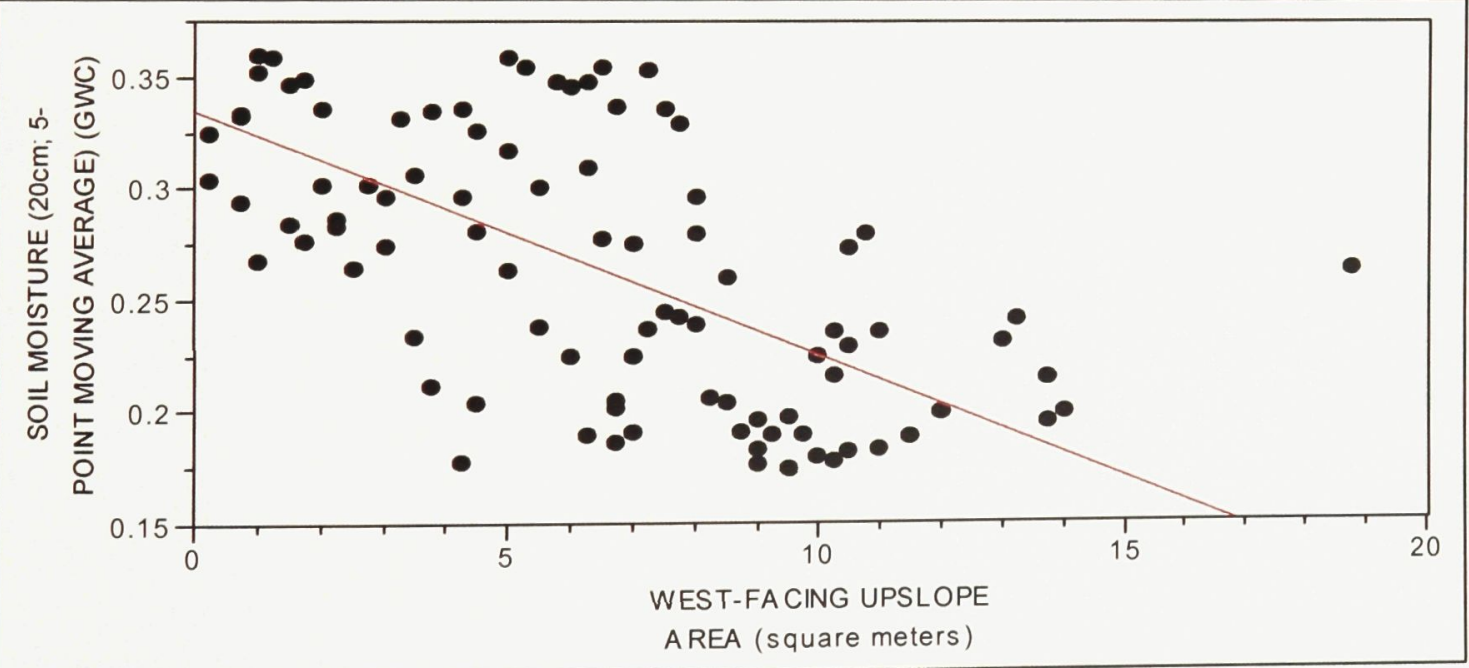

$\mathrm{R}^{2}=$

0.37

$\mathrm{R}=$

$-0.56$

$\mathrm{P}=$

$<.0001$

$\mathrm{N}=85$

(C)

Figure 7.4 - Bivariate correlation of seasonal average soil moisture $(20 \mathrm{~cm}$; 5-point moving average) (GWC) and TI (A), slope (degrees) (B) and upslope area $\left(\mathrm{m}^{2}\right)(\mathbf{C})$ on the west-facing hillslope of the test basin. 
The relationship between NPP and soil moisture remained negatively correlated and weak when restricting the analysis to the west-facing hillslope $\left(R=-0.30, R^{2}=0.09\right.$, $\mathrm{P}=<.0045, \mathrm{~N}=85$ ) (Figure 7.5). Mean productivity was $72.2 \mathrm{~g} \mathrm{~m}^{-2}$ on this hillslope, down from a basin-wide mean of $81.7 \mathrm{~g} \mathrm{~m}^{-2}$ (Figure 7.6) which can be attributed to the higher erosion and decreased vegetative cover in this landscape position.

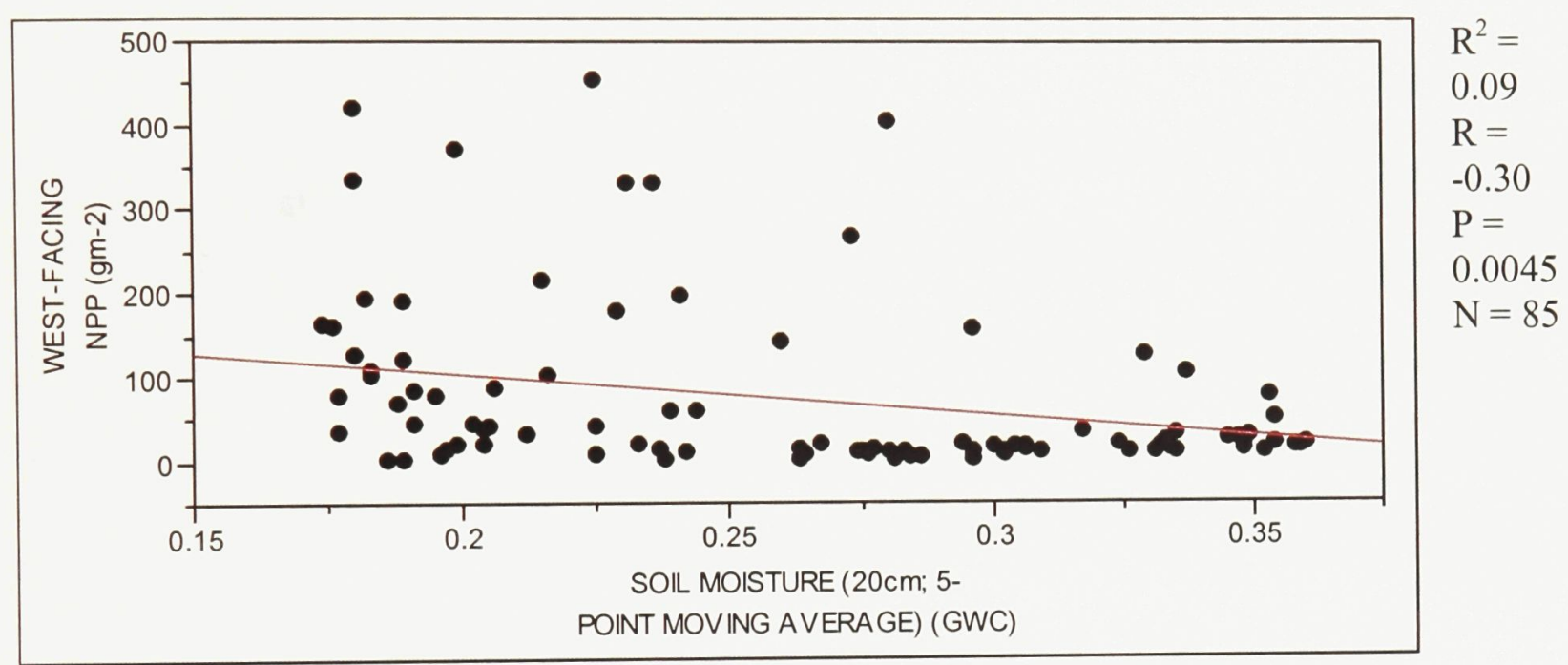

Figure 7.5 - Bivariate correlation of NPP $\left(\mathrm{g} \mathrm{m}^{-2}\right)$ and seasonal average soil moisture $(20 \mathrm{~cm}$; 5 point moving average) (GWC) on the west-facing hillslope of the test basin.

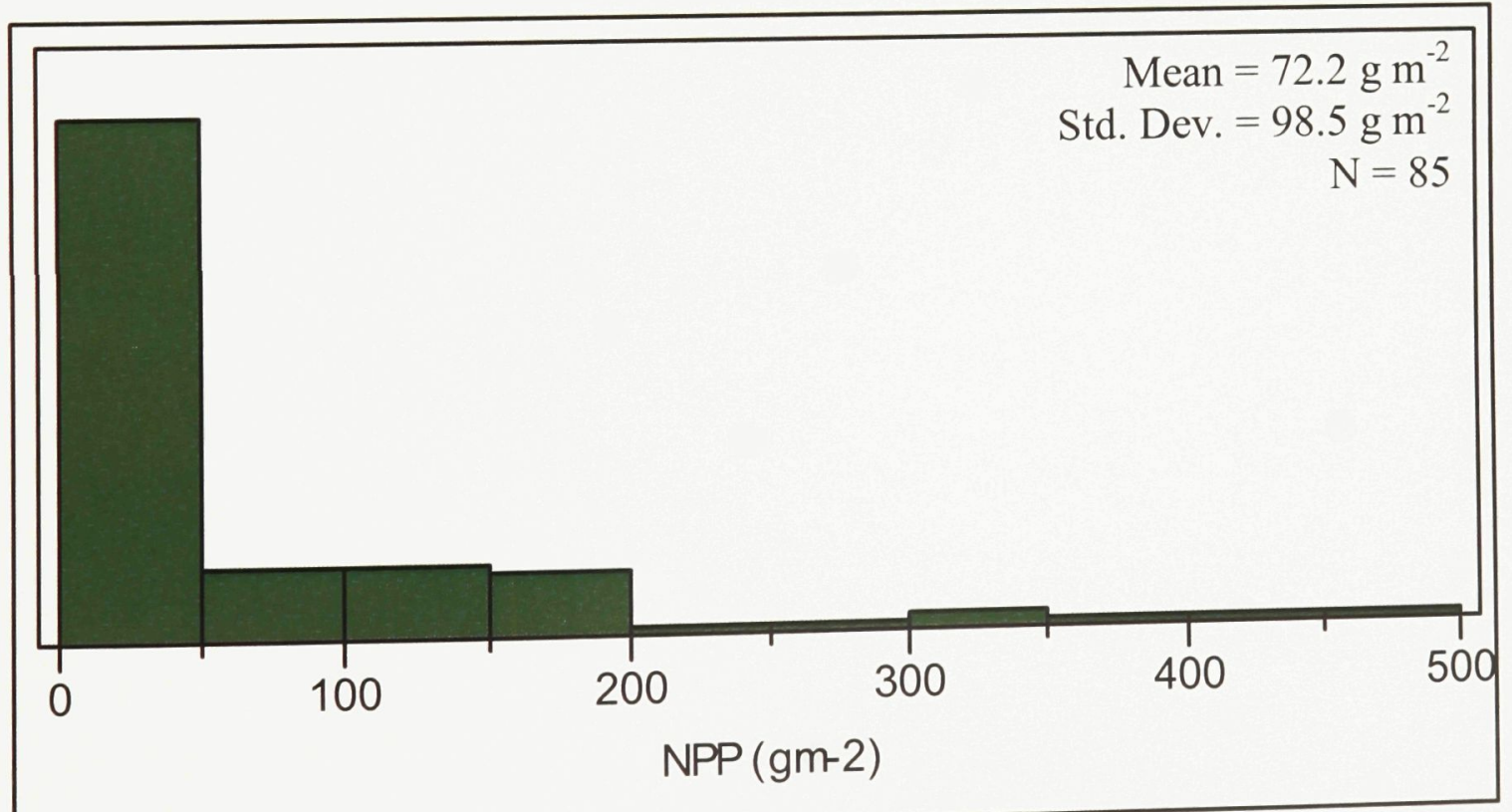

Figure 7.6 - Distribution of NPP measurements on the west-facing hillslope of the test basin $\left(\mathrm{g} \mathrm{m}^{-2}\right)$. 
Two of the hypothesized relationships involving NPP on the west-facing hillslope were strengthened. TI's account of the variance in NPP increased, but only to $8 \%$ ( $\mathrm{R}=$ $\left.0.28, \mathrm{R}^{2}=0.08, \mathrm{P}=0.008, \mathrm{~N}=85\right)$. Slope correlated positively with $\mathrm{NPP}$ again $(\mathrm{R}=$ $0.40, R^{2}=0.16, P=0.0002, N=85$ ), while upslope area accounted for $44 \%$ of the variance in NPP $\left(R=0.66, \mathrm{R}^{2}=0.44, \mathrm{P}=<.0001, \mathrm{~N}=85\right)$ (Figure 7.7$)$; a $19 \%$ increase from the basin-wide correlation.

The increase in the average and variability of NPP with respect to upslope area was also observed on the west-facing hillslope, when the upslope area reached a size of approximately $7.5 \mathrm{~m}^{2}$. The increase occurred at a higher upslope area when viewed on this hillslope (as opposed to an upslope area of approximately $5.0 \mathrm{~m}^{2}$ on both hillslopes), which can be attributed to higher erosion and a greater abundance of areas where grass dominance has become disrupted. The region of the basin to which this increase corresponded remained unchanged. A threshold may exist on this hillslope, and upslope area is influencing NPP, but other factors are contributing to the variance in NPP at varying degrees. 


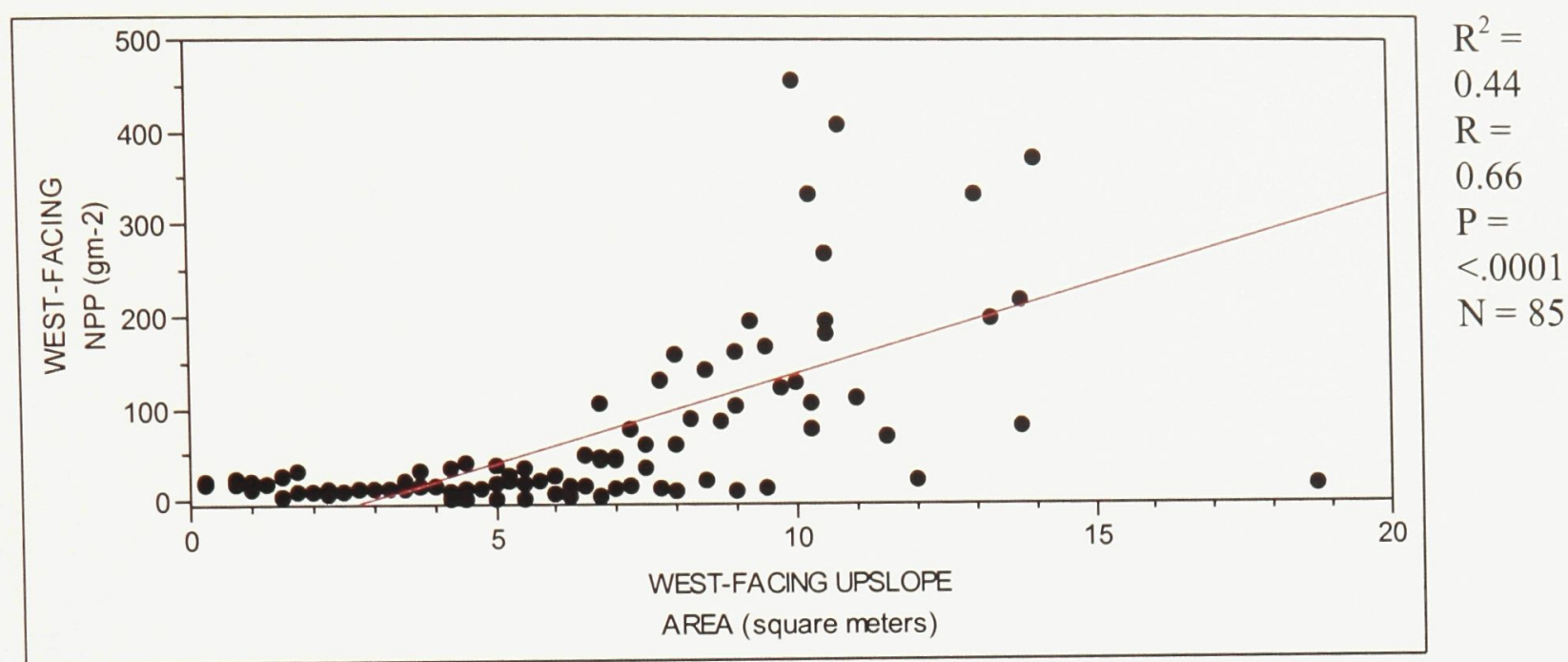

Figure 7.7 - Bivariate correlation of NPP $\left(\mathrm{g} \mathrm{m}^{-2}\right)$ and upslope area $\left(\mathrm{m}^{2}\right)$ on the west-facing hillslope of the test basin.

\subsubsection{2 - East-Facing Hillslope}

None of the hypothesized relationships involving soil moisture was strengthened by restricting the analysis the to the east-facing hillslope samples. There was no correlation between soil moisture and TI $\left(R=0.02, R^{2}=<0.000, P=0.7502, N=189\right)$. Slope's account of the variance in soil moisture dropped to $3 \%\left(R=-0.18, R^{2}=0.03, P=\right.$ 0.014, $\mathrm{N}=189$ ) (Figure 7.8(A)), down from a 17\% basin-wide correlation. Upslope area remained negatively correlated with soil moisture on this hillslope and was weak $\left(\mathrm{R}=-0.17, \mathrm{R}^{2}=0.03, \mathrm{P}=0.0215, \mathrm{~N}=189\right.$ ) (Figure $7.8(\mathrm{~B})$ ). Soil moisture variability remained high, and there was an increased range in slope values on the east-facing hillslope compared to the west-facing one. 


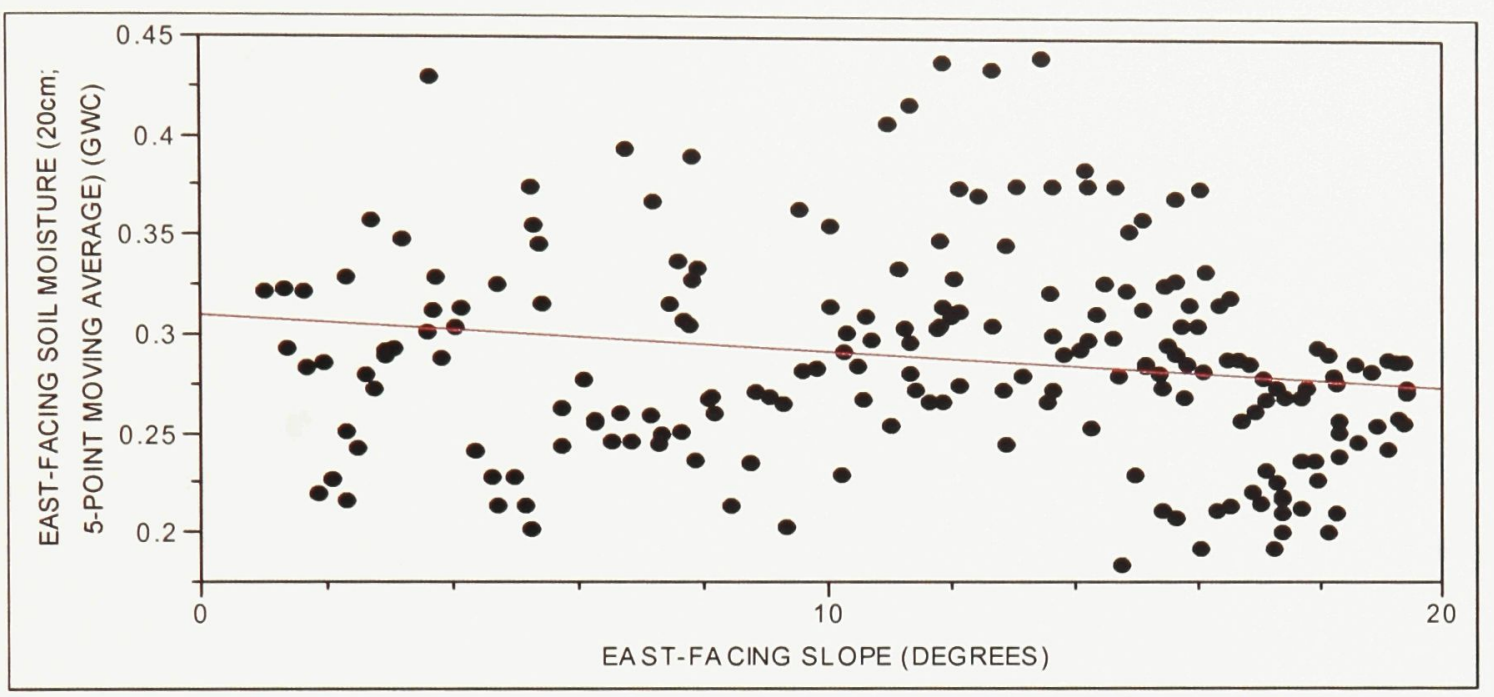

$\mathrm{R}^{2}=$

0.03

$\mathrm{R}=$

$-0.18$

$\mathrm{P}=$

0.014

$\mathrm{N}=$

189

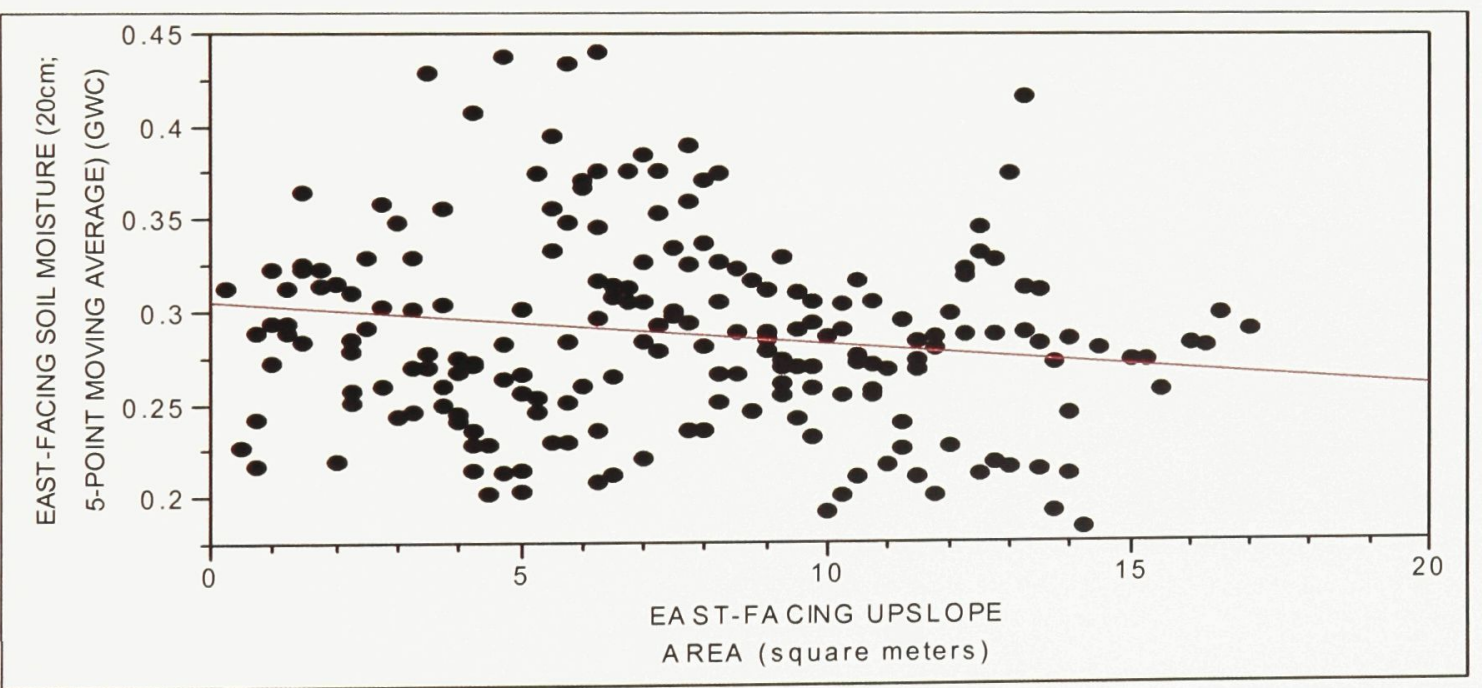

$\mathrm{R}^{2}=$

0.03

$\mathrm{R}=$

$-0.17$

$\mathrm{P}=$

0.0215

$\mathrm{N}=189$

Figure 7.8 - Bivariate correlation of seasonal average soil moisture $(20 \mathrm{~cm}$; 5-point moving average) (GWC) and slope (degrees) (A) and upslope area $\left(\mathrm{m}^{2}\right)(\mathbf{B})$ on the east-facing hillslope of the test basin. 
There continued to be no correlation between NPP and soil moisture when restricting the analysis to the east-facing hillslope samples $\left(\mathrm{R}=0.13, \mathrm{R}^{2}=0.02, \mathrm{P}=\right.$ $0.067, \mathrm{~N}=189$ ) (Figure 7.9). Over half the NPP values were between $0 \mathrm{~g} \mathrm{~m}^{-2}$ and $50 \mathrm{~g}$ $\mathrm{m}^{-2}$, highlighting the low production in this landscape position, which may be a factor in the observed relationship (Figure 7.10).

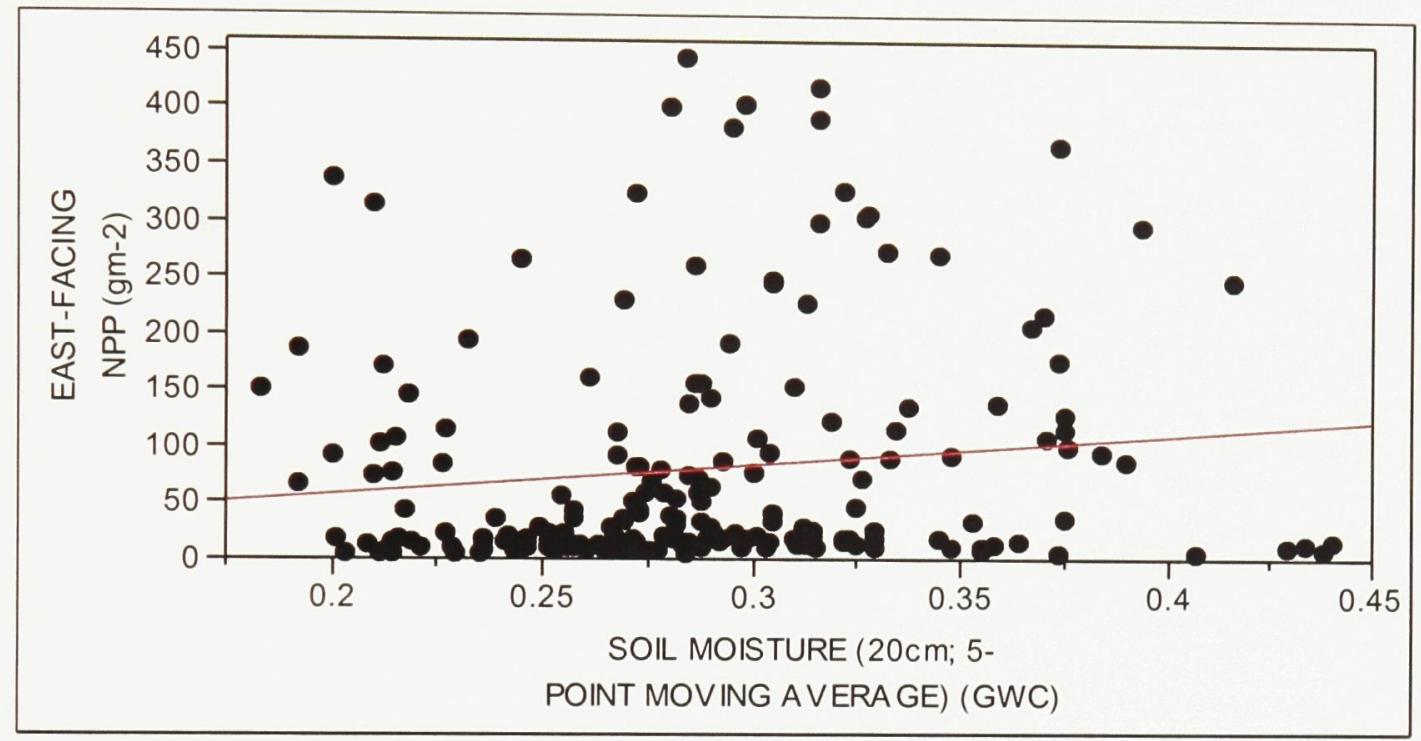

$\mathrm{R}^{2}=$ 0.02 $\mathrm{R}=$ 0.13 $\mathrm{P}=$ 0.067 $\mathrm{N}=$ 189

Figure 7.9 - Bivariate correlation of NPP $\left(\mathrm{g} \mathrm{m}^{-2}\right)$ and seasonal average soil moisture $(20 \mathrm{~cm}$; 5 point moving average) (GWC) on the east-facing hillslope of the test basin.

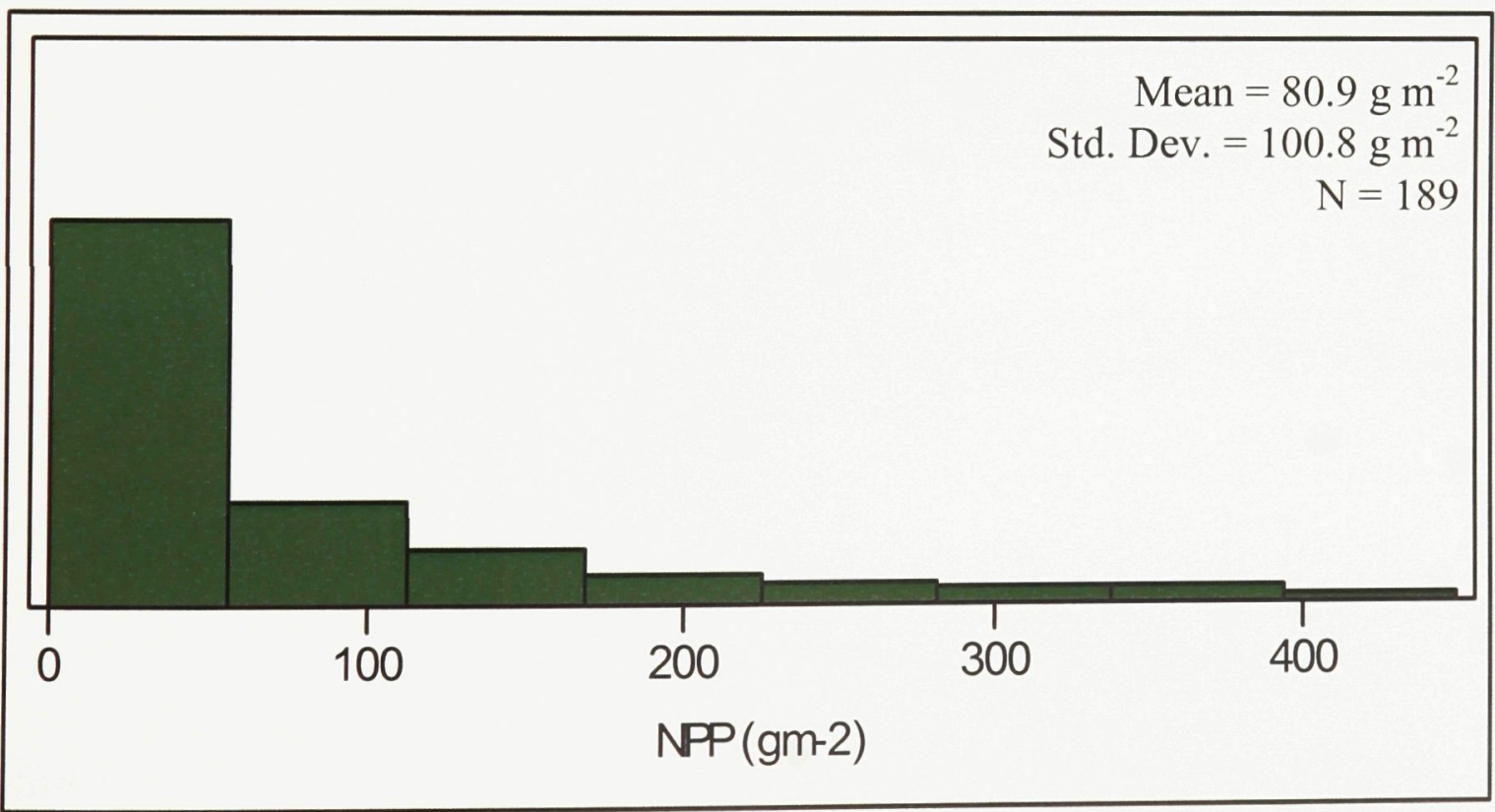

Figure 7.10 - Distribution of NPP measurements on the east-facing hillslope of the test basin $\left(\mathrm{g} \mathrm{m}^{-2}\right)$. 
Only one of the hypothesized relationships involving NPP was strengthened when restricting the analysis to the east-facing hillslope samples. TI's account of the variance in NPP increased to $11 \%\left(\mathrm{R}=0.33, \mathrm{R}^{2}=0.11, \mathrm{P}=<.0001, \mathrm{~N}=189\right)$, compared to a $3 \%$ basin-wide correlation. Slope was positively correlated with NPP again $\left(R=0.33, R^{2}=\right.$ $0.11, \mathrm{P}=<.0001, \mathrm{~N}=189$ ), and upslope area accounted for $21 \%$ of the variance in NPP $\left(\mathrm{R}=0.46, \mathrm{R}^{2}=0.21, \mathrm{P}=<.0001, \mathrm{~N}=189\right) ;$ a negligible drop from a $25 \%$ basin-wide correlation. There remained an observed increase in the average and variability of NPP with respect to upslope area in this landscape position (Figure 7.11), when the upslope area reached approximately $5.0 \mathrm{~m}^{2}$ in size. The region of the basin to which this increase corresponded remained unchanged.

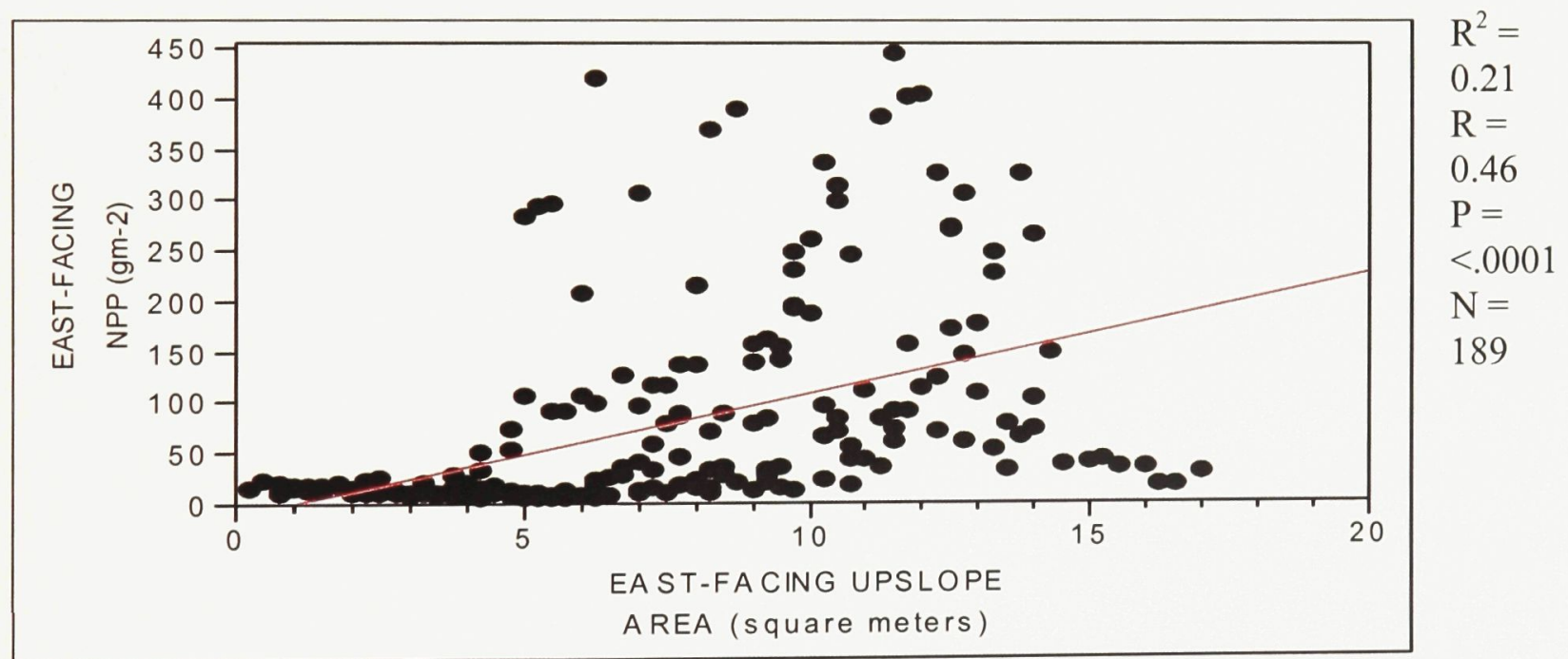

Figure 7.11 - Bivariate correlation of NPP $\left(\mathrm{g} \mathrm{m}^{-2}\right)$ and upslope area $\left(\mathrm{m}^{2}\right)$ on the east-facing hillslope of the test basin.

\subsubsection{Segregation by Drainage Zone}

Further testing of the hypothesis was carried out by checking whether the immediate surroundings of the drainage line had more consistently predictable soil moisture and productivity dynamics (Figure 7.12). 


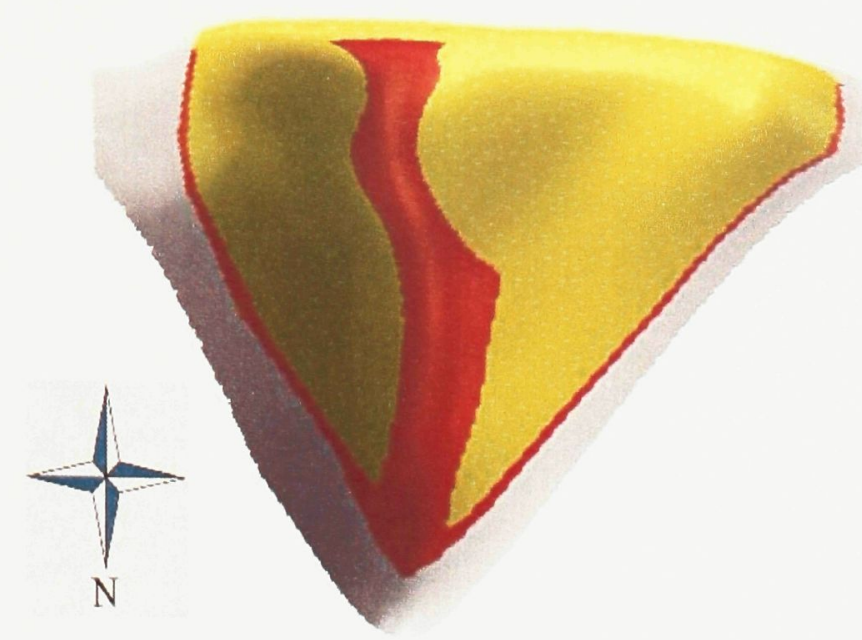

Figure 7.12 - Drainage zone of the basin (in red), as defined by those portions of the basin where TI values were greater than 5.5 and the elevation was less than $851 \mathrm{~m} \mathrm{ASL}(<851 \mathrm{~m})$. Vertical exaggeration $=3.0$.

Figure 7.13 shows the relationships of the drainage zone soil moisture against TI, slope, and upslope area. There was no correlation between soil moisture and TI ( $\mathrm{R}=$ $0.15, \mathrm{R}^{2}=0.02, \mathrm{P}=0.2078, \mathrm{~N}=74$ ) (Figure 7.13(A)), while slope's account of the variance in soil moisture increased from a basin-wide value of $17 \%$, to a drainage zone correlation of $50 \%\left(\mathrm{R}=-0.71, \mathrm{R}^{2}=0.50, \mathrm{P}=<.0001, \mathrm{~N}=74\right)$ (Figure 7.13(B)). Upslope area continued to correlate negatively with soil moisture in the drainage zone $(\mathrm{R}=-0.60$, $\mathrm{R}^{2}=0.36, \mathrm{P}=<.0001, \mathrm{~N}=74$ ) (Figure 7.13(C)). Soil moisture was variable along the drainage zone, with measurements dispersed across the range of TI values, causing TI's correlation with soil moisture to lose any significance. Slope's high account of the variance in soil moisture suggests that less moisture is found near the basin outlet, because slope increased further down the drainage zone. While this trend was in the hypothesized direction, it opposes the expectation of increased soil moisture accumulation at the basin outlet. Figure 7.14 shows the distribution of soil moisture and TI values in the drainage zone. 


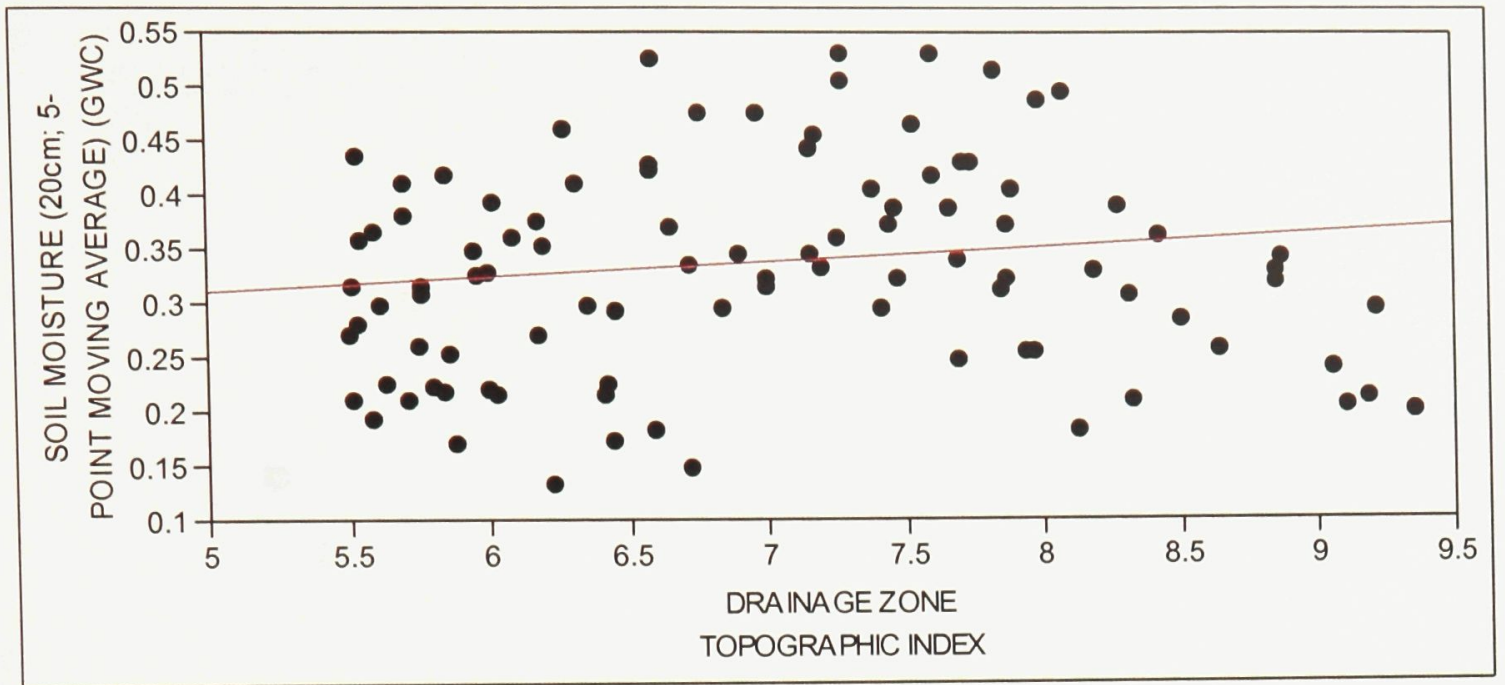

$\mathrm{R}^{2}=$

0.02

$\mathrm{R}=$

0.15

$\mathrm{P}=$

0.2078

$\mathrm{N}=74$

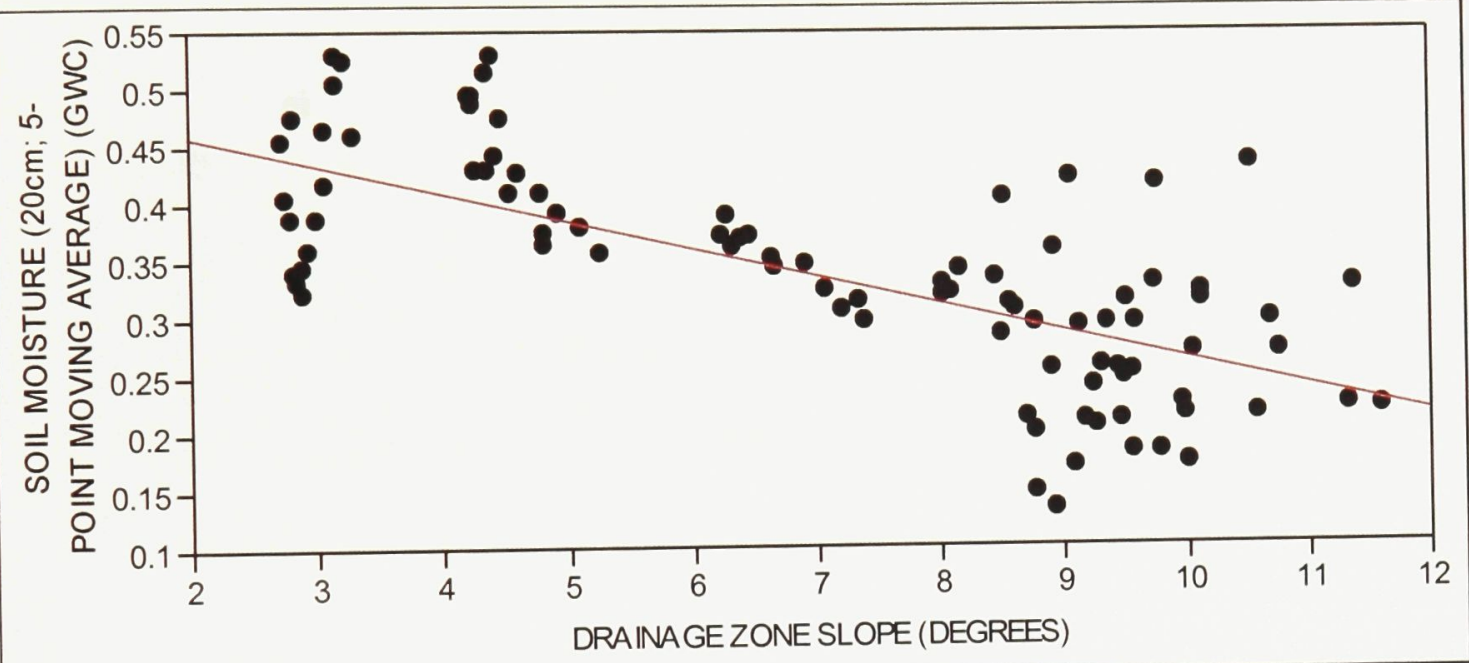

(A)

$\mathrm{R}^{2}=$

0.50

$\mathrm{R}=$

$-0.71$

$\mathrm{P}=$

$<.0001$

$\mathrm{N}=74$

(B)

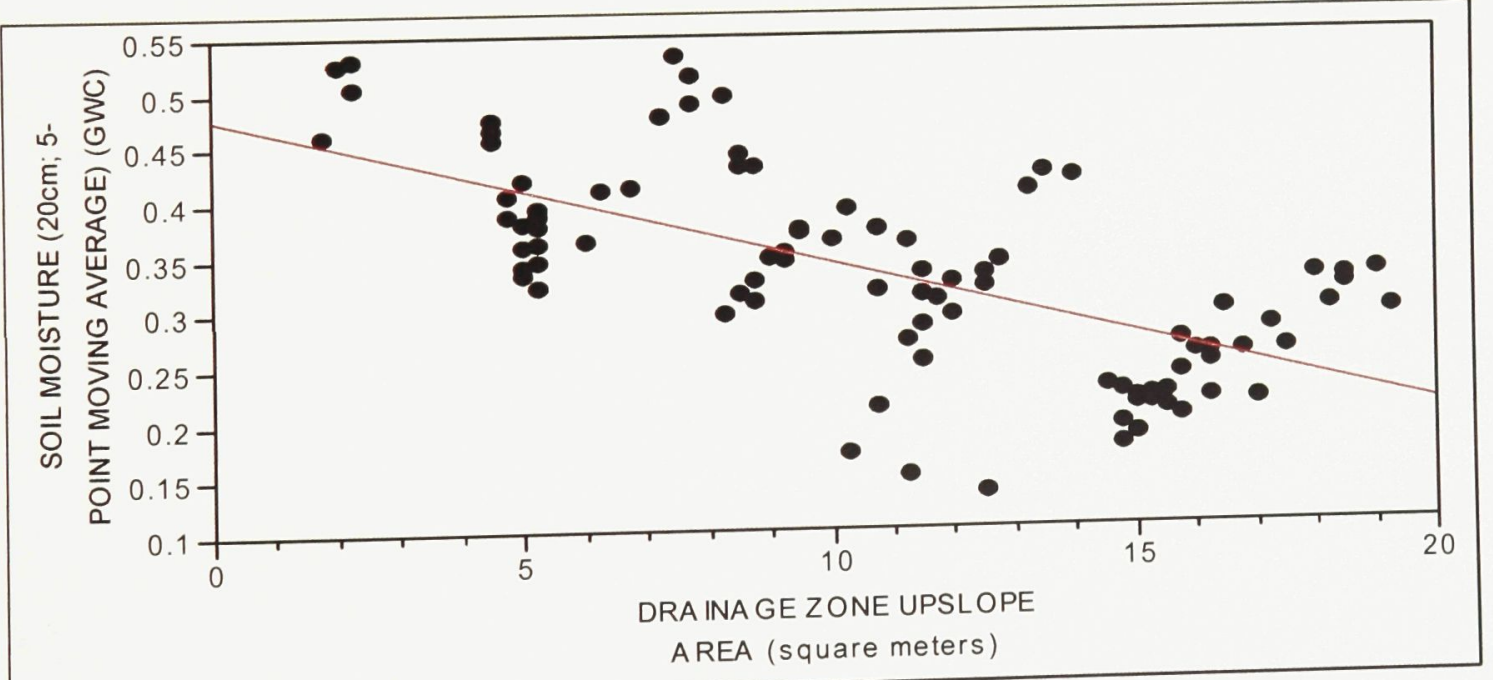

$\mathrm{R}^{2}=$

0.36

$\mathrm{R}=$

$-0.60$

$\mathrm{P}=$

$<.0001$

$\mathrm{N}=74$

(C)

Figure 7.13 - Bivariate correlation of seasonal average soil moisture $(20 \mathrm{~cm} ; 5$-point moving average) (GWC) and TI (A), slope (degrees) (B) and upslope area $\left(\mathrm{m}^{2}\right)(\mathbf{C})$ in the drainage zone of the test basin. 

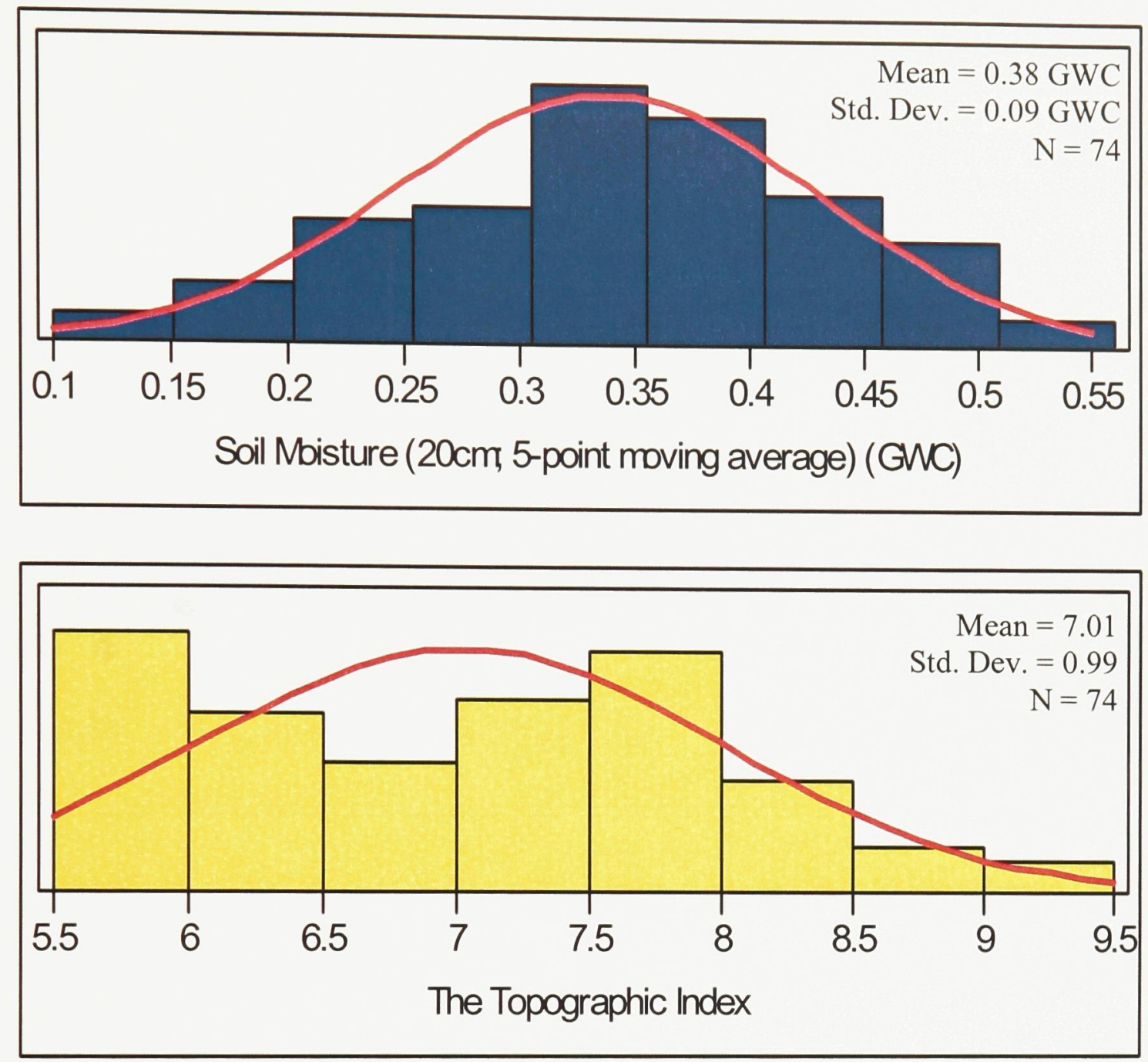

Figure 7.14 - Distributions of TI values and seasonal average soil moisture $(20 \mathrm{~cm}$; 5-point moving average) (GWC) in the drainage zone of the test basin.

Restricting the analysis to the within-drainage zone samples did not strengthen the relationship between NPP and soil moisture $\left(R=-0.22, \mathrm{R}^{2}=0.05, \mathrm{P}=0.0608, \mathrm{~N}=74\right)$ (Figure 7.15). It is difficult to draw any conclusions from this relationship, except that NPP varied greatly along the drainage zone and a relationship with soil moisture in this portion of the basin cannot be empirically detected. 


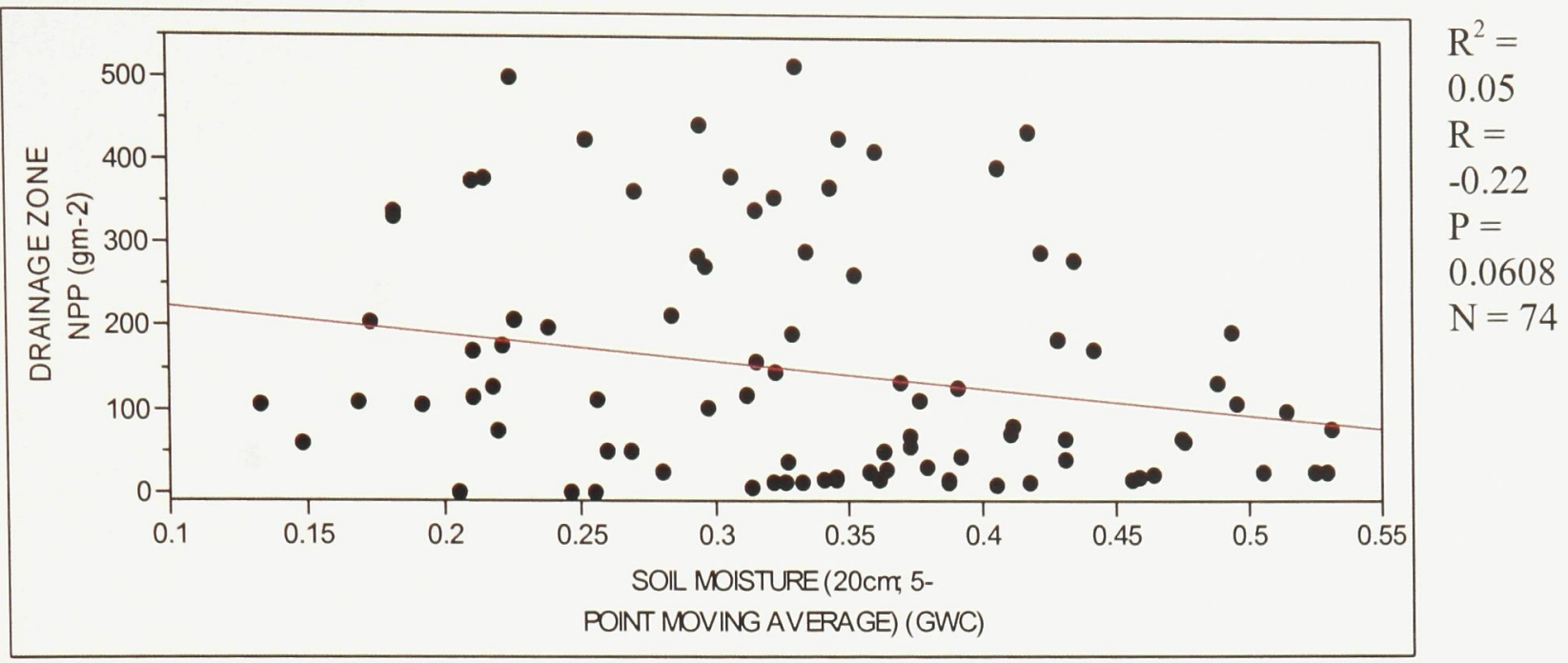

Figure 7.15 - Bivariate correlation of NPP $\left(\mathrm{g} \mathrm{m}^{-2}\right)$ and seasonal average soil moisture $(20 \mathrm{~cm}$; 5 point moving average) (GWC) in the drainage zone of the test basin.

None of the hypothesized relationships involving NPP was strengthened in the drainage zone. NPP did not correlate with TI $\left(\mathrm{R}=-0.07, \mathrm{R}^{2}=0.001, \mathrm{P}=0.5403, \mathrm{~N}=\right.$ 74); a change in relationship trend from the basin-wide correlation, while slope correlated positively with NPP again $\left(\mathrm{R}=0.51, \mathrm{R}^{2}=0.26, \mathrm{P}=<.0001, \mathrm{~N}=74\right)($ Figure $7.16(\mathbf{A}))$. The predictive power of upslope area on NPP dropped to $17 \%\left(\mathrm{R}=0.41, \mathrm{R}^{2}=0.17, \mathrm{P}=\right.$ $<.0001, \mathrm{~N}=74$ ) (Figure $7.16(\mathrm{~B})$ ) from a basin-wide value of $25 \%$. This was the lowest account of variance in NPP for all landscape positions. NPP's relationships with slope and upslope area demonstrate that vegetation further down the basin is more productive than vegetation found closer to the top, as steeper slopes and an increased upslope area resulted in higher NPP. One could conclude that productivity is not constrained by soil moisture along the drainage zone because there are areas where the topographic variables predicted high NPP, but low soil moisture. 


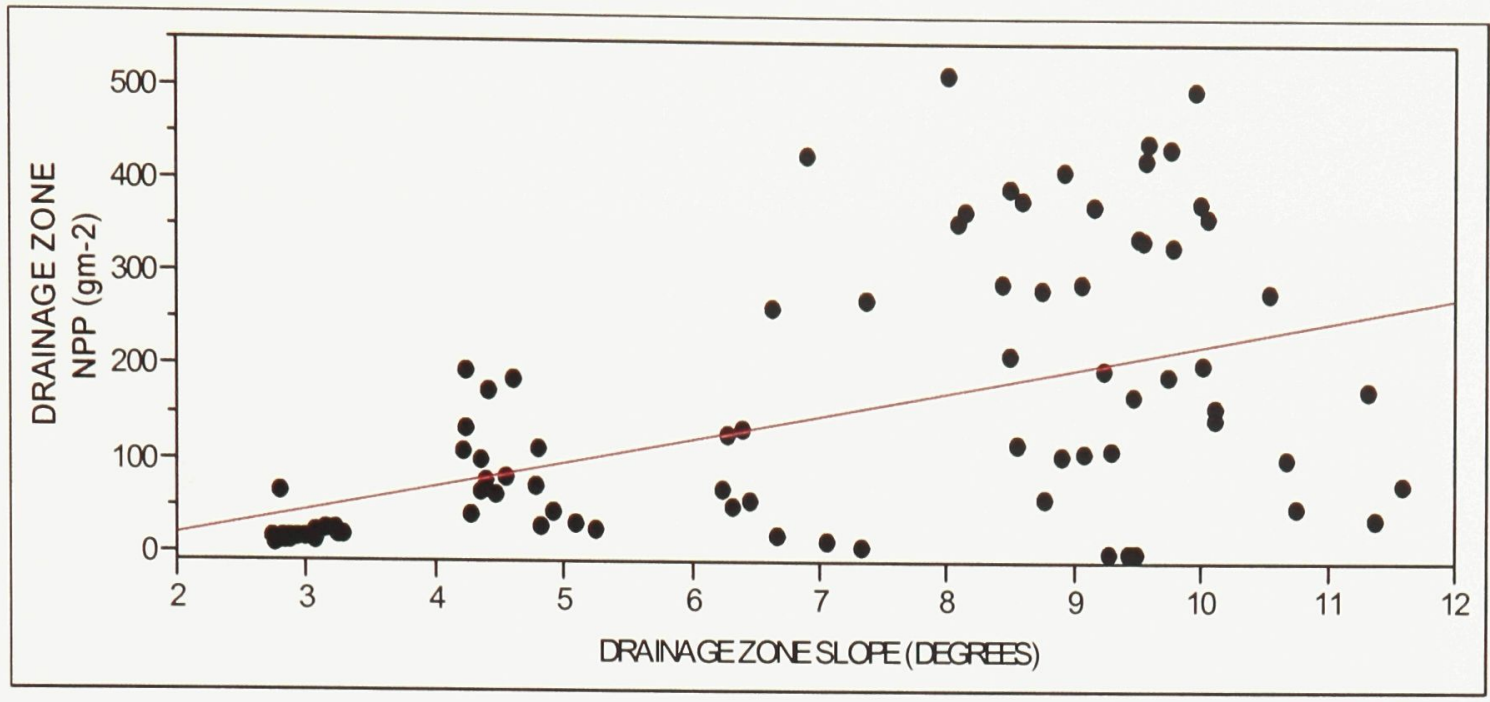

$\mathrm{R}^{2}=$

0.26

$\mathrm{R}=$

0.51

$\mathrm{P}=$

$<.0001$

$\mathrm{N}=74$

(A)

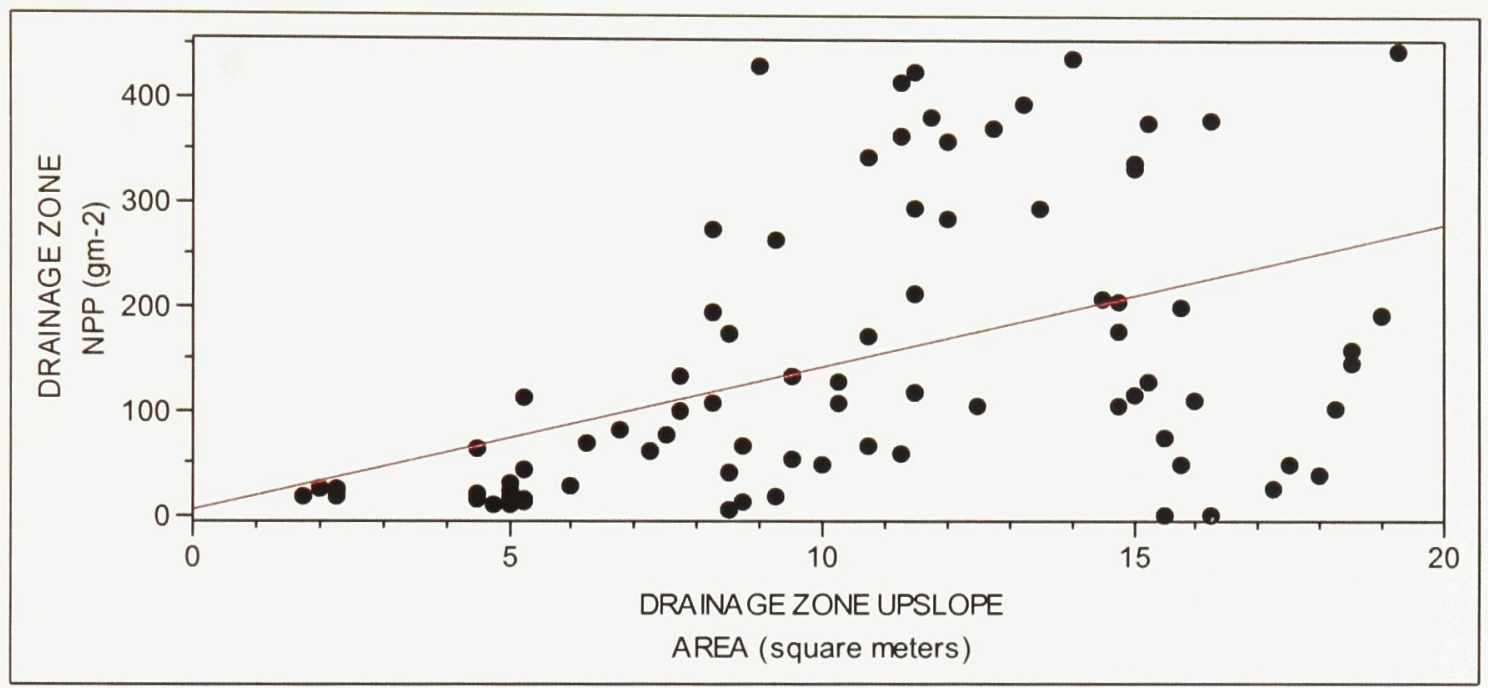

$\mathrm{R}^{2}=$

0.17

$\mathrm{R}=$

0.41

$\mathrm{P}=$

0.0003

$\mathrm{N}=74$

Figure 7.16 - Bivariate correlation of NPP $\left(\mathrm{g} \mathrm{m}^{-2}\right)$ and slope (degrees) (A) and upslope area $\left(\mathrm{m}^{2}\right)$ (B) in the drainage zone of the test basin.

\subsection{Segregation by Vegetation Type}

Further testing was carried out by dividing the data by dominant vegetation cover.

Figure 7.17 illustrates the diversity of vegetation cover in the test basin. 


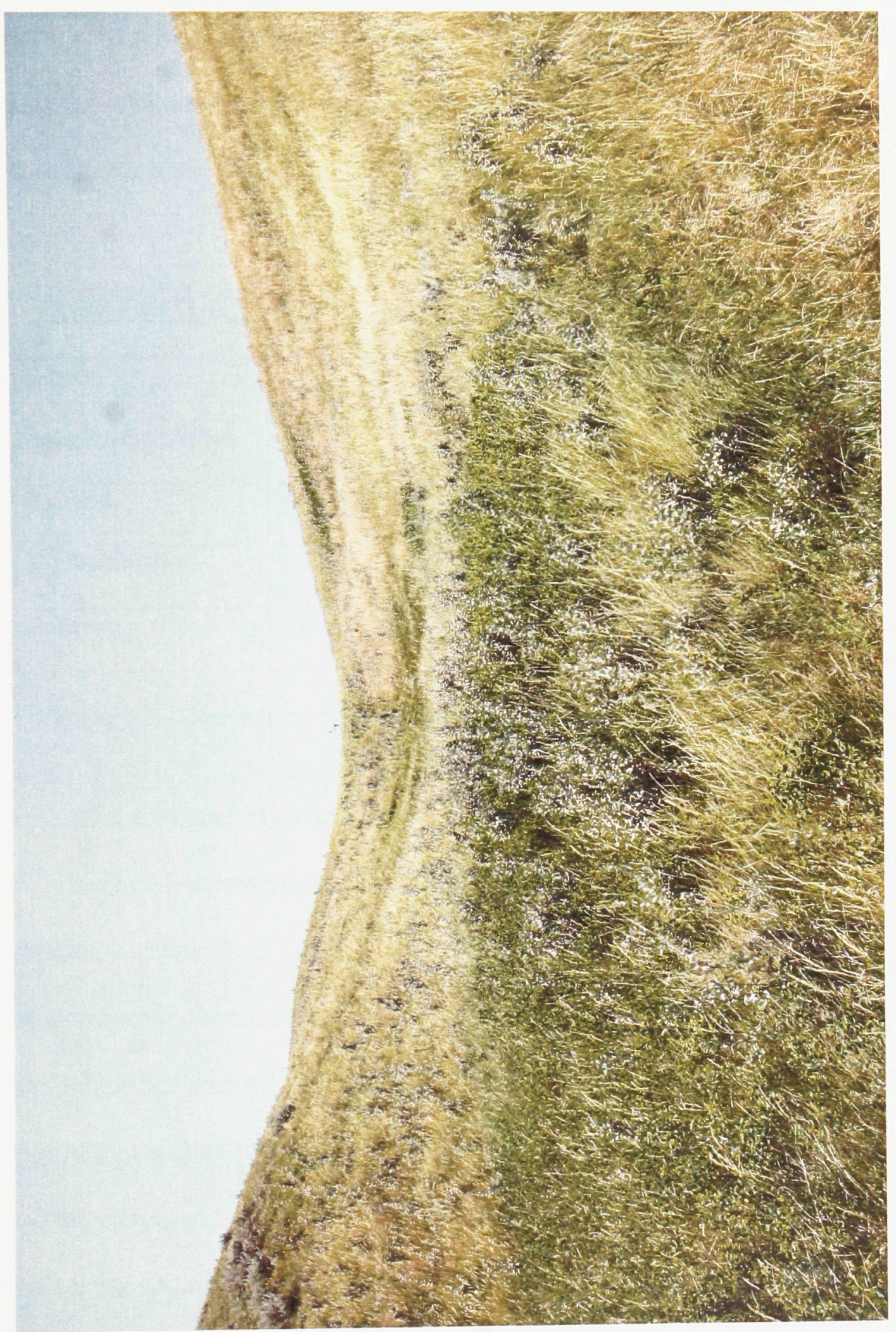

离

ज

ฮ

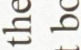

.

홍

응

5 흠

흉

荥

$>$

पू

홍

क.

른

밈

of

政

용

$\stackrel{2}{\exists}$

氙 哭

20

홀

응

ㅍㅇㅇ

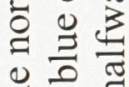

응 종

릉

을

政

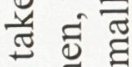

है क्ञ क

क त

ज

Q

$\cong$

응

휼

50

응

들

1 글

동

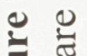

至 
Table 7.2 summarizes the distribution of sample points that fall within each vegetation category. The majority of the sampled basin (58.7\%) was dominated by grasses, with selaginella/lichen comprising of approximately $20.7 \%$ of the basin vegetation. Forbs/shrubs, juniper and eroded areas comprised the final $20 \%$ of the sampled basin coverage.

\begin{tabular}{|l|c|c|}
\hline VEGETATION TYPE & SAMPLE POINTS & \% OF SAMPLE SIZE \\
\hline Grass & 304 & $58.7 \%$ \\
\hline Selaginella/Lichen & 107 & $20.7 \%$ \\
\hline Eroded & 46 & $8.8 \%$ \\
\hline Forbs/Shrubs & 37 & $7.1 \%$ \\
\hline Juniper & 24 & $4.7 \%$ \\
\hline
\end{tabular}

Table 7.2 - Distribution of vegetation cover at the sample points in the test basin.

\subsubsection{General Moisture and NPP Patterns}

Table 7.3 summarizes the relationships among the variables in each of the vegetation communities. Many of the trends observed at the different landscape positions were also seen in dominant vegetation covers. As a general trend, the strength of the relationships between soil moisture and the topographic variables increased among most communities, while the strength of the relationships between NPP and the topographic variables increased in selaginella/lichen communities, forb/shrub communities, and eroded areas. A minimal number of relationships increased in strength in the eroded areas of the basin, but given that the sample size was quite small $(n=36)$ and that little vegetation was present in these areas, the results may be of little value. 


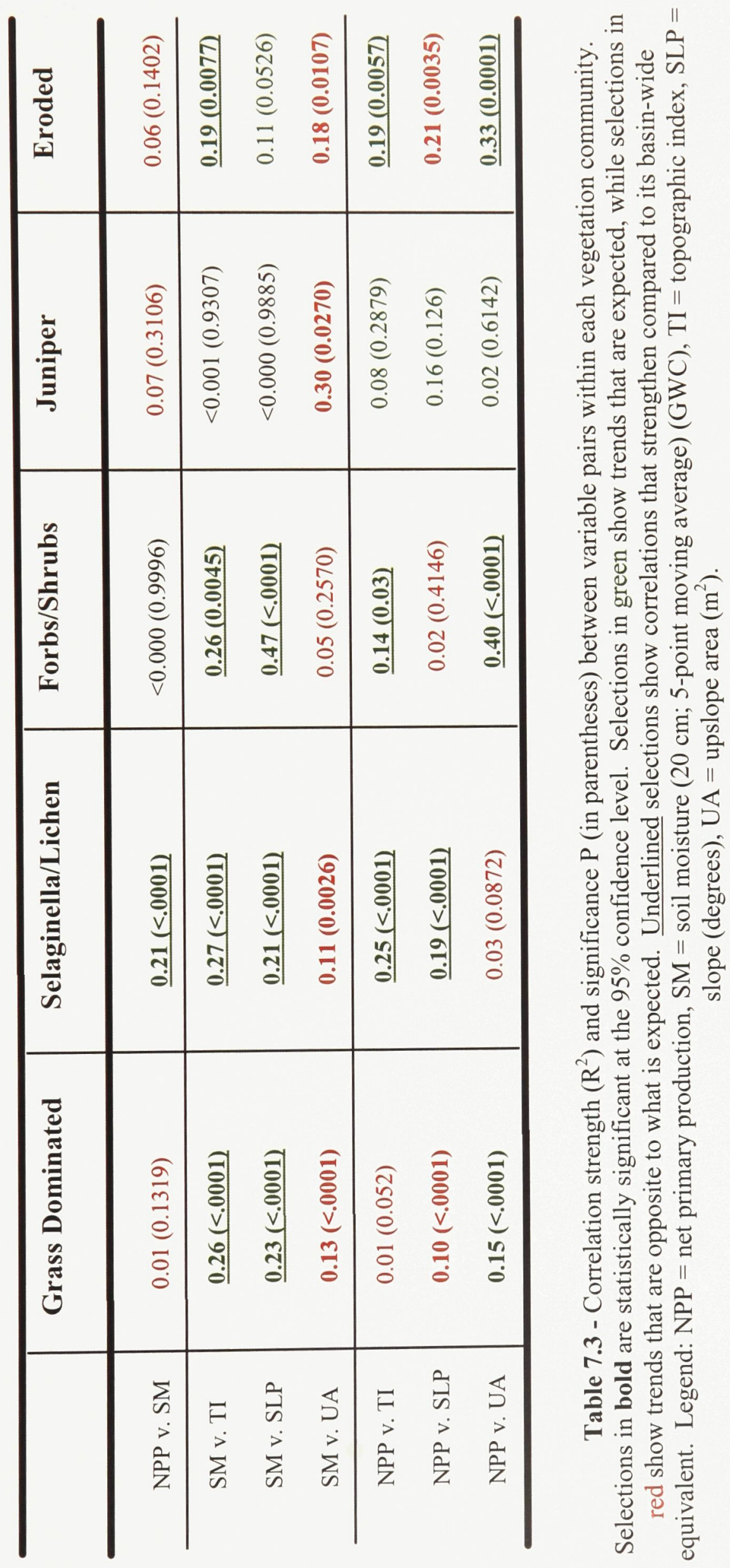




\subsubsection{Grass Dominated Areas}

The distribution of soil moisture in grass dominated areas of the basin (Figure 7.19) was very similar to the distribution of soil moisture across the entire basin (see Figure 6.5 on page 48), with similar means and standard deviations. TI accounted for $26 \%$ of the variance in soil moisture in grass dominated areas $\left(\mathrm{R}=0.51, \mathrm{R}^{2}=0.26, \mathrm{P}=\right.$ $<.0001, \mathrm{~N}=258$ ) (Figure 7.18(A)), up from a 17\% basin-wide value. Slope's account of the variance in soil moisture increased to $23 \%$ in this community $\left(R=-0.48, R^{2}=0.23, P\right.$ $=<.0001, \mathrm{~N}=258)$ (Figure 7.18(B)), while upslope area continued to correlate negatively with soil moisture $\left(\mathrm{R}=-0.36, \mathrm{R}^{2}=0.13, \mathrm{P}=<.0001, \mathrm{~N}=258\right)$ (Figure 7.18(C)). 


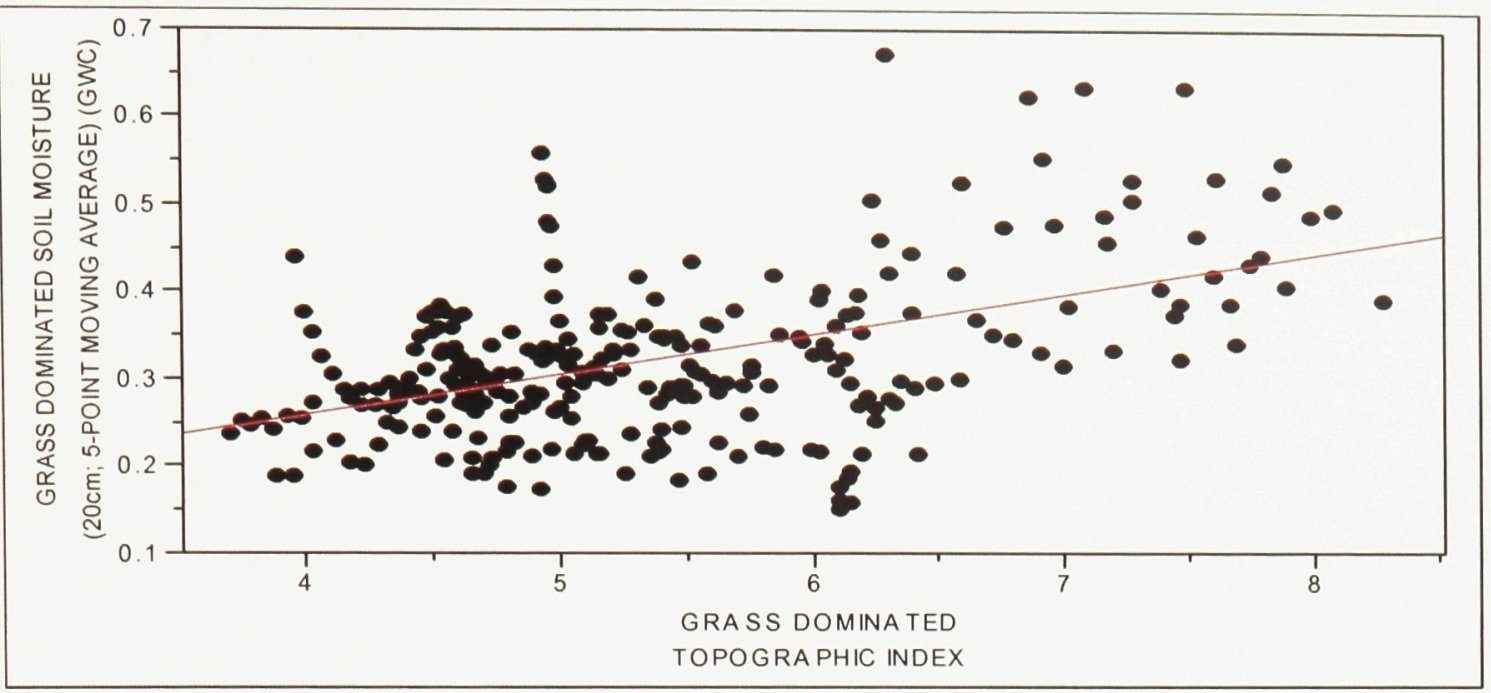

$\mathrm{R}^{2}=$

0.26

$\mathrm{R}=$

0.51

$\mathrm{P}=$

$<.0001$

$\mathrm{N}=$

258

(A)

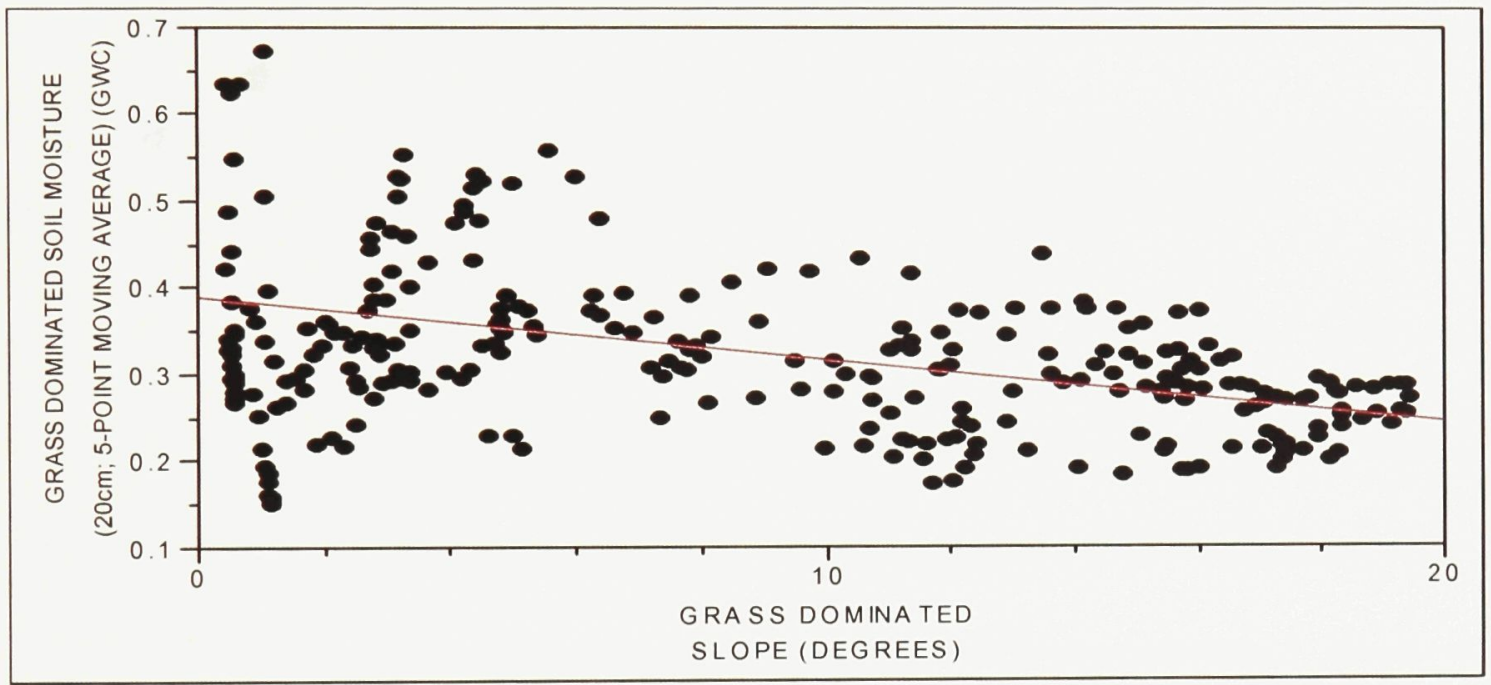

$\mathrm{R}^{2}=$

0.23

$\mathrm{R}=$

$-0.48$

$\mathrm{P}=$

$<.0001$

$\mathrm{N}=258$

(B)

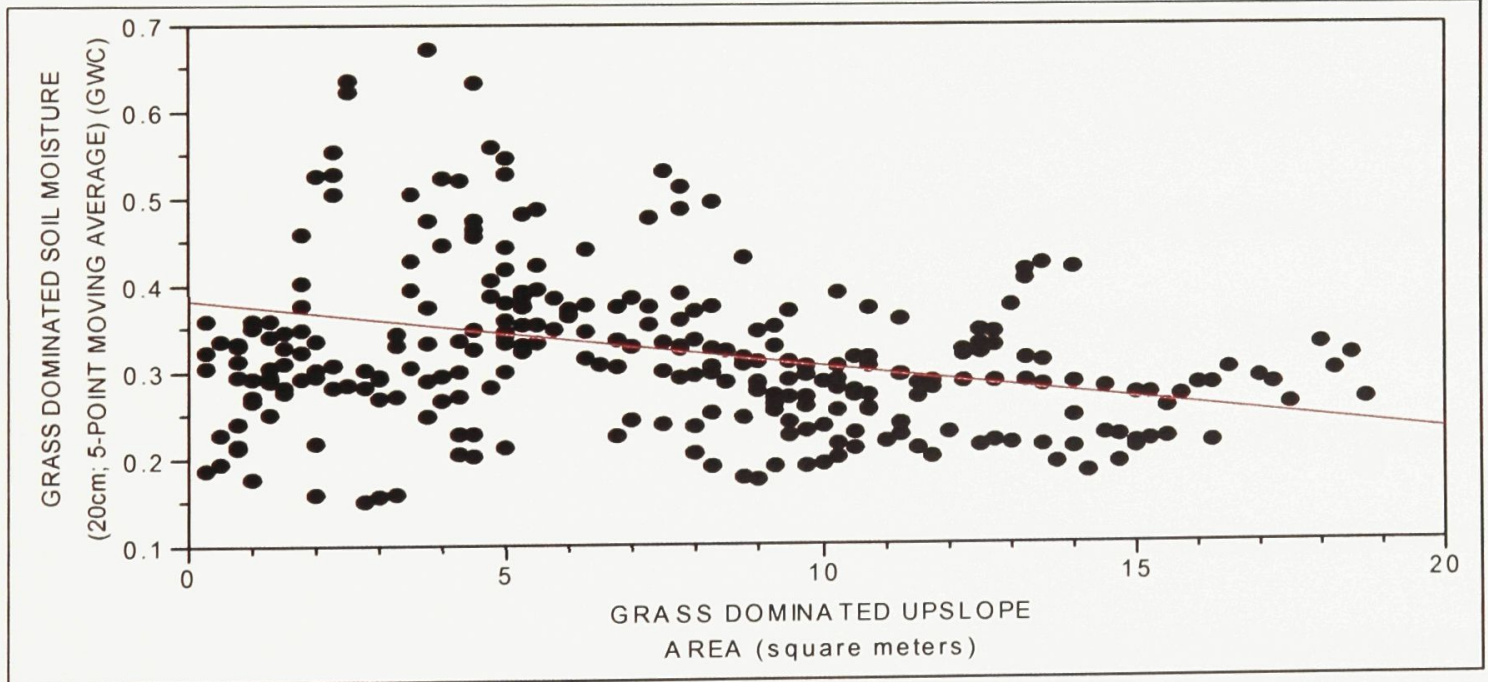

$\mathrm{R}^{2}=$

0.13

$\mathrm{R}=$

$-0.36$

$\mathrm{P}=$

$<.0001$

$\mathrm{N}=258$

(C)

Figure 7.18 - Bivariate correlation of seasonal average soil moisture $(20 \mathrm{~cm}$; 5-point moving average) (GWC) and TI (A), slope (degrees) (B) and upslope area $\left(\mathrm{m}^{2}\right)(\mathbf{C})$ in grass dominated areas of the test basin. 


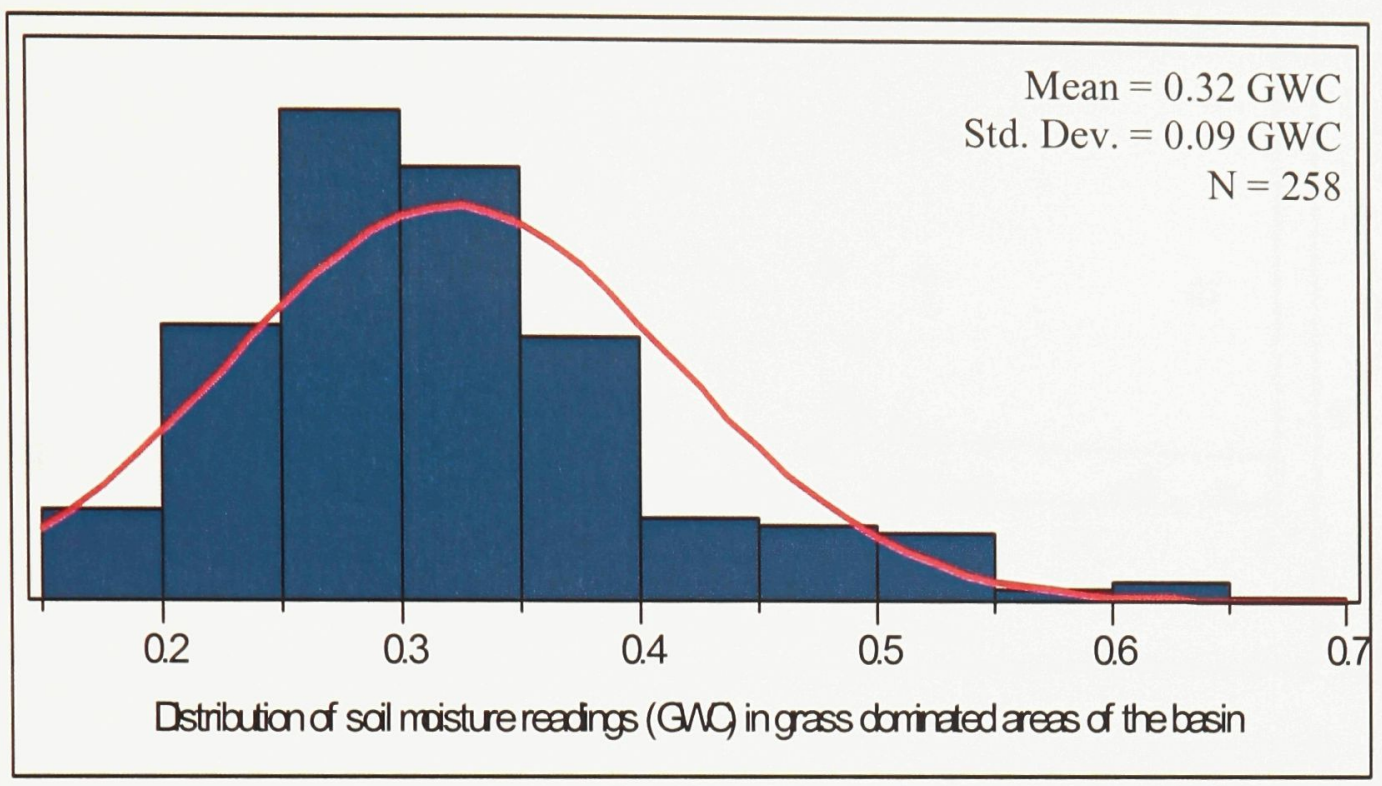

Figure 7.19 - Distribution of seasonal average soil moisture readings $(20 \mathrm{~cm}$; 5-point moving average) (GWC) in grass dominated areas of the basin.

NPP's relationship with soil moisture remained unchanged $\left(R=-0.10, R^{2}=0.01\right.$, $\mathrm{P}=0.1319, \mathrm{~N}=258)($ Figure $7.20(\mathbf{A}))$. A vast majority of NPP estimates were low, interspersed with relatively few points where high NPP was estimated, which may explain the noted results. None of the other hypothesized relationships were strengthened when restricting the analyses to grass dominated samples. NPP and TI were not correlated $\left(R=-0.12, R^{2}=0.01, P=0.052, N=268\right)$, while slope remained positively correlated with NPP $\left(\mathrm{R}=0.32, \mathrm{R}^{2}=0.10, \mathrm{P}=<.0001, \mathrm{~N}=268\right)$. Upslope area explained $15 \%$ of the variance in NPP $\left(\mathrm{R}=0.38, \mathrm{R}^{2}=0.15, \mathrm{P}=<.0001, \mathrm{~N}=268\right)($ Figure $7.20(\mathrm{~B}))$, representing a marginal drop in relationship strength. These results remained consistent, implying that grasses are more productive in areas with larger upslope areas, especially when that area is greater than approximately $5.0 \mathrm{~m}^{2}$, as indicated by the increase in the average and variability of NPP as shown in Figure 7.20(B)). 


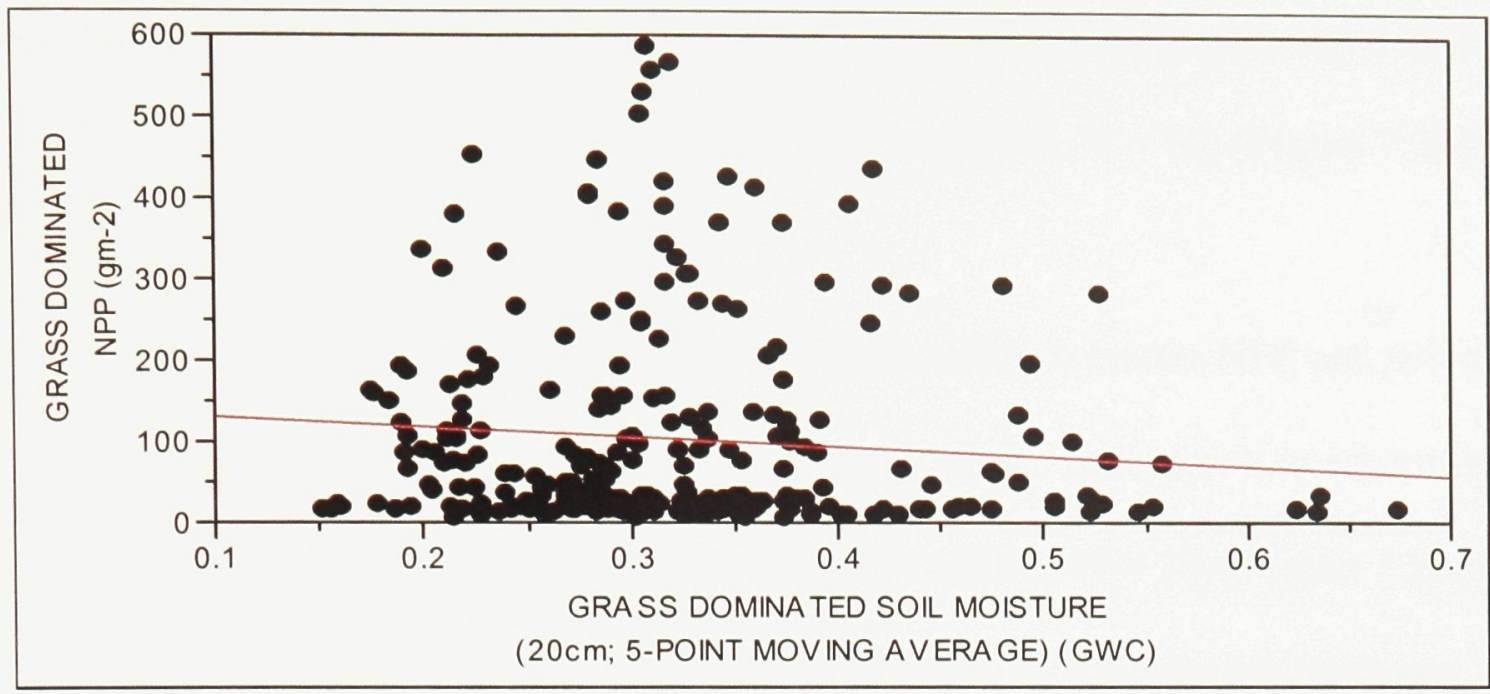

$\mathrm{R}^{2}=$

0.01

$\mathrm{R}=$

$-0.10$

$\mathrm{P}=$

0.1319

$\mathrm{N}=$

258

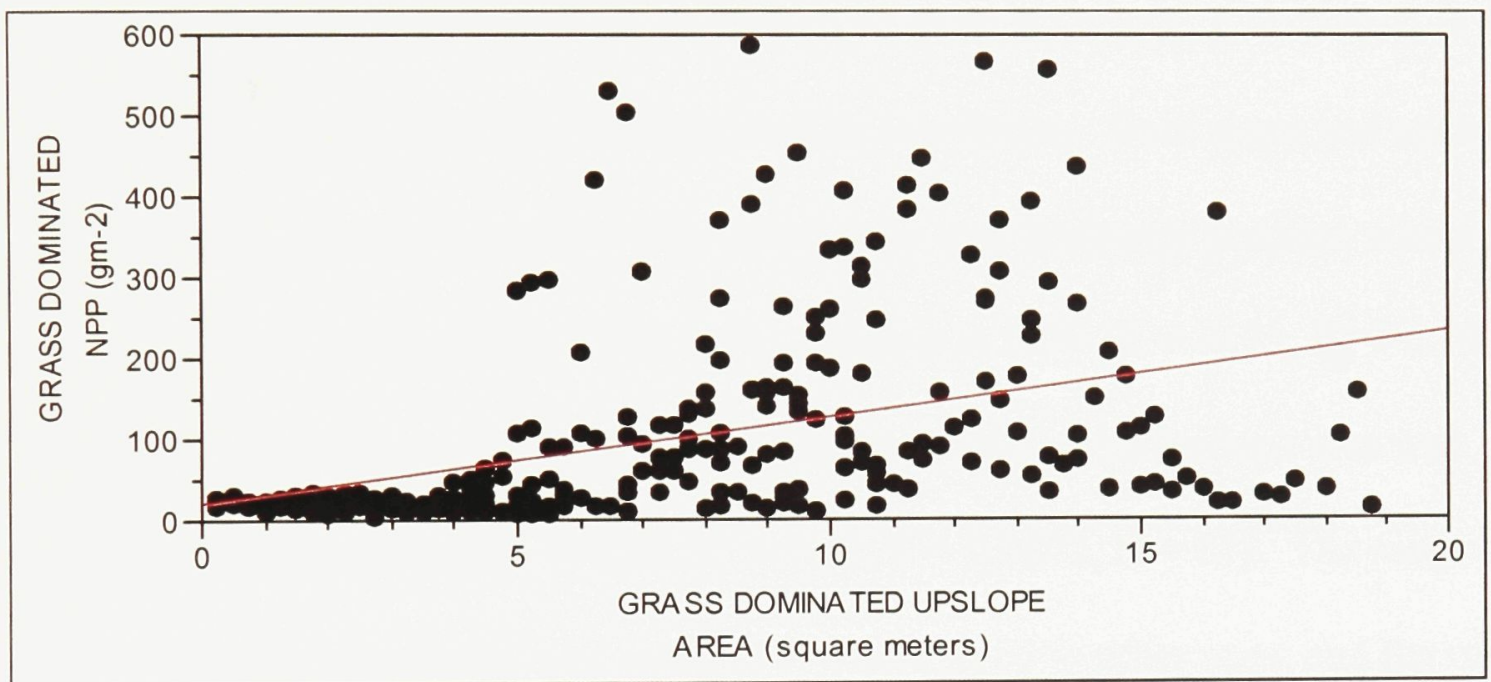

(A)

$\mathrm{R}^{2}=$

0.15

$\mathrm{R}=$

0.38

$\mathrm{P}=$

$<.0001$

$\mathrm{N}=$

268

(B)

Figure 7.20 - Bivariate correlation of NPP $\left(\mathrm{g} \mathrm{m}^{-2}\right)$ and seasonal average soil moisture $(20 \mathrm{~cm}$; 5 point moving average) (GWC) (A) and upslope area $\left(\mathrm{m}^{2}\right)(\mathbf{B})$ in grass dominated areas of the test basin.

\subsubsection{Selaginella/Lichen Dominated Areas}

Two of the relationships involving soil moisture were strengthened in selaginella/lichen dominated areas. TI accounted for $27 \%$ of the variance in soil moisture $\left(\mathrm{R}=0.52, \mathrm{R}^{2}=0.27, \mathrm{P}=<.0001, \mathrm{~N}=79\right)($ Figure $7.21(\mathrm{~A}))$, a $10 \%$ increase compared to the basin-wide value. Slope's account of the variance in soil moisture increased to $21 \%$ $\left(\mathrm{R}=-0.46, \mathrm{R}^{2}=0.21, \mathrm{P}=<.0001, \mathrm{~N}=79\right)($ Figure $7.21(\mathrm{~B}))$, up from a $17 \%$ basin-wide 
value. Soil moisture's relationship with upslope area remained unchanged, and continued to correlate negatively $\left(\mathrm{R}=-0.33, \mathrm{R}^{2}=0.11, \mathrm{P}=0.0026, \mathrm{~N}=79\right)$ (Figure 7.21(C)).

The only increase in strength of the relationship between NPP and soil moisture was observed in the selaginella/lichen dominated areas. Soil moisture accounted for $21 \%$ of the variance in NPP $\left(\mathrm{R}=0.52, \mathrm{R}^{2}=0.21, \mathrm{P}=<.0001, \mathrm{~N}=79\right)$ (Figure 7.22(A)), whereas no correlation existed in all other communities or landscape positions. TI accounted for $25 \%$ of the variance in NPP $\left(\mathrm{R}=-0.46, \mathrm{R}^{2}=0.25, \mathrm{P}=<.0001, \mathrm{~N}=87\right)$ (Figure 7.22(B)), up from the $17 \%$ basin-wide correlation. Both slope and upslope area related negatively with NPP; the only community and landscape position where this was the case. Slope accounted for $19 \%$ of the variance in NPP $\left(R=-0.33, R^{2}=0.19, P=\right.$ $<.0001, \mathrm{~N}=87$ ) (Figure 7.22(C)), while the relationship with upslope area was statistically insignificant $\left(\mathrm{R}=-0.17, \mathrm{R}^{2}=0.03, \mathrm{P}=0.0872, \mathrm{~N}=87\right)$. The range of soil moisture in this community was small (34\%) compared to other ones, and the community was very dry (over half of the soil moisture readings were less than $0.28 \mathrm{GWC}$ [Figure 7.23]). It should also be noted that the range of productivity was only $33.7 \mathrm{~g} \mathrm{~m}^{-2}$ (mean = $14.42 \mathrm{~g} \mathrm{~m}^{-2}$, std. dev. $=7.58 \mathrm{~g} \mathrm{~m}^{-2}$ ); a much smaller range than was seen in other communities; a factor that may have lead to the observed trends. 


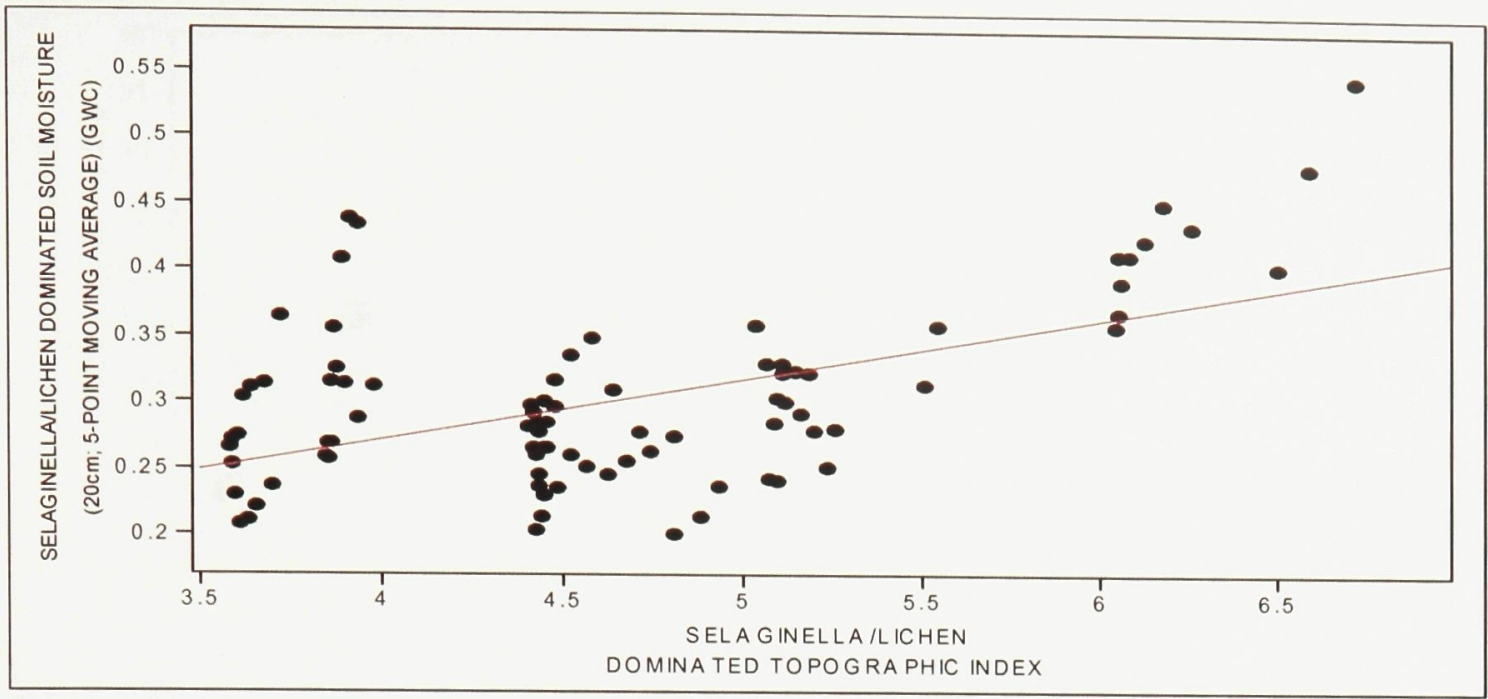

$\mathrm{R}^{2}=$

0.27

$\mathrm{R}=$

0.52

$\mathrm{P}=$

$<.0001$

$\mathrm{N}=79$

(A)

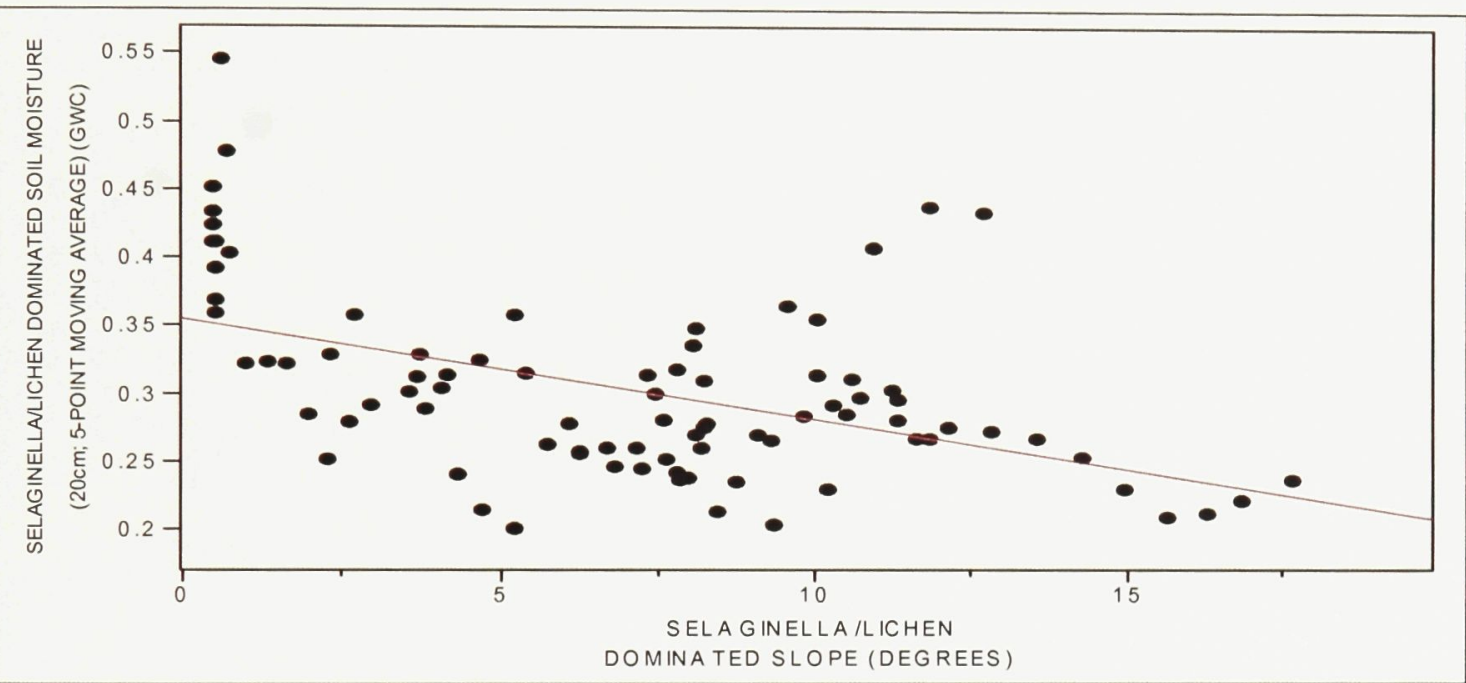

$\mathrm{R}^{2}=$

0.21

$\mathrm{R}=$

$-0.46$

$\mathrm{P}=$

$<.0001$

$\mathrm{N}=79$

(B)

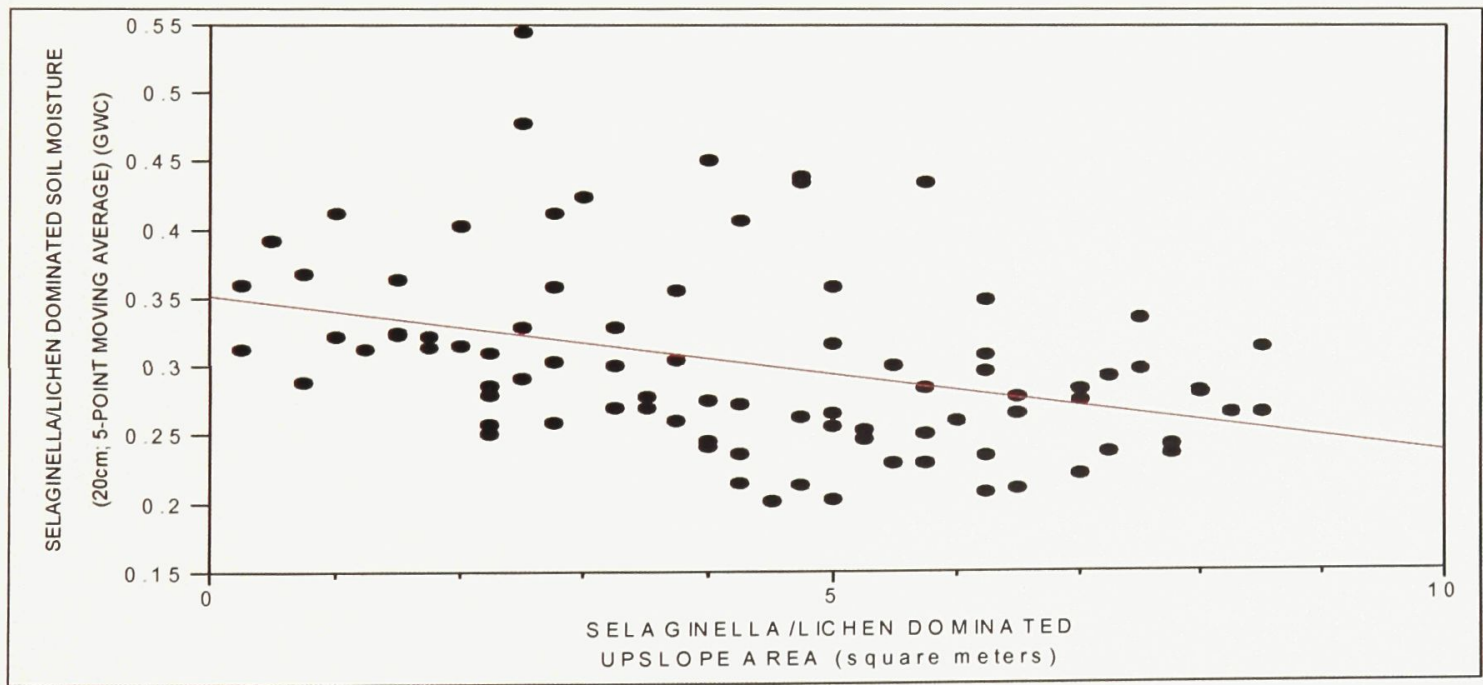

$\mathrm{R}^{2}=0.11$

$\mathrm{R}=$

$-0.33$

$\mathrm{P}=$

0.026

$\mathrm{N}=79$

Figure 7.21 - Bivariate correlation of seasonal average soil moisture $(20 \mathrm{~cm}$; 5-point moving average) (GWC) and TI (A), slope (degrees) (B) and upslope area $\left(\mathrm{m}^{2}\right)(\mathbf{C})$ in selaginella/lichen dominated areas of the test basin. 


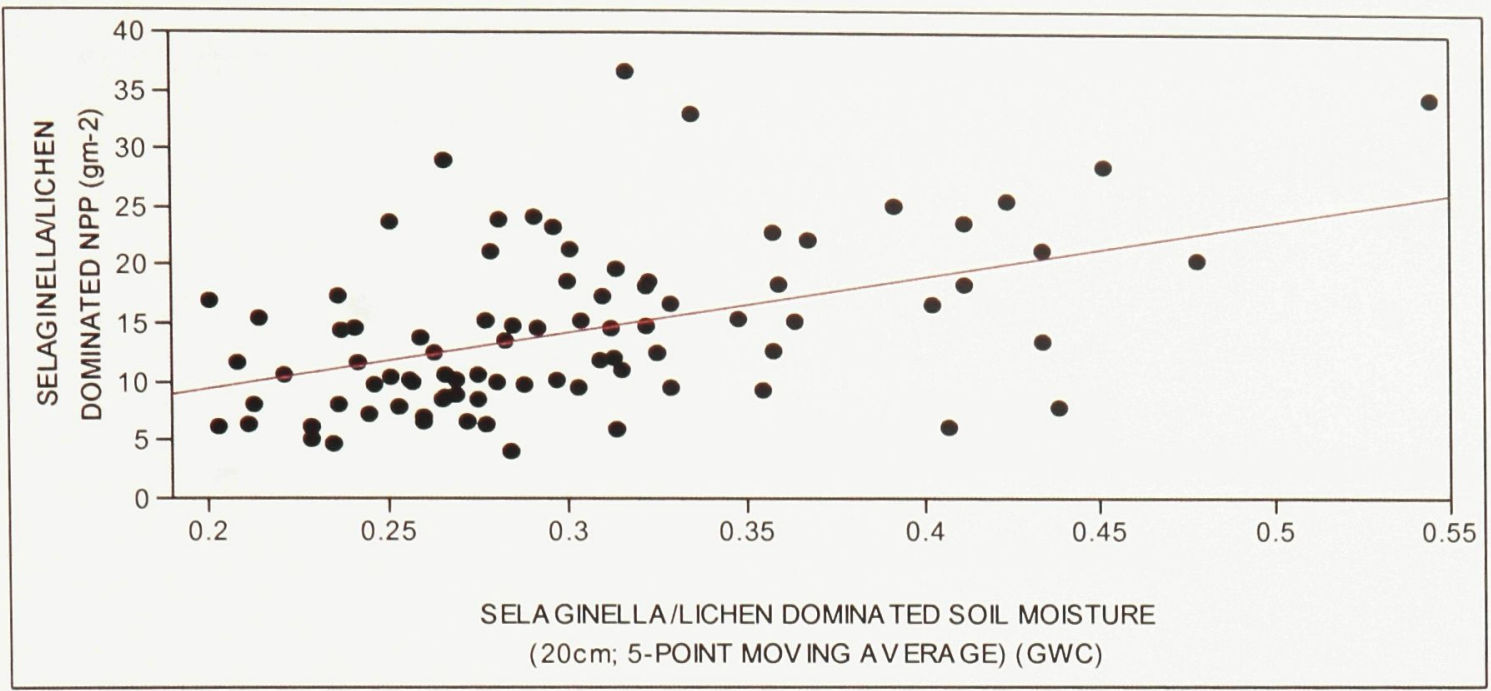

$\mathrm{R}^{2}=$

0.21

$\mathrm{R}=$

0.46

$\mathrm{P}=$

$<.0001$

$\mathrm{N}=79$

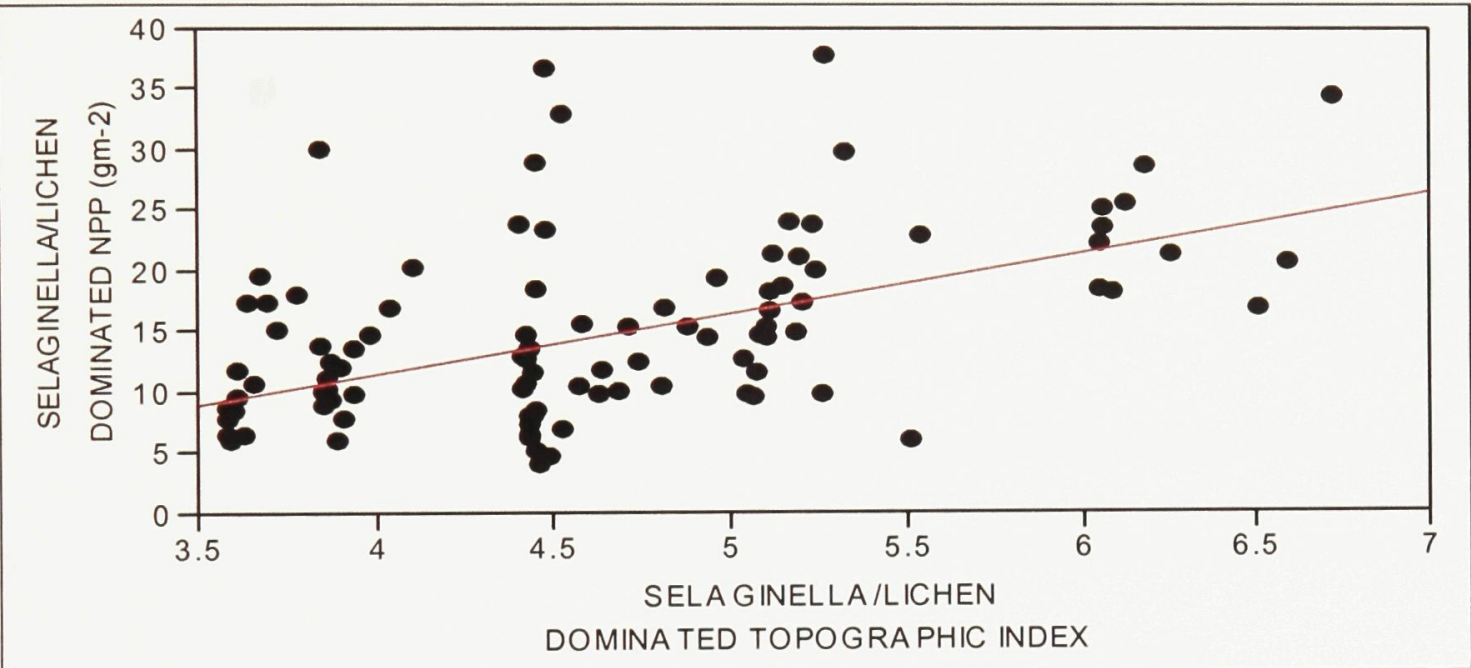

$\mathrm{R}^{2}=$

0.25

$\mathrm{R}=$

0.50

$\mathrm{P}=$

$<.0001$

$\mathrm{N}=87$

(B)

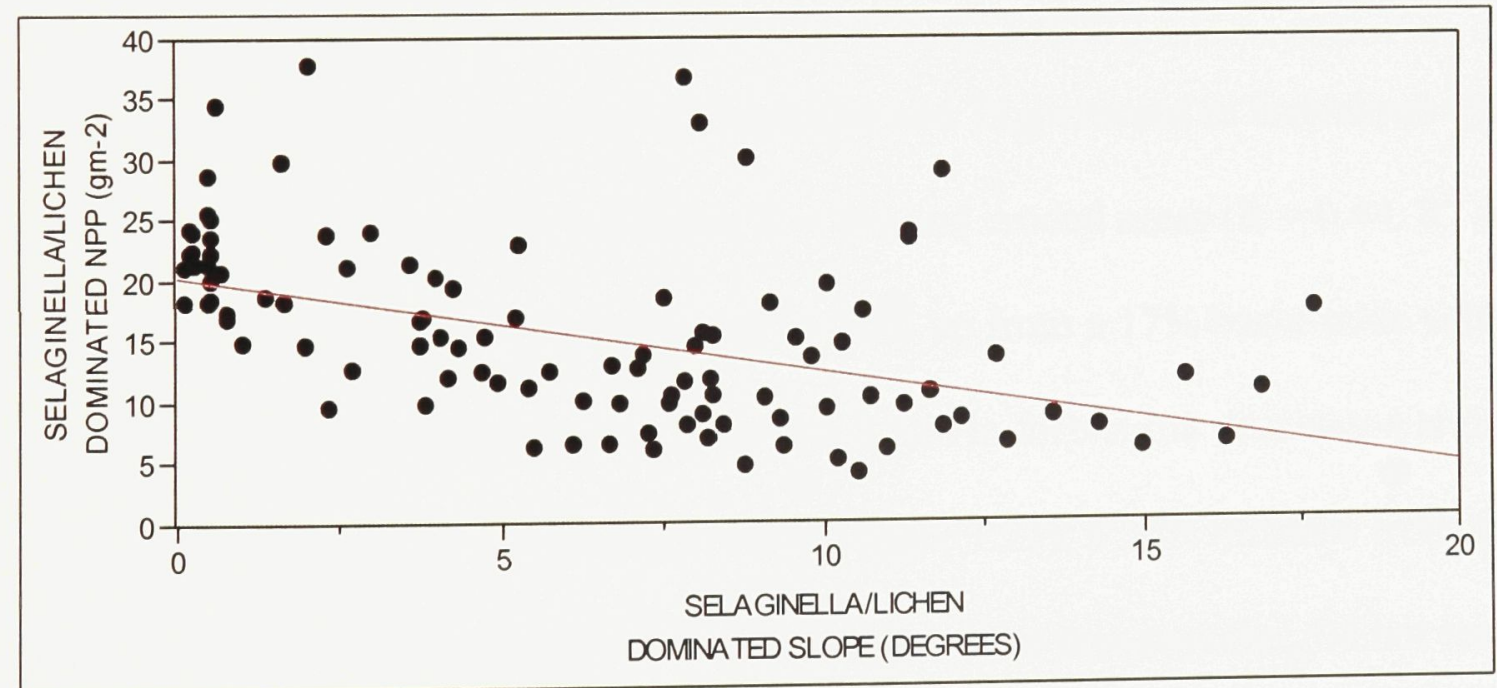

$\mathrm{R}^{2}=$

0.19

$\mathrm{R}=$

$-0.43$

$\mathrm{P}=$

$<.0001$

$\mathrm{N}=87$

(C)

Figure 7.22 - Bivariate correlation of NPP $\left(\mathrm{g} \mathrm{m}^{-2}\right)$ and seasonal average soil moisture $(20 \mathrm{~cm}$; 5 point moving average) (GWC) (A), TI (B), and slope (degrees) (C) in selaginella/lichen dominated areas of the test basin. 


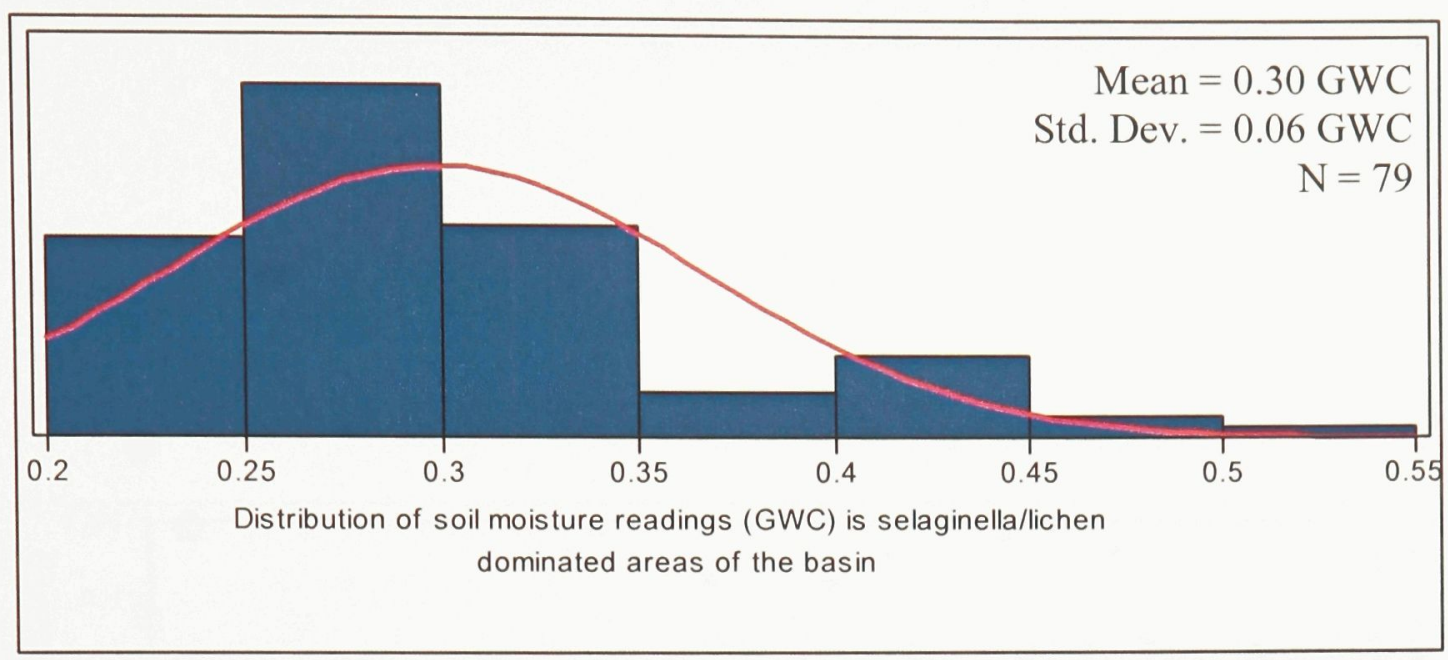

Figure 7.23 - Distribution of seasonal average soil moisture readings $(20 \mathrm{~cm}$; 5 -point moving average) (GWC) in selaginella/lichen dominated areas of the basin.

\subsubsection{Other Vegetation Covers}

The three remaining vegetation covers are examined in this section. Combined, the forbs/shrubs communities, juniper communities and eroded areas of the basin accounted for about $20 \%$ of the vegetation cover across the basin.

The relationship between soil moisture and TI increased in forb/shrub dominated areas $\left(\mathrm{R}=0.51, \mathrm{R}^{2}=0.26, \mathrm{P}=0.0045, \mathrm{~N}=29\right)$ and eroded areas $\left(\mathrm{R}=0.44, \mathrm{R}^{2}=0.19, \mathrm{P}\right.$ $=0.007, \mathrm{~N}=36)($ Figure $7.24(\mathbf{A})$ and $(\mathbf{B}))$, both up from a 17\% basin-wide value. Slope accounted for $47 \%$ of the variance in soil moisture in forb/shrub dominated areas $\left(\mathrm{R}=-0.69, \mathrm{R}^{2}=0.47, \mathrm{P}=<.0001, \mathrm{~N}=29\right)($ Figure 7.25$) ;$ a $30 \%$ increase from the basinwide correlation. Restricting the analysis to these three communities did not result in increased relationship strength between soil moisture and upslope area. In juniper dominated areas, no statistically significant correlations involving soil moisture or NPP were found. 


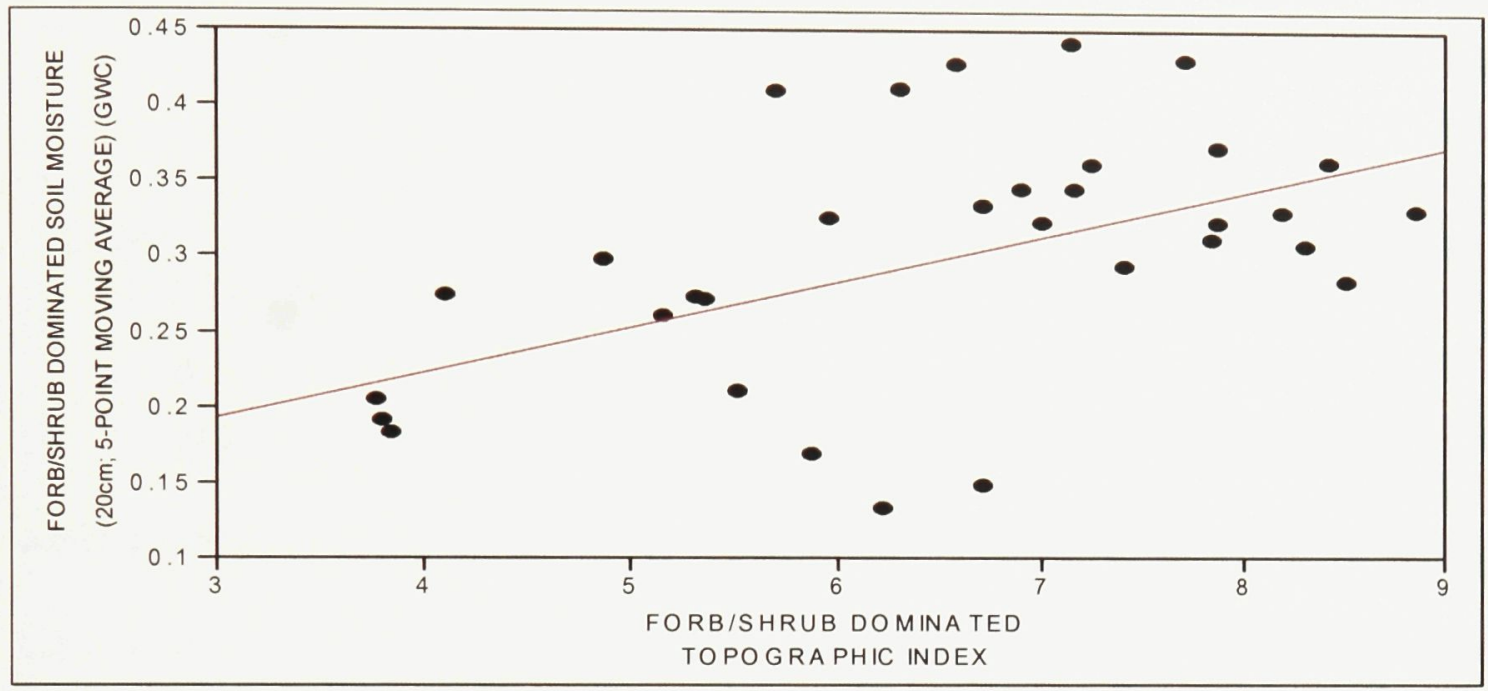

$\mathrm{R}^{2}=$

0.26

$\mathrm{R}=$

0.51

$\mathrm{P}=$

0.0045

$\mathrm{N}=29$

(A)

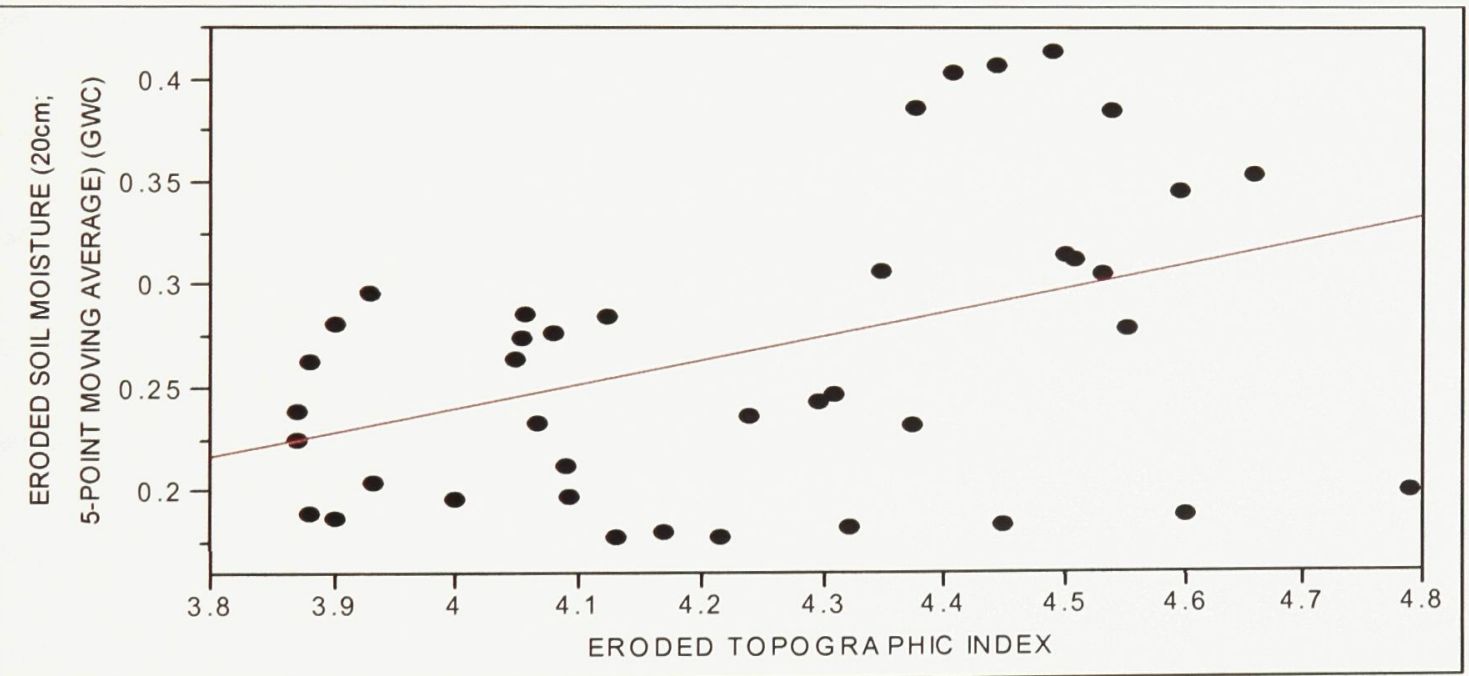

$\mathrm{R}^{2}=$

0.19

$\mathrm{R}=$

0.44

$\mathrm{P}=$

0.0077

$\mathrm{N}=39$

(B)

Figure 7.24 - Bivariate correlation of seasonal average soil moisture $(20 \mathrm{~cm} ; 5$-point moving average) (GWC) and TI in forb/shrub dominated areas (A) and in eroded areas (B) of the test basin. 


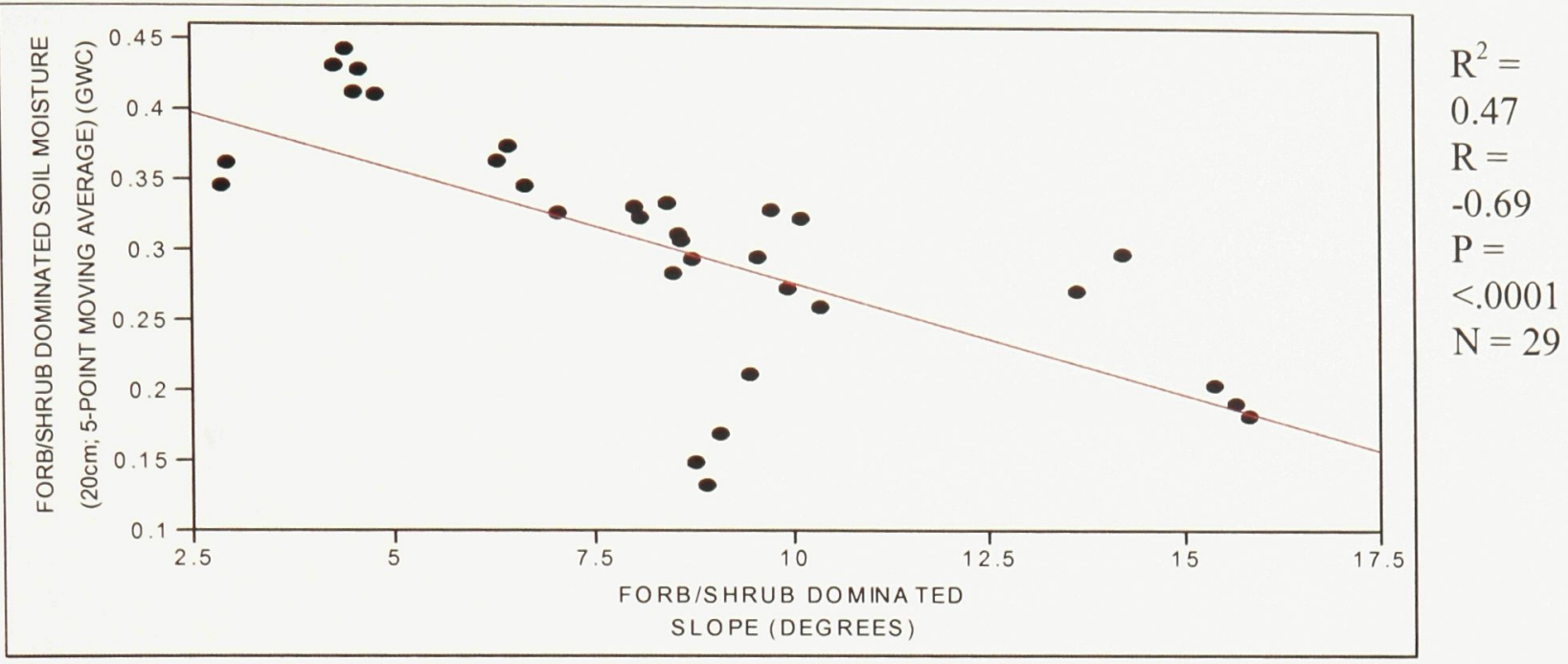

Figure 7.25 - Bivariate correlation of seasonal average soil moisture (20 cm; 5-point moving average) (GWC) and slope (degrees) in forb/shrub dominated areas of the test basin.

No correlations existed between NPP and soil moisture in any of the remaining communities and no conclusions could be drawn from the relationships. This may be because productivity values were low in these areas, which is expected given the increased presence of bare soil. Several of the hypothesized relationships involving NPP were strengthened when restricting analysis to the remaining communities. TI's account of the variance in NPP increased in forb/shrub dominated areas $\left(\mathrm{R}=0.37, \mathrm{R}^{2}=0.14, \mathrm{P}=\right.$ $0.03, \mathrm{~N}=33)$ and eroded areas $\left(\mathrm{R}=0.44, \mathrm{R}^{2}=0.19, \mathrm{P}=0.0057, \mathrm{~N}=39\right)$, but never to more than $19 \%$. Slope continued to correlate positively with NPP and the relationships were statistically insignificant, and upslope area's account of the variance in NPP increased from a basin-wide value of $25 \%$ to $40 \%$ in forb/shrub dominated areas ( $\mathrm{R}=$ $\left.0.64, \mathrm{R}^{2}=0.40, \mathrm{P}=<.0001, \mathrm{~N}=33\right)$ and $33 \%$ in eroded areas $\left(\mathrm{R}=0.57, \mathrm{R}^{2}=0.33, \mathrm{P}=\right.$ $0.0001, \mathrm{~N}=39$ ) (Figure 7.26(A) and $(\mathbf{B})$ ). The increase in the average and variability of NPP in relation to upslope area was observed in these communities, but the trend is less dominant and can be considered irrelevant in these cases because of the smaller sample sizes and because there was little to no vegetation present, especially in eroded areas. 


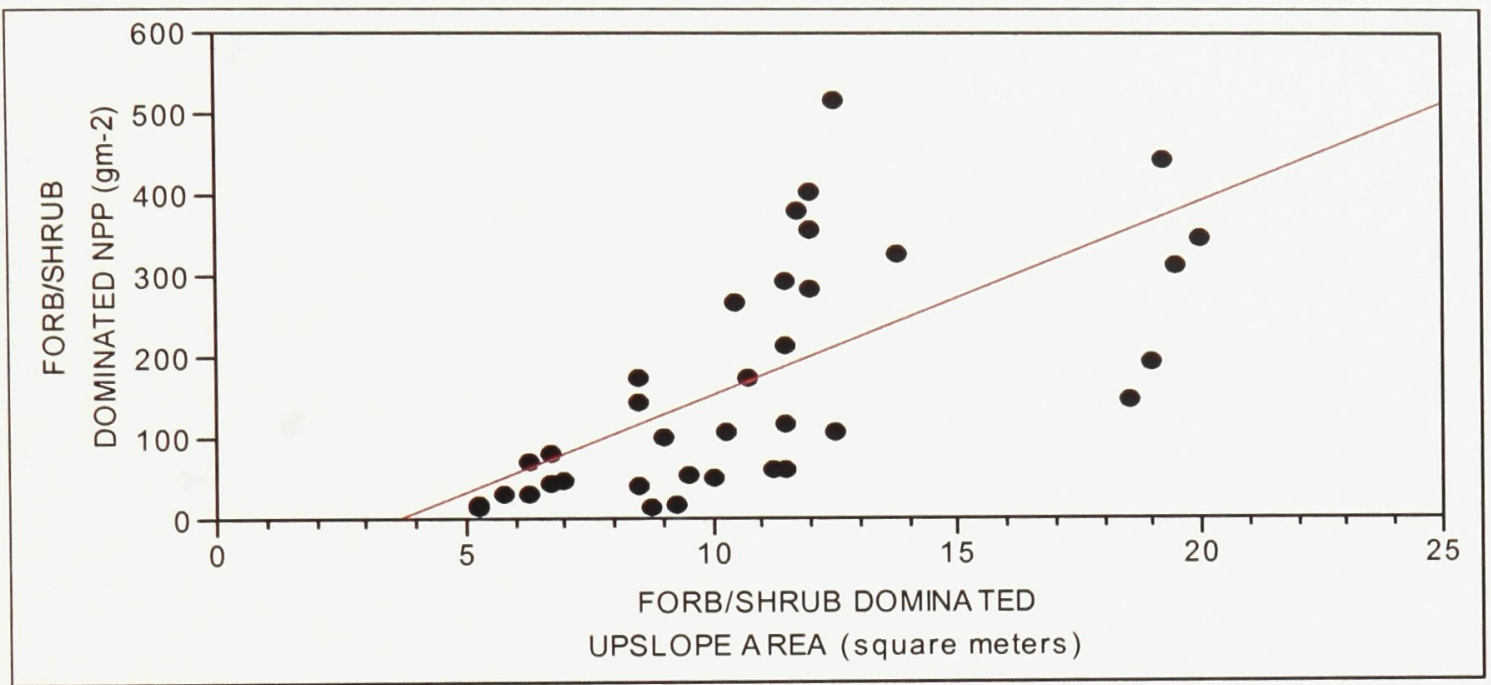

$\mathrm{R}^{2}=$

0.40

$\mathrm{R}=$

0.64

$\mathrm{P}=$

$<.0001$

$\mathrm{N}=33$

(A)

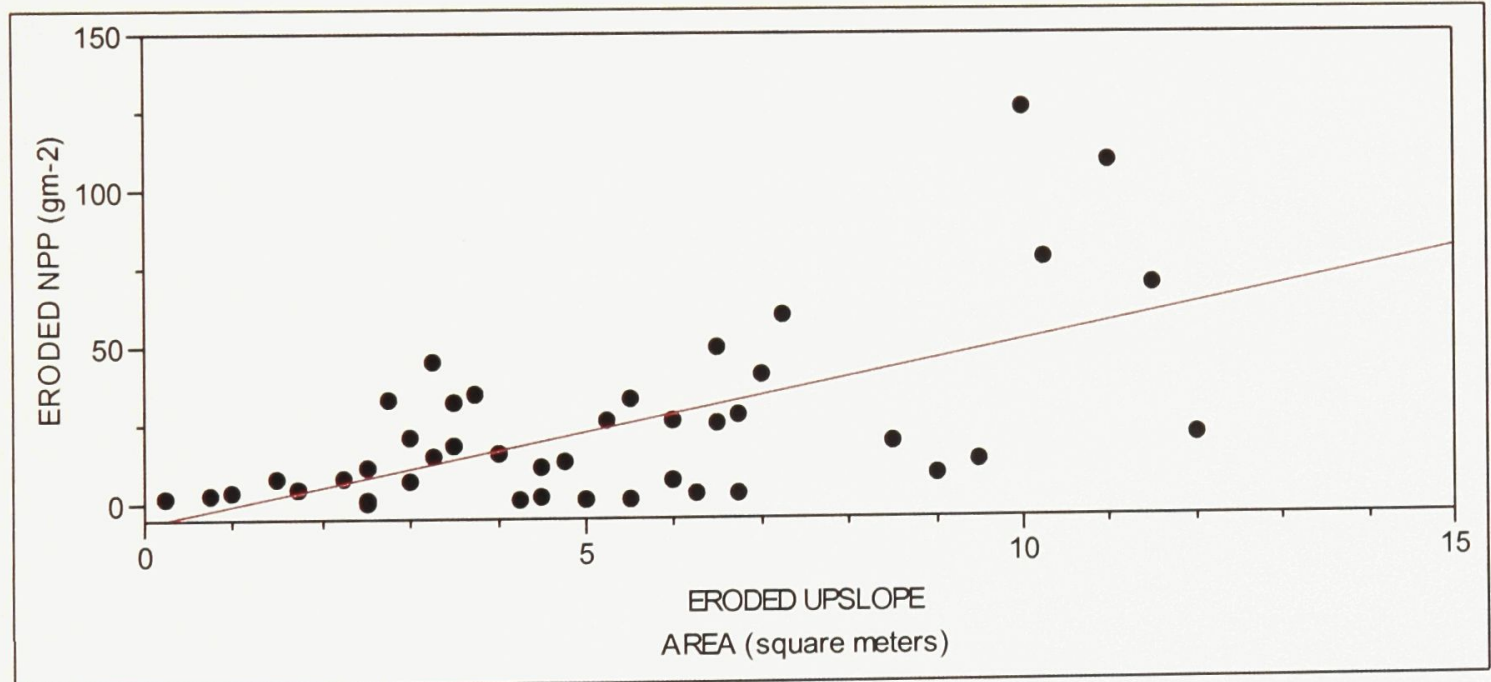

$\mathrm{R}^{2}=$

0.33

$\mathrm{R}=$

0.57

$\mathrm{P}=$

0.0001

$\mathrm{N}=39$

(B)

Figure 7.26 - Bivariate correlation of NPP $\left(\mathrm{g} \mathrm{m}^{-2}\right)$ and upslope area $\left(\mathrm{m}^{2}\right)$ in forb/shrub dominated areas (A) and eroded areas (B) of the test basin. 


\subsection{SYNTHESIS}

\subsection{Hypotheses Summary}

The three hypotheses of this thesis were designed to improve our understanding about the dynamics of grassland systems, including how well the TI applies to predict soil moisture in drier environments, how the distribution of soil moisture across hillslopes relates to topography in this environment, and if any correlations and/or thresholds of above-ground NPP of grasslands with respect to topography or soil moisture availability exist. Extending from that logic were tests to see whether the individual components of TI were correlated with soil moisture in such a way that would contribute to the predictive power of TI for soil moisture. As a result, a mix of relationships was found among the different landscape segregations and vegetation communities. The validity of the proposed hypotheses will be summarized in this section and some explanation into what may have caused the observed patterns will be offered.

As a general summary, TI explained between $3 \%$ and $27 \%$ of the variance in soil moisture. Increased explanations of the variance in soil moisture occurred among specific vegetation communities. Slope explained between $3 \%$ and $61 \%$ of the variance in soil moisture, with the highest explanations of variance occurring on the west-facing hillslope and in the drainage zone, while upslope area failed to explain a significant amount of the variance in soil moisture at any segregation, and all trends were opposite to the hypothesized direction. NPP and soil moisture do not correlate in the test basin, with the only significant relationship occurring in the selaginella/lichen communities. TI explained between $3 \%$ and $25 \%$ of the variance in NPP, with the highest explanation of 
variance also occurring in the selaginella/lichen communities, while NPP was consistently positively correlated with slope (opposite to the hypothesized trend), except in the selaginella/lichen communities. Upslope area explained between $15 \%$ and $44 \%$ of the variance in NPP, and the highest explanations of variance differed among the data segregations.

The hypothesis that soil moisture is positively correlated with TI was valid with soil moisture integrated across a $20 \mathrm{~cm}$ depth, and averaged across both space and time. Across the entire basin, soil moisture and TI had a statistically significant correlation, but had generally low predictive power, explaining $17 \%$ of the variance in soil moisture. Further examination revealed that the relationship between soil moisture and slope was negative, which is in the hypothesized direction, accounting for $17 \%$ of the variance in soil moisture across the entire basin. The hypothesis that soil moisture would be positively correlated with upslope area in the test basin is rejected, as it failed to explain a significant amount of the variance in soil moisture.

The second hypothesis, that NPP will be positively related to soil moisture, was rejected. The direction of the relationship between NPP and TI was in the hypothesized direction, but TI had low predictive power for NPP, explaining only $3 \%$ of the variance in NPP, meaning that although the hypothesis of a positive relationship could be defended statistically, it could be of little practical use. Further tests revealed that NPP was positively correlated with slope (opposite to the hypothesized trend), but the hypothesized positive relationship between NPP and upslope area was valid, explaining 
$25 \%$ of the variance in NPP. Therefore, upslope area is capturing some combination of the factors that promote vegetation growth in the basin.

The third hypothesis, that the reduced heterogeneity within specific landscape positions and vegetation communities will strengthen the relationships among NPP, soil moisture and the topographic variables, is rejected, although several of the specific relationships increased in strength when the data were segregated. Among the different landscape positions, the relationship between soil moisture and the topographic variables failed to increase in most cases, except on the west-facing hillslope, where there was a noted increase in the account of the variance in soil moisture by TI and slope. Slope best predicted soil moisture on the west-facing hillslope; a hillslope that contains less vegetation than other parts of the basin and includes a highly eroded section near the east end of transect 8 . While steeper slopes are expected to have less soil moisture, the moisture holding capacity of the soil on the west-facing hillslope may be lower which could be an important confounding factor. Soil moisture was also well predicted by slope in the drainage zone of the basin. However, it should be noted that the steepest slopes in the basin occur in and around the drainage zone, nearer to the outlet defined in this study.

TI explained between $19 \%$ and $27 \%$ of the variance in soil moisture in the different vegetation communities, which was always stronger than the $17 \%$ basin-wide correlation. In areas with the most dominant types of vegetation cover (grasses, selaginella/lichen, forbs/shrubs), the variance in soil moisture was consistently explained best by TI and slope, with those relationships acting in the hypothesized directions, and 
there was an average increase of $11 \%$ in their explanation of the variance in soil moisture when compared to the entire basin. TI explained $19 \%$ of the variance in soil moisture in eroded areas, while there was no correlation between soil moisture and the topographic variables in the juniper communities. Soil moisture's relationship with the topographic variables in these areas was consistent with the entire basin. TI and slope behaved as hypothesized with some increased accounts of variance, but upslope area still did not behave as hypothesized, and had weak explanations of variance in soil moisture.

Vegetation in this environment is adapted to compete for moisture. Even very light precipitation events $(\sim 5 \mathrm{~mm})$ have proven to be ecologically significant (Sala and Lauenroth, 1985). As such, vegetation does not normally have access to much soil moisture continuously across the growing season. This may explain why soil moisture among the different landscape positions and vegetation communities failed to explain more of the variance in NPP than the entire basin. Variables that predicted an increase in NPP, did not predict increased soil moisture as well. Because there was not one single variable that accounted for increased variance in both NPP and soil moisture, the results were weak relationships between the two variables in the basin. This suggests that in these environments, NPP does not rely solely on local soil moisture, but more on an integration of controlling factors, including the routing of upslope moisture and nutrients, especially during episodic events. Areas with the greatest upslope area will be in the more sheltered/concave portions of the basin which will likely have lowered turbulence and lower incoming radiation, both which will reduce moisture losses to evapotranspiration. 
In terms of predicting NPP, upslope area proved to be the strongest predictor, and slope failed to explain any of the variance in NPP, except in the selaginella/lichen communities. The only conclusions that could be drawn were that slope and NPP are generally independent of one another in the test basin, but upslope area explained between $15 \%$ and $44 \%$ of the variance in NPP, depending on basin position or vegetation community. The west-facing hillslope, forbs/shrub communities, and eroded areas showed an increase in the account of variance in NPP compared to the entire study site, while all others showed negligible decreases. Despite the variation in correlation strength, one of the most consistently observed patterns at most segregations was the increase in the average and variability of NPP when relating it with upslope area. In these relationships, the average and variability of NPP increased in response to a 5.0 to $7.5 \mathrm{~m}^{2}$ range in upslope area size. This corresponded to the regions within the concave portion of the test basin and up to the transition between the backslope and the shoulders, just as the basin sides began to increase in slope towards the drainage zone, as shown by the red areas in Figure 8.1. This illustrates that productivity is much lower in the uplands area of the basin. One could conclude that $5.0-7.5 \mathrm{~m}^{2}$ is a threshold of upslope area in terms of predicting NPP. Areas with higher upslope area within the basin will be more sheltered, meaning that they are likely to have decreased losses of soil moisture through evapotranspiration, and probably also have increased nutrient and organic material accumulation (i.e. the catena effect). The only areas that did not exhibit this trend were the selaginella/lichen communities, which generally dominate the exposed uplands with low upslope area. 


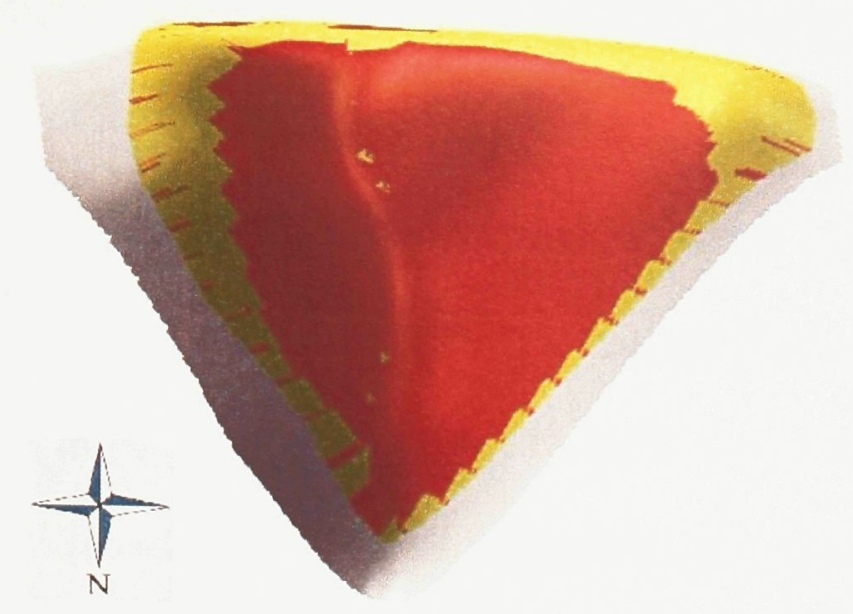

Figure 8.1 - Areas in the test basin with upslope areas $>5.0 \mathrm{~m}^{2}$ (in red). The range and variability of NPP increased in the red areas, which corresponded to an increase in upslope area. Vertical exaggeration $=3.0$.

\subsection{Additional Research Findings and Explanations of Results}

The only regions where both soil moisture and NPP were best predicted by the topographic variables were in areas where grass dominance is reduced, such as the selaginella/lichen communities and the forb/shrub communities. It can be concluded that areas where grass dominance has become disrupted show stronger relationships, probably due to increased bare soil exposure, quicker water infiltration, and a decreased loss to evapotranspirtation. Slope's account of the variance in soil moisture increased in these regions, similar to the findings of Gómez-Plaza et al. (2001) where slope was the stronger predictor in burnt areas with little vegetation. This is further highlighted by the fact that the only part of the basin where soil moisture had a respectable explanation of the variance in NPP was in the selaginella/lichen communities. In other parts of the basin, soil moisture did not account for any of the variance in NPP, and these parts of the basin had more biomass and a greater abundance of plant cover. The productivity of plants in 
areas where grass dominance has been disrupted (selaginella/lichen, forbs/shrubs) was predicted more strongly by the topographic variables than by soil moisture. These trends highlight the fact that despite the role played by abiotic controls measured in this study, there are numerous other factors that control NPP, and as vegetation cover decreases, this variability is minimized. Furthermore, this study focused on above-ground biomass only, hiding important below-ground dynamics which probably increase in importance as vegetation cover rises. In semi-arid grassland environments, competition for water is an important factor in terms of plant growth, particularly in terms of the spatial patterns of roots and the capacity for resource uptake (Hook and Lauenroth, 1994). Grasses in particular have adapted to these conditions by situating much of their root biomass well within the top $30 \mathrm{~cm}$ of the soil (Golluscio et al., 1998), and these important root-zone dynamics (e.g. root distribution) were not captured in the present study.

TI's two components, slope and upslope area, did not individually correlate with soil moisture in directions that would be consistent with a strong relationship between TI itself and soil moisture. In the present study, the trends shown by soil moisture against upslope area were not in the hypothesized direction, while in most cases, the opposite was true for slope. If the correlations of soil moisture with slope and upslope area were in the hypothesized directions, TI would have accounted for an increased amount of the variance in soil moisture. What this demonstrates is that soil moisture is predicted with more confidence based on slope, rather than using TI or upslope area. In terms of predicting NPP, the opposite is true; upslope area accounted for the highest variance, but its trend with slope was rarely in the hypothesized direction. This suggests that soil 
moisture is best predicted by a local measurement (i.e. slope), but NPP is best predicted by an integrated measure (i.e. upslope area), where the position within the basin becomes the more important factor.

Lower correlations between soil moisture and NPP can probably be attributed to the relatively low rainfall during this study. As the climate becomes drier, soil moisture is affected more by vertical fluxes rather than lateral flow, meaning that the extent of upslope contributing areas to the basin are reduced, effectively rendering them hydrologically disconnected from the rest of the basin (Grayson et al., 1997; Western et al., 1999). The dry environment of GNP can be characterized by a climate where evapotranspiration exceeds total rainfall, and Aryal (2003) noted that if evapotranspiration exceeds rainfall, only portions of the catchment are hydrologically active, leading to inaccurate results if models that are based on the entire catchment are used. This could explain why not all relationships conformed to the hypothesized trends. There would be a better chance at stronger correlations in a year with a greater range in soil moisture, caused by higher or more frequent rainfall, because the environment would have been, at least for a time, closer to the conditions in which the TI-based approach has been shown to work well.

During initial data analysis, shallow measurements $(12 \mathrm{~cm})$ showed no consistent relationships, and measurements integrated over a greater depth $(20 \mathrm{~cm})$ began to produce relationships that made sense. This was because shallower soil moisture is more affected by evapotranspiration and other external variables, whereas deeper soil moisture 
is less affected by these external factors. This has been shown by Singh et al (1998), who examined moisture below the evaporative zone, with moisture levels monitored at $15 \mathrm{~cm}$ intervals providing estimates covering 22.5 to $97.5 \mathrm{~cm}$ depths and concluded that in these environments, major losses of soil moisture occur through bare soil evaporation, mainly due to small and sparse precipitation events. Surface moisture is either lost quickly by evapotranspiration or taken up by the vegetation, with very little moisture remaining in the soil surface zone of the profile. These types of precipitation events may have lead to the observed results in the present study, and to the correlations being more consistent using the $20 \mathrm{~cm}$ probe measurements compared to the $12 \mathrm{~cm}$ probes. This effect could have been countered with more measurements at greater depths, at specific locations with longer term probes, but it would have been difficult to carry out the spatial intensity of the present study at greater depths or increased temporal frequency. Increased moisture at depth has been confirmed in this environment (Figure 8.2) by a recent (2008) measurement campaign in GNP (R. Virk, pers. comm., 2008). It is possible that soil moisture stored in the profile below the zone of evaporation may be the most important factor contributing to the growth and stability of grassland vegetation and should be incorporated into future studies. 


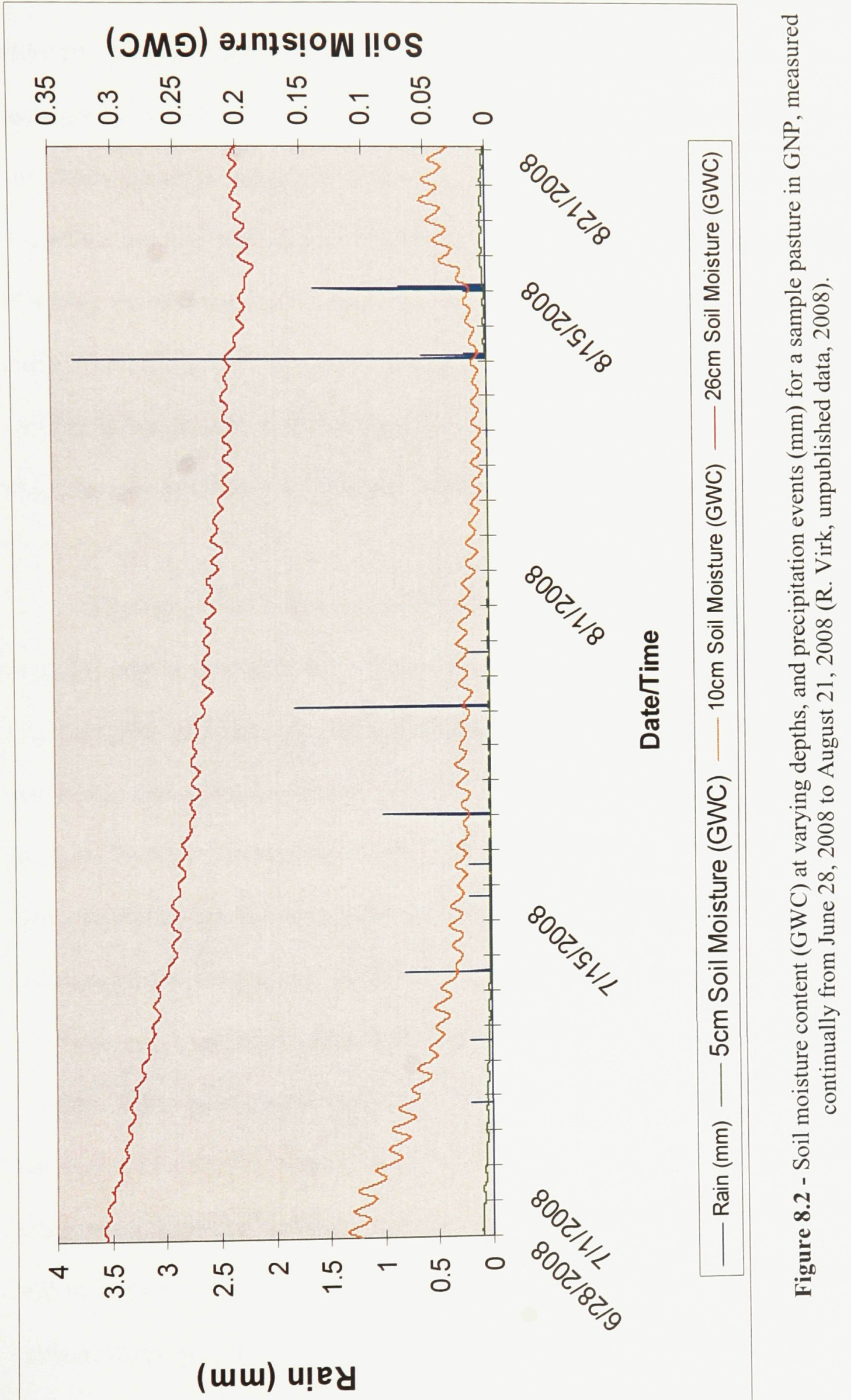


In this particular study, broad relationships (i.e. across the whole basin) are affected by a wide range of variability, whereas narrower, more specific relationships (i.e. segregating the data by specific parts of the basin) are affected in parts by high local variability, a narrow range in soil moisture, dry conditions, and small sample sizes. Therefore, in order to find more meaningful relationships, it may just be a matter of choosing the relevant scale; a scale between looking at data across the whole basin (where individual dynamics may be acting separately because of the variability) and looking at data in unique landscape positions and vegetation communities (where the range may be too narrow to find any meaningful relationships).

The narrow distribution of soil moisture across the basin (shown in Figure 6.5 on page 48) may be attributed to soil texture and the low amount of precipitation during and preceding the study period. Although soil samples were not collected for physical analysis in this study, a prior soil survey indicates that predominant soil texture in the basin is clay/loam, and is described as moderately to excessively stony. This lead to high local variability in soil texture between sample points, because at some sample points the moisture probes were able to easily enter the soil, down to both depths $(12 \mathrm{~cm}$ and 20 $\mathrm{cm}$ ), whereas at other points, the probes were unable to enter the soil at all, due to all the pebbles. This would occasionally happen between adjacent points, where the soil texture was such that a reading could be easily taken at one point, but at the very next point, one metre away, a reading could not be taken because the probe was obstructed by stones, further emphasizing the variability in texture. Moisture is more easily drained from coarser, stony soil, leading to low moisture in the basin (at least in the upper profile); the overall stony nature of the soil combined with the fact that this characteristic was highly 
variable from point to point, could be an important reason for the observed relationships.

\subsection{Research Limitations}

The lower or absent correlations in this study were potentially limited by the methods chosen, and a few suggestions as to how the methods could be improved are presented in this section.

One improvement would be to increase the number of soil moisture readings taken at any given sample point to account for the local variability, perhaps in a method similar to Carlyle (2006). In that study, several (5) measurements were taken within a $1 \mathrm{~m}$ radius of a central sampling point to account for the local variation in soil moisture. These measurements can then be averaged to obtain one representative reading per sample site. However, measurements in Carlyle (2006) were only at the $5 \mathrm{~cm}$ depth, so this becomes difficult as the depth of the measurements increases, providing feasibility problems. The sparse soil moisture calibration data and relatively weak fit of the calibration also inserted uncertainty into all soil moisture data. A better calibration equation would lead to more confidence and could have lead to different conclusions. In conjunction with this, the sampling grid may have not been large enough or dense enough to capture the variability across the basin. Sampling points $0.5 \mathrm{~m}$ apart and transects closer together may help in improving some of the relationships, but the grid would have to be of feasible size for the nature of the research and for the timeline involved. 
Data segregation was carried out in an attempt to find patterns within the large variability across the basin. Locally, the soil moisture readings were quite erratic, especially further down the basin, and this may have overwhelmed any topographic trends. It can be concluded that the topographic variables are important in controlling soil moisture, but are not the only variables affecting its distribution. However, while every effort was made to segregate the data in a logical fashion, the landscape positions and vegetation communities were potentially not defined well enough, or segregated properly. Future studies would benefit from a further segregation of the data; one that looks at upper and lower portions of the basin, as well as flatter areas that have little to no variability in soil moisture, in order to encompass a greater range of conditions. A more systematic approach could have been used to define these parts of the basin, such as Park's pedogeomorphological unit classification system (Park et al., 2001). Landscape units of similar geomorphological and pedological regimes can be classified into one of five categories: interfluve, shoulder, backslope, footslope, and toeslope (Figure 8.3).

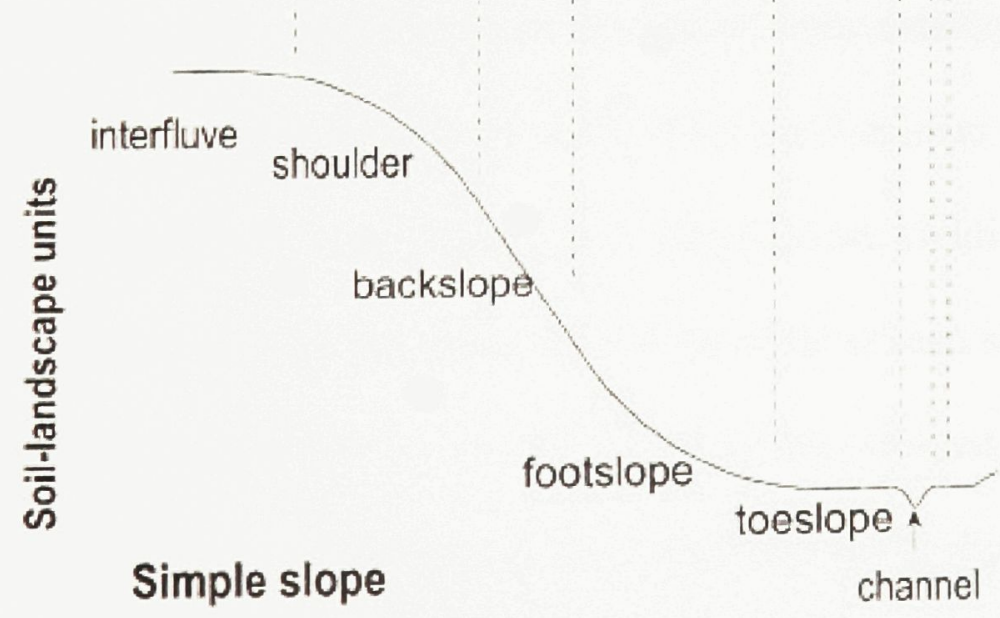

Figure 8.3 - Schematic two-dimensional diagram of Park's pedogeomorphological unit classification system (figure source: Park et al., 2001). 
Using these classifications, one could isolate those parts of the basin falling on the shoulder, backslope and footslope only and consider those areas to be the hillslopes of the basin. Furthermore, results would have captured the full dynamics of the drainage system if the test basin extents included the flatter ground further north from the outlet used in this study and did not stop at the basin walls at the outlet. However, extending the basin into the flatter ground to the north may have included landscapes and inputs from adjacent drainage systems, introducing data outside of the study area into the analysis. Extending from this, and based on the results of this study, there is evidence that future studies should extend the variables to include topographic measures of concavity and convexity, as they have also been shown to be related to soil moisture and productivity.

Methods to determine the dominant vegetation cover may not have been accurate. At each sample point, the dominant vegetation cover was determined by looking at photographs taken along the transects. Without any direct measurement of the vegetation cover at each sample point, some subjectivity was introduced when establishing the dominant class of vegetation. Results may have improved if the dominant vegetation cover was determined through direct sampling of each sample point, yielding more accurate and true representation of the dominant vegetation cover at each sample point. But given the time restraints on the field season for this study, this was not feasible and photographs were used instead. The biomass measurements also have inherited uncertainty due to the limitations of the NDVI calibration, however, the strength of this correlation was judged to be typical for this type of measurement. 
Soil chemistry can be an important factor affecting plant available moisture and plant growth. Specifically, soil $\mathrm{pH}$ has been shown to be an important variable influencing plant distribution and species (Giesler et al., 1998; Sorensen et al., 2005). While soil $\mathrm{pH}$ was not studied in this research, it could be incorporated into future studies in these environments. Also, TDR techniques often systematically overestimate the water content in dry, saline environments such as the one found in GNP (Wyseure et al. 1997). This was initially thought to be a potential problem, as salinization can be a problem in the broader area, but the calibration of the probe was designed to counter this.

Based on these potential limitations, an ideal study in this environment should incorporate soil moisture measurements below the zone of evaporation only, the texture of the soil and its chemical properties, a basin that includes a wider range of landscape classifications (including the flatter portion of the drainage basin beyond the outlet), more topographic measures (i.e. concavity and convexity), and should address micrometeorological drivers. Combining these with a sampling strategy based on the spatial structure of soil moisture variability may produce more consistent and meaningful relationships among the variables in this environment. 


\subsection{CONCLUSION}

Topography has been shown to be a major influence on the distribution of soil moisture in North America and in humid environments, and NPP is highly constrained by minimally available soil moisture in semi-arid environments. Because of that, this paper was presented to test the relationships among three important variables in grasslands: NPP, soil moisture, and topography (as expressed by the TI and its two main components, slope and upslope area), in order to determine how well the TI applies to predict soil moisture in drier environments, to improve our understanding about the dynamics of semi-arid grassland systems, and to examine any relationships between NPP and soil moisture or topography. This was accomplished by testing the following hypotheses;

i) that soil moisture will be positively correlated with TI (and, by extension, slope will be negatively correlated and upslope areas positively correlated),

ii) that above-ground NPP will be positively related to soil moisture and TI (and, by extension, slope will be negatively correlated and upslope areas positively correlated), and

iii) that the reduced heterogeneity within specific landscape positions and vegetation communities will strengthen the relationships among NPP, soil moisture and topography. 
The main findings of this research are:

Topography was found to be an important factor in controlling soil moisture, but the relationships between specific topographic measures and soil moisture were different than previously shown in wetter environments. While the TI has proved valuable for predicting soil moisture in wetter environments and it appears to hold some power in this study, it never accounted for more than $27 \%$ of the variability in soil moisture, in any region of the basin. Slope by itself was a much better predictor of soil moisture than TI. The relationship between soil moisture and upslope area was never in the hypothesized direction, and this weakened the correlation between soil moisture and TI. Moisture integrated across greater depths $(\sim 20 \mathrm{~cm})$ is more affected by topography in this environment, while the shallower soil moisture $(\sim 12 \mathrm{~cm})$ did not produce any consistent correlations among the different segregations.

NPP and soil moisture were independent of one another, except in the presence of flatter terrain and in areas where grass dominance has been disrupted, as shown by only being positively correlated in selaginella/lichen communities. TI is a stronger predictor of NPP when the data is segregated by vegetation cover, while slope failed to predict NPP in any region of the basin, expect in the selaginella/lichen communities. Upslope area was the single strongest and most consistent predictor of NPP, with a threshold of approximately $5.0 \mathrm{~m}^{2}$ resulting in a noticeable increase in the average and variability of NPP. This trend was seen at all landscape position segregations and vegetation communities, and corresponded to regions within the concave portion of the test basin 
and up to the transition between the backslope and the shoulders, just as the basin sides began to increase in slope towards the drainage zone. This suggests that one could expect vegetation to be more productive in terrain with an upslope area of at least $5.0 \mathrm{~m}^{2}$. Vegetation communities with less above-ground biomass appeared to lead to stronger results, both in terms of predicting NPP and soil moisture. One could also conclude that the integrative measurement of upslope area plays an important role in predicting NPP and the local measurement of slope may be the strongest predictor of soil moisture.

The results of this study are important in providing information on how topography affects both the distribution of soil moisture and the NPP of northern mixed grasses. Based on this research one can conclude that the TI is not a strong predictor of soil moisture across a hillslope in drier environments, because there are other dynamics contributing its distribution in these environments, and they need to be considered in future models. Results of this research also provide some insight into the different adaptations that these grasses have for precipitation and temperature regimes and their potential responses to climate change. 


\subsection{REFERENCES}

Aryal, S.K., Mein, R.G. and O'Loughlin, E.M. (2003). The concept of effective length in hillslopes: assessing the influence of climate and topography on the contributing areas of catchments, Hydrological Processes, 17:131-151

Bennett, R.J. and R.J. Chorley (1978). Environmental systems: philosophy, analysis and control, Princeton University Press, New Jersey, 624pp.

Beven, K.J. and M.J. Kirkby (1979). A physically-based variable contributing area model of basin hydrology, Hydrological Sciences - Bulletin, 24(1):43-69

Beven, K.J. (1997). TOPMODEL: A critique, Hydrological Processes, 11:1069-1085

Brady, N.C. and R.R. Weil (2002). The nature and properties of soils, thirteenth edition, Pearson Education, Inc., New Jersey, 960pp.

Briggs, J.M and A.K. Knapp (1995). Interannual variability in primary production in tallgrass prairie: climate, soil moisture, topographic position, and fire as determinants of aboveground biomass, American Journal of Botany, 82(8):1024-1030

Burke, I.C., C.M. Yonker, W.J. Parton, C.V. Cole, K. Flach and D.S. Schimel (1989). Texture, climate and cultivation effects on soil organic matter content in U.S. grassland soils, Soil Science Society of America Journal, 53:800-805.

Burt, T.P. and D.P. Butcher (1985). Topographic controls of soil moisture distributions, Journal of Soil Science, 36:469-486

Campbell Scientific, Inc (2001). HydroSense Instruction Manual: Revision 2/01, Available online at: http://www.campbellsci.com/documents/manuals/hydrosns.pdf

Canada Centre for Remote Sensing (2008). Fraction of photosynthetically active radiation (FPAR), Natural Resources Canada, Last Modified 2008-01-10, Available at: http://ccrs.nrcan.gc.ca/optic/veg/veg2_e.php

Carlyle, Stephen Anthony (2006). Changing nature of topographic control on surface soil moisture of prairie pothole complexes along a climate gradient, M.Sc. Thesis, The University of Western Ontario, London, Ontario, Canada, 101pp.

Coupland, R.T. (1992). Mixed Prairie. In: R.T. Coupland (Editor), Natural grasslands introduction and western hemisphere. Ecosystems of the World. Elsevier, Amsterdam; New York, pp. 151-182.

Daly, E. and A. Porporato (2006). Impact of hydroclimatic fluctuations on the soil water balance, Water Resources Research, 42:doi:10.1029/2006WR004606 
Davidson, A., S. Wang and J. Wilmshurst (2006). Remote sensing of grassland-shrubland vegetation water content in the shortwave domain, International Journal of Applied Earth Observation and Geoinformation, 8:225-236

Freer, J., J. McDonnell, K.J. Beven, D. Brammer, D. Burns, R.P. Hooper and C. Kendal (1997). Topographic controls on subsurface storm flow at the hillslope scale for two hydrologically distinct small catchments, Hydrological Processes, 11:1347-1352

Fuhlendorf, S.D. and F.E. Smeins, 1996. Spatial scale influence on long term temporal patterns of a semi-arid grassland, Landscape Ecology, 11(2): 107-113

Giesler, R., M. Hogberg, and P. Hogberg (1998). Soil chemistry and plants in Fennoscandian boreal forest as exemplified by a local gradient, Ecology, 79:119-137

Golluscio, R.A., O.E. Sala, and W.K. Lauenroth (1998). Differential use of large summer rainfall events by shrubs and grasses: a manipulative experiment in the patagonian steppe, Oecologia, 115:17-25

Gómez-Plaza, A., M. Martínez-Mena, J. Albaladejo, and V.M. Castillo (2001). Factors regulating spatial distribution of soil water content in small semiarid catchments, Journal of Hydrology, 253:211-226

GRASS Development Team (2006). Geographic Resources Analysis Support System (GRASS). v. 6.2. GNU General Public License

Gray, D.M., J.W. Pomeroy, and R.J. Granger (1989). Modelling snow transport, snowmelt and meltwater infiltration in open northern regions, In Northern Lakes and Rivers, Mackay WC (ed.) Occasional Publication No. 22, Boreal Institue for Northern Studies, University of Albert: Edmonton, 8-22

Grayson, R.B., A.W. Western, F.H.S. Chiew and G. Bloschl (1997). Preferred states in spatial soil moisture patterns: local and nonlocal controls, Water Resources Research, 33:2897-2908

Grayson, R.B. and A.W. Western (1998). Towards areal estimation of soil water content from point measurements: time and space stability of mean response, Journal of Hydrology, 207:68-82

Grayson, R.B. and A.W. Western (2001). Terrain and the distribution of soil moisture, Hydrological Processes, 15:2689-2690

Grzesiak, S., M.T. Grzesiak, W. Filek, T. Hura and J. Stabryla (2002). The impact of different soil moisture and soil compaction on the growth of triticale root system, Acta Physiologiae Plantarum, (24)3:331-342 
Hayashi, M., G. van der Kamp, and R. Schmidt (2003). Focused infiltration of snowmelt water in partially frozen soil under small depressions, Journal of Hydrology, 270:214-229

Hillel, D. (1998). Environmental soil physics, Academic Press, USA, 771pp.

Hills, T.C., and S.G. Reynolds (1969). Illustrations of soil moisture variability in selected areas and plots of different sizes, Journal of Hydrology, 8:27-47

Hjerdt, K.N., J.J. McDonnell, J. Seibert and A. Rdhe (2004). A new topographic index to quantify downslope controls on local drainage, Water Resources Research, 40(5):W05602

Hook, P.B. and W.K. Lauenroth (1994). Root system response of a perennial bunchgrass to neighbourhood-scale soil water heterogeneity, Functional Ecology, 8:738-745

Hornberger, G.M., J.P. Raffensperger, P.L. Wiberg and K.N. Eshleman (1998). Elements of physical hydrology, The John Hopkins University Press, Baltimore, 302pp.

Johnston, R.J., D. Gregory and D.M. Smith (1994). The dictionary of human geography Third Edition, Blackwell Publishers Limited, Great Britain, 724pp.

Jorgensen, S.E. and G. Bendoricchio (2001). Fundamentals of ecological modelling third edition, Elsevier Science Limited, Great Britain, 530pp.

Klinkenberg, B. (2005). Topographic Indices and Their Effect on Hydrologic Processes, The University of British Columbia, Last Updated 1998-12-11, Available at: http://www.geog.ubc.ca/courses/klink/g470/class98/sharma/indices.html

Knapp, A.K., J.T. Fahnestock, S.P. Hamburg, L.B. Statland, T.R. Seastedt and D.S. Schimel (1993). Landscape patterns in soil-plant water relations and primary production in tallgrass prairie, Ecology, 74:549-560

Kravchenko, A.N., D.G. Bullock and C.W. Boast (2000). Joint multifractal analysis of crop yield and terrain slope, Agronomy Journal, 92:1279-1290

Kravchenko, A.N. and D.G. Bullock (2000). Correlation of corn and soybean grain yield with topography and soil properties, Agronomy Journal, 92:75-83

Kravchenko, A.N. and D.G. Bullock (2002). Spatial variability of soybean quality data as a function of field topography: I. Spatial Data Analysis, Crop Science, 42:804-815

Krcho, J. (1973). Morphometric analysis of relief on the basis of geometric aspect of field theory, Bratislava, Slovak Pedagogical Publishers, Acta Geographica Universitae Comenianae, Geographica Physica 1, 425pp. 
Krcho, J. (1991). Georelief as a subsystem of landscape and the influence of morphometric parameters of georelief on spatial differentiation of landscape-ecological processes, Ecology/CSFR/(10):115-157

Kristoffersen, A. O. and H. Riley (2005). Effects of soil compaction and moisture regime on the root and short root growth and phosphorus uptake of barley plants growing on soils with varying phosphorus status, Nutrient Cycling in Agreoecosystems, 72:135-146

Ladson, A.R. and I.D. Moore (1992). Soil water prediction on the Konza prairie by microwave remote sensing and topographic attributes, Journal of Hydrology, 138:385407

Lapen D.R. and M.L. Martz (1996). An investigation of the spatial association between snow depth and topography in a prairie agricultural landscape using digital terrain analysis, Journal of Hydrology, 184:277-298

Lauenroth, W.K. and O.E. Sala (1992). Long-term forage production of North American shortgrass steppe, Ecological Applications, 2:397-403

Lillesand, T.M. and Kiefer, R.W. (1994) Remote sensing and image interpretation - third edition, John Wiley \& Sons, Inc., 750pp

Long, S.P., M.E. Garcia, S.K. Imbamba et al. (1989). Primary productivity of natural grass ecosystems of the tropics: a reappraisal, Plant and Soil, 115:155-166

Long, S.P., M.B. Jones and M.J. Roberts (eds) (1992). Primary productivity of grass ecosystems of the tropics and sub-tropics, Chapman \& Hall, London, 267pp.

Martinez, C., G.R. Hancock, D. Kalma and T. Wells (2007). Spatio-temporal distribution of near-surface and root zone soil moisture at the catchment scale, Hydrological Processes, DOI: 10.1002/hyp.6869

Meteorological Service of Canada (1997). Canadian Daily Climate Data, 1967 - 1996, [Microsoft Excel Data files]

Meteorological Service of Canada (2004). Canadian climate data search on-line Canada's national climate archive, Last Updated 2008-10-09, Available at: http://www.climate.weatheroffice.ec.gc.ca/climateData/canada_e.html

Miller, M.P., M.J. Singer and D.R. Nielsen (1988). Spatial variability of wheat yield and soil properties on complex hills, Soil Science Society of America Journal, 52:1133-1141

Milne, G. (1935). Some suggested units of classification and mapping for east African soils, Soil Res., 4:183-198 
Milne, G. (1936). Normal erosion as a factor in soil profile development, Nature, $138: 548-549$

Mitasova, H. and L. Mitas (1993). Interpolation by regularized spline with tension: I. theory and implementation, Mathematical Geology, 25(6):641-655

Mitasova, H. and J. Hofierka (1993). Interpolation by regularized spline with tension: II. application to terrain modeling and surface geometry analysis, Mathematical Geology, 25:657-667

Mitchell, S.W., F. Csillag and C. Tague (2005). Impacts of spatial partitioning in hydroecological models: predicting grassland productivity with RHESSys, Transactions in GIS, 9(3): 421-442

Moore, I.D., G.J. Burch and D.H. Mackenzie (1988). Topographic effects on the distribution of surface soil water and the location of ephemeral gullies, ASAE, 31:10981107

Moore, R.D. and J.C. Thompson (1996). Are water table variations in a shallow forest soil consistent with the TOPMODEL concept? Water Resources Research, 32:663-669

Nadian, H., S.E. Smith, A.M. Alston and R.S. Murray (1997), Effects of soil compaction on plant growth, phosphorus uptake and morphological characteristics of vesciulararbuscular mycorrhizal colonization of Trifolium subterraneum, The New Phytologist, $135: 303-311$

Neteler, M. and H. Mitasova (2004). Open source GIS: a grass GIS approach $-2^{\text {nd }}$ edition, Kluwer Academic Publishers, 401pp

Neteler, M. and H. Mitasova (2008). Open source GIS: a grass GIS approach $-3^{\text {rd }}$ edition, Springer Press, 406pp

Nyberg, L. (1996). Spatial variability of soil water content in the covered catchment at Gardsjon, Sweden, Hydrological Processes, 10:89-103

Ojima, D.S., W.J. Parton, M.B. Coughenor, J.M.O. Scurlock, T.B. Kirchner, T.G.F. Kittel, D.O. Hall, D.S. Schimel, E.G. Moya, T.G. Gilmarov, T.R. Seastedt, A. Kamnalrut, J.I. Kinyamario, S.P. Long, J-C. Menaut, O.E. Sala, R.J. Scholes and J.A.v. Veen, (1996). Impact of climate and atmospheric carbon dioxide changes on grasslands of the world. In: D.O.H. A.I. Breymeyer, J.M. Melillo, and G.I. Ågren (Editor), Global Change: Effects on Coniferous Forests and Grasslands, John Wiley \& Sons, pp. 271-311

Onset Computer Corporation (2007). Soil Moisture Smart Sensors (S-SMx-M005), Document \# 11426-A Available at: http://www.microdaq.com/occ/documents/ssmc_manual.pdf 
Parks Canada (2002). GNP of Canada management plan, Parks Canada, Western Canada Service Centre, 79pp.

Parks Canada (2003). Daily Weather Data, Val Marie, GNP, 1994 - 2003, [Microsoft Excel Data files]

Parks Canada (2005a). Parks Canada - GNP of Canada - weather, Last Updated 2008-1022, Available at: http://www.pc.gc.ca/pn-np/sk/grasslands/visit/visit3_E.asp

Parks Canada (2005b). [GNP Holdings (as of 2002) and Roads] [map], 1:2,300,000 approx. Grasslands National Park Map Files [ESRI Shapefiles] Parks Canada, 2005, Using: ArcMap [GIS Software], Version 9.2, ESRI, 1999-2006

Parks Canada (2005c). [GNP Roads] [map], 1:295,000 approx. Grasslands National Park Map Files [ESRI Shapefiles] Parks Canada, 2005, Using: ArcMap [GIS Software], Version 9.2, ESRI, 1999-2006

Park, S.J., K. McSweeney and B. Lowery (2001). Identification of the spatial distribution of soils using a process-based terrain characterization, Geoderma, 103:249-272

Parton, W.J., M.B. Coughenor, J.M.O. Scurlock, D.S. Ojima, T.G. Gilmanov, R.J. Scholes, D.S. Schimel, T.B. Kirchner, J-C. Menaut, T.R. Seastedt, E.G. Moya, A. Kamnalrut, J.I. Kinyamario and D.O. Hall (1996). Global grassland ecosystem modelling: development and test of ecosytem models for grassland systems. In: A.I. Breymeyer, D.O. Hall, J.M. Melillo and G.I. Ågren (Editors), Global Change: Effects on Coniferous Forests and Grasslands, John Wiley \& Sons, pp. 229-269

Paruelo, J.M., W.K. Lauenroth, I.C. Burke and O.E. Sala (1999). Grassland precipitationuse efficiency varies across a resource gradient, Ecosystems, 2:64-68

Pennock, D.J., F. Walley, M. Solohub, B.C. Si and G. Hnatowich (2001).

Topographically controlled yield response of canola to nitrogen fertilizer, Soil Science Society of America Journal, 65:1838-1845

Pomeroy J.W., and D.M. Gray (1994). Sensitivity of snow relocation and sublimation to climate and surface vegetation. In: Snow and Ice Covers: Interactions with Atmosphere and Ecosystems, Jones HG Davies TD Ohmura A, Morris EM (eds). IAHS Publication No. 223. IAHS Press: Wallingford, UK, 213-226

Pomeroy J.W., and D.M. Gray (1995). Snowcover accumulation, relocation and management. NHRI Science Report No. 7, Environment Canada, Saskatoon, 144

Pomeroy, J.W., D.M. Gray, and P.G. Landine (1993). The prairie blowing snow model: characteristics, validation, operation, Journal of Hydrology, 144:165-192 
Rhoades, C.C., S.L. Brosi, A.J. Dattilo and P. Vincelli (2003). Effect of soil compaction and moisture on incidence of phytopthora root rot on American chestnut (Castanea dentata) seedlings, Forest and Ecology Management, 184:47-54

Roberts, M.J., S.P. Long, L.L. Tieszen and C.L. Beadle (1993). Measurement of plant biomass and net primary production, pp. 1-21, In: Photosynthesis and Production in a Changing Environment: a Field and Laboratory Manual (eds Hall DO et al.), Chapman \& Hall, London, 464pp.

Rose, R. (2001). FOR 442 - Silviculture: Reforestation, College of Forestry, Oregon State University, Last Updated 2001, Available at:

http://www.cof.orst.edu/cof/teach/for442/glossary/gloss 1.htm

Sala, O.E., and W.K. Lauenroth (1985). Root profiles and the ecological effect of rainshowers in arid and semiarid regions, American Midland Naturalist, 114(2):406-408

Sala, O.E., W.J. Parton, L.A. Joyce and W.K. Lauenroth (1988). Primary production of the central grassland region of the United States, Ecology, 69(1):40-45

Scurlock, J.M.O., K. Johnson and J. Olson (2002). Estimating net primary productivity from grassland biomass dynamics measurements, Global Change Biology, 8:736-753

Si, B.C. and R.E. Farrell (2004). Scale-dependent relationship between wheat yield and topographic indices: a wavelet approach, Soil Science Society of America Journal, 68:577-587

Sinai, G., D. Zaslavsky and P. Golan (1981). The effect of soil surface curvature on moisture and yield - beer sheba observation, Soil Science, 132:367-375

Singh,J.S., D.G. Milchunas, and W.K. Lauenroth, (1998). Soil water dynamics and vegetation patterns in a semiarid grassland, Plant Ecology, 134:77-89

Sorensen R., U. Zinko, and J. Seibert (2005). On the calculation of the topographic wetness index: evaluation of different methods based on field observations, Hydrology and Earth System Sciences, 10, 101-112

Sulebak, J.R., L.M. Tallaksen, and B. Erichsen (2000). Estimation of areal soil moisture by use of terrain data. Geografiska Annaler: Series A, Physical Geography, 82(A)(1):89105

Tague, C.L. and L.E. Band (2004). RHESSys: Regional hydro-ecologic simulation system - an object-oriented approach to spatially distributed modeling of carbon, water, and nutrient cycling, Earth Interactions, 8(19):1-42

Tague, C.T., L. Band, S.E. Brun, R. Fernandes and D. Tenenbaum (2001). Regional hydroecological simulation system: RHESSys user's manual, Version 5.4 
Theirfelder, T.K., R.B. Grayson, D. von Rosen and A.W. Western (2003). Inferring the location of catchment characteristic soil moisture monitoring sites. Covariance Structures in The Temporal Domain, Journal of Hydrology, 280:13-32

Timlin, D., Y. Pachepsky, V.A. Snyder and R.B. Bryant (1998). Spatial and temporal variability of corn yield on a hillslope, Soil Science Society of America Journal, 62:764773

University of Saskatchewan (1991). [Soils_project] [map], 1:3,200 approx. Saskatchewan Institute of Pedology, 1991 [ESRI Shapefiles], Using: ArcMap [GIS Software], Version 9.2, ESRI, 1999-2006

Virk, R. (2008). Unpublished data, in preparation for doctoral thesis, Department of Geography and Environmental Studies, Carleton University, Ottawa, Ontario, Canada

Walker, B.H. and J.L. Langridge (1996). Modelling plant and soil water dynamics in semi-arid ecosystems with limited site data, Ecological Modelling, 87(1-3):153-167

Webb, W.L., S. Szarek, W. Lauenroth, R. Kinerson, and M. Smith (1978). Primary productivity and water use on native forest, grassland and desert ecosystems, Ecology, 59:1239-1247

Webb, W.L., W.K. Lauenroth, S.R. Szarek, and R.S. Kinerson (1983). Primary production and abiotic controls in forests, grasslands and desert ecosystems in the United States, Ecology, 64:134-151

Western, A.W. and R.B. Grayson (1998). The Tarrawarra data set: soil moisture patterns, soil characteristics, and hydrological flux measurements, Water Resources Research, 34(10):2765-2768

Western, A.W., R.B. Grayson, G. Bloschl, G.R. Willgoose and T.A. McMahon (1999). Observed spatial organization of soil moisture and its relation to terrain indices, Water Resources Research, 35(3):797-819

Western, A.W. and G. Bloschl (1999). On the spatial scaling of soil moisture, Journal of Hydrology, 217:203-224

Western, A.W., S. Zhou, R.B. Grayson, T.A. McMahon, G. Bloschl and D.J. Wilson (2004). Spatial correlation of soil moisture in small catchments and its relationship to dominant spatial hydrological processes, Journal of Hydrology, 286:113-134

Wigmosta, M.S., L.W. Vail and D.P. Lettenmaier (1994). Distributed hydrologyvegetation model for complex terrain. Water Resources Research, 30(6):1665-1679

Wilson, D.J., A.W. Western, R.B. Grayson, A.A. Berg, M.S. Lear, M. Rodell, J.S. Famiglietti, R.A. Woods and T.A. McMahon (2003). Spatial distribution of soil moisture 
over 6 and $30 \mathrm{~cm}$ depth, Mahurangi river catchment, New Zealand, Journal of Hydrology, 276:254-274

Wilson, D.J., A.W. Western and R.B. Grayson (2005). A terrain and data-based method for generating the spatial distribution of soil moisture, Advances in Water Resources, 28:43-54

Wolock, D.M., G.M. Hornberger, K.J. Beven and W.G. Campbell (1989). The relationship of catchment topographic and soil hydraulic characteristics to lake alkalinity in the northeastern United States: Water Resources Research, 25(5):829-837.

Wyseure, G.C.L., M.A. Mojid and M.A. Malik (1997) Measurement of volumetric water content by TDR in saline soils, European Journal of Soil Science, 48(2):347-354

Yang, C., C.L. Peterson, G.J. Shropshire and T. Ottawa (1998). Spatial variability of field topography and wheat yield in the Palouse region of the pacific northwest, $A S A E, 41: 16-$ 27

Zavlasky, D. and G. Sinai (1981). Surface hydrology I. explanation of phenomena, Journal of Hydraulic Engineering Division, American Society of Civil Engineers, 107:116

Zeleke, T.B. and B.C. Si (2004). Scaling properties of topographic indices and crop yield: multifractal and joint multifractal approaches, Agronomy Journal, 96:1082-1090 


\section{APPENDIX A - Soil Survey Class Attributes}

\begin{tabular}{|c|c|}
\hline Description: & soil cover for GNP \\
\hline Topology: & polygon \\
\hline Projection: & UTM zone 13 \\
\hline Datum: & NAD27 \\
\hline Date: & Digitized during the fall of 1992 \\
\hline Source: & $\begin{array}{l}\text { Survey done by the Saskatchewan Institute of Pedology (U of S) in May } 1991 . \\
\text { Digitized at the Centre for GIS, U of R. }\end{array}$ \\
\hline Note: & $\begin{array}{l}\text { soil dataset covers those areas owned by the park. For more information refer to } \\
\text { 'Grasslands National Park Soil Survey' Report }\end{array}$ \\
\hline
\end{tabular}

\section{Attributes:}

- $\quad$ unique (unique identifier)

- mapunit (soil association has been used to name soils that have been formed in a similar geological deposit with in a particular soil zone). This attribute contains a large number of unique values. Therefore, it is not described in this report.

- $\quad$ slope (slope class)

$1=0-0.5 \%$ nearly level

$2=0.5-2 \%$ very gentle slopes

$3=2-5 \%$ gentle slopes

$4=5-10 \%$ moderate slopes

$5=10-15 \%$ strong slopes

$6=15-30 \%$ steep slope

$7=30-45$ very steep slopes

- Idfrm (landform)

$$
\begin{aligned}
& a=\text { apron } \\
& f=\text { fan } \\
& h=\text { hummocky } \\
& l=\text { inclined } \\
& \text { l = level } \\
& m=\text { rolling } \\
& r=\text { ridged } \\
& t=\text { terraced } \\
& u=\text { undulating } \\
& \text { Erosional Modifiers } \\
& c=\text { channeled } \\
& d=\text { dissected } \\
& g=\text { gullied }
\end{aligned}
$$

- $\quad$ texture (soil texture)

$$
\begin{aligned}
& \text { gs = gravelly sand } \\
& \mathrm{s}=\text { sand } \\
& \text { gls = gravelly loamy sand } \\
& \text { Is = loamy sand } \\
& \text { Ifs = loamy fine sand }
\end{aligned}
$$

Salinity (development salinity degree). The soil salinity symbol is made up of 3 components indicating the extent of saline soils. For example;

1WPA corresponds to:

1 - extent class

W - degree class

PA - landscape position

Salinity Extent Class Limits:

$0=0 \%$ of area affected $1=0-3 \%$ of area affected $2=3-10 \%$ of area affected $3=10-20 \%$ of area affected $4=20-40 \%$ of area affected 
Soil Salinity Degree:

nonsaline $=0-2$ [electrical conductivity of $0-60 \mathrm{~cm}$. depth $\left(\mathrm{m}^{\mathrm{s}} / \mathrm{cm}\right)$ ]. There are no visible effects of salt on the growth of crops. No yield loss.

(W) weak $=2-4$ [electrical conductivity of $0-60 \mathrm{~cm}$. depth $\left(\mathrm{m}^{\mathrm{s}} / \mathrm{cm}\right)$ ]. Yields of very sensitive crops may be restricted. Cereals are generally unaffected.

(M) moderate $=4-8$ [electrical conductivity of 0-60 cm. depth $\left.\left(\mathrm{m}^{\mathrm{s}} / \mathrm{cm}\right)\right]$. Yields of many crops are restricted. Wheat yields may be reduced by $30 \%$.

(S) strong $=8-16$ [electrical conductivity of 0-60 cm. depth $\left.\left(\mathrm{m}^{\mathrm{s}} / \mathrm{cm}\right)\right]$. Only tolerant crops yield satisfactorily. Wheat yields may be reduced by $60 \%$.

(V) very strong $=16+$ [electrical conductivity of $0-60 \mathrm{~cm}$. depth $\left(\mathrm{m}^{\mathrm{s}} / \mathrm{cm}\right)$ ]. Only tolerant crops yield satisfactorily. Wheat yields may be reduced by $80-100 \%$.

Landscape Position:

$\mathrm{P}=$ Saline soils occur on the edges of depressions, sloughs or runways. All soils in the bottoms of depressions are leached and nonsaline.

$A=$ Saline soils occur throughout the bottoms of depressions and sloughs.

$\mathrm{D}=$ Saline soils extend throughout the bottoms of dissections and small runways.

$\mathrm{S}=$ Saline soils occurs on the sides of hills and slopes well above any slough or depression.

I = Saline soil parent materials within $60 \mathrm{~cm}$. of the soil surface generally occur on knolls and upper slopes.

- $\quad$ stones (stones rating)

$$
\begin{aligned}
& 0=\text { nonstony } \\
& 1=\text { slightly stony } \\
& 2=\text { moderately stony } \\
& 3=\text { very stony } \\
& 4=\text { exceedingly stony } \\
& 5=\text { excessively stonly } \\
& U=\text { unclassified }
\end{aligned}
$$

- $\quad$ acidity (surface $\mathrm{pH}$ )

$X=$ less than 5.5 (moderately acid)

$A=5.5$ to 6.0 (slightly acid)

$B=6.1$ to $6.7 \quad$ (slightly acid to neutral)

$\mathrm{C}=6.8$ to 7.5 (neutral to slightly alkaline)

$\mathrm{D}=$ greater than 7.5 (alkaline)

$$
\begin{aligned}
& \mathrm{X} 1=\mathrm{X} 5 \mathrm{~A} 3 \mathrm{~B} 2 \\
& \mathrm{~A} 0=\mathrm{A} 5 \mathrm{~B} 5 \\
& \mathrm{~A} 1=\mathrm{A} 7 \mathrm{~B} 2 \mathrm{C} 1 \\
& \mathrm{~A} 2=\mathrm{A} 5 \mathrm{~B} 2 \mathrm{C} 3 \\
& \mathrm{~A} 3=\mathrm{A} 3 \mathrm{~B} 4 \mathrm{C} 3 \\
& \mathrm{~A} 4=\mathrm{A} 3 \mathrm{~B} 3 \mathrm{C} 3 \mathrm{D} 1 \\
& \mathrm{~B} 0=\mathrm{B} 7 \mathrm{~A} 2 \mathrm{C} 1 \\
& \mathrm{~B} 1=\mathrm{B} 4 \mathrm{C} 4 \mathrm{~A} 2 \\
& \mathrm{~B} 2=\mathrm{B} 7 \mathrm{C} 3 \\
& \mathrm{~B} 3=\mathrm{B} 5 \mathrm{C} 5 \\
& \mathrm{~B} 4=\mathrm{B} 6 \mathrm{C} \text { D1 } \\
& \mathrm{B} 5=\mathrm{B} 7 \mathrm{~A} 3 \\
& \mathrm{C} 1=\mathrm{C} 5 \mathrm{~B} 4 \mathrm{D} 1 \\
& \mathrm{C} 2=\mathrm{C} 7 \mathrm{~B} 3 \\
& \mathrm{C} 3=\mathrm{C} 7 \mathrm{~B} 2 \mathrm{D} 1 \\
& \mathrm{C} 4=\mathrm{C} 9 \mathrm{D} 1 \\
& \mathrm{C} 5=\mathrm{C} 5 \mathrm{~B} 2 \mathrm{D} 3 \\
& \mathrm{C} 6=\mathrm{C} 7 \mathrm{D} 3 \\
& \mathrm{C} 7=\mathrm{C} 6 \mathrm{D} 4 \\
& \mathrm{D} 1=\mathrm{D} 5 \mathrm{C} 5 \\
& \mathrm{D} 2=\mathrm{D} 7 \mathrm{C} 3 \\
& \mathrm{D} 3=\mathrm{D} 9 \mathrm{C} 1 \\
& \mathrm{D} 4=\mathrm{D} 5 \mathrm{C} 3 \mathrm{~B} 3
\end{aligned}
$$

Percent Surface $\mathrm{pH}$ class:

For example: SYMBOL B1 = B4C4A2 means:

$\mathrm{B} 4$ - $40 \%$ of surface area has a $\mathrm{pH}$ in the "B" range (6.1-6.7)

C4 - $40 \%$ of surface areas has a $\mathrm{pH}$ in the "C" range (6.8-7.5)

A2 - $20 \%$ of surface areas has a $\mathrm{pH}$ in the "A" range (5.5-6.0) 
- $\quad$ pasteros (past wind and water erosion)

$\mathrm{U}=$ Unclassified

W0 $=$ Unaffected. No evidence of past wind or water erosion.

$\mathrm{W} 1=$ Weak. Soils are slightly eroded.

$\mathrm{W} 1 \mathrm{~K}=$ The knolls have slightly thinner horizons and are lighter in color than

midslopes. There is no noticeable thickening of the surface horizon on mid to lower

slope.

$\mathrm{W} 1 \mathrm{~B}=$ Wind has removed part of the soil resulting in thinner $\mathrm{A}$ horizons. There is

very little mixing of the $A$ and $B$ horizons and little sign of soil accumulation on mid and lower slopes.

$W 1 G=A$ few very shallow dissections are present indicating very slight evidence of water erosion

$\mathrm{W} 2$ = Moderate. soils are moderately eroded.

$\mathrm{W} 2 \mathrm{~K}=$ Eroded knolls make up 5-15\% of the area. The knolls are much lighter in color than midslopes. There is not a thickening of the surface horizon on lower slopes due to accumulation of upper slope material.

$\mathrm{W} 2 \mathrm{~B}=$ Wind has removed part of the $\mathrm{A}$ horizon resulting in moderately thin $\mathrm{A}$ horizon. There is slight mixing of $A$ and $B$ during tillage and some evidence of accumulation near fencelines and windbreaks.

$\mathrm{W} 2 \mathrm{G}=$ Shallow dissections are present. The dissections may easily be crossed by farm implements and have little effect cultivation. There is evidence of rill erosion (small channels a few centimetres deep, occurring after substantial rains or snowmelt).

$\mathrm{W} 3$ = Strong. Soils are strongly eroded.

$\mathrm{W} 3 \mathrm{~K}=$ Eroded knolls make up $15-40 \%$ of the area. The knolls are much lighter in color than

midslopes. A large portion of the A horizon has been removed and redistributed to lower slopes. On knolls, subsoil has been incorporated into the cultivated horizon.

W3B $=$ Wind has removed a significant amount of the A horizon. Regular tillage results in a thorough mixing of the $B$ horizon with the remaining $A$ horizon. Accumulation of wind-blown material occurs along fencelines and windbreaks.

W3G = District dissections are present. The dissections may be crossed by farm implements with some difficulty, and have a moderate effect on cultivation. These dissections should be seeded to grass to prevent further damage from erosion.

$\mathrm{W} 4=$ Severe. Soils are severely eroded.

$\mathrm{W} 4 \mathrm{~K}=$ Eroded knolls make up $40-70 \%$ of the area. The eroded knolls are white in color, with light colors extending well onto the midslope position. Erosion has destroyed the soil profile on upper slopes.

$\mathrm{W} 4 \mathrm{~B}=$ Wind has removed most of the $\mathrm{A}$ horizon and frequently part of the $\mathrm{B}$ horizon. Occasional blowout areas are present, creating a very unstable surface.

$\mathrm{W} 4 \mathrm{G}=$ Occasional shallow gullies are present. The gullies cannot be crossed by farm implements, and therefore, should not be cultivated for annual cropping. Reclamation for improved pastures is difficult unless erosion can be controlled.

$\mathrm{W} 5=$ Very Severe. soils are very severely eroded.

W5K = Eroded knolls make up greater than $70 \%$ of the area. The knolls and midslopes are white in color. Erosion has destroyed the soil profile on upper and midslope positions.

$\mathrm{W} 5 \mathrm{~B}=$ Wind has removed most of the soil profile. Blowout holes are numerous and easily carved into the subsoil or parent material. Areas between blowouts are deeply buried by eroded soil material. At best, this land should be utilized for native or improved pasture.

$W 5 G=$ Deep gullies occur frequently. Soil profiles have been destroyed except in small areas between gullies. These areas should be permanently. Reclamation of eroded areas is a different process.

- $\quad$ primcamp (degree of overall limitations for primitive campground use)

$\mathrm{PC7}=$ not feasible

PC6 $=$ very severe

$\mathrm{PC5}=$ severe

PC4 $=$ moderate

$\mathrm{PC} 3=$ some

$\mathrm{PC2}=$ slight

$\mathrm{PC} 1=$ not limitation

$\mathrm{N}=$ not rated

- hetrails (capability classes for hiking equestrian trails)

$$
\begin{aligned}
& \text { HE7 }=\text { not feasible } \\
& \text { HE6 }=\text { very severe } \\
& \text { HE5 }=\text { severe } \\
& \text { HE4 }=\text { moderate } \\
& \text { HE3 }=\text { some } \\
& \text { HE2 }=\text { slight } \\
& \text { HE1 }=\text { no limitations } \\
& \mathrm{N}=\text { not rated }
\end{aligned}
$$


- $\quad$ transport (degree of overall limitation for transportation corridor use)

$$
\begin{aligned}
\text { TC7 } & =\text { not feasible } \\
\text { TC6 } & =\text { very severe } \\
\text { TC5 } & =\text { severe } \\
\text { TC4 } & =\text { moderate } \\
\text { TC3 } & =\text { some } \\
\text { TC2 } & =\text { slight } \\
\text { TC1 } & =\text { no limitation } \\
\mathrm{N} & =\text { not rate }
\end{aligned}
$$

- $\quad$ picnic (capability classes for picnic areas)

$$
\begin{aligned}
& \text { PA7 }=\text { not feasible } \\
& \text { PA6 }=\text { very severe } \\
& \text { PA5 }=\text { severe } \\
& \text { PA4 }=\text { moderate } \\
& \text { PA3 }=\text { some } \\
& \text { PA2 }=\text { slight } \\
& \text { PA1 }=\text { no limitation } \\
& \mathrm{N}=\text { not rated }
\end{aligned}
$$

- $\quad$ erode (susceptibility classes for erosion)

$$
\begin{aligned}
& \text { ER7 = very high } \\
& \text { ER6 }=\text { high } \\
& \text { ER5 }=\text { moderately high } \\
& \text { ER4 }=\text { moderate } \\
& \text { ER3 = some } \\
& E R 2=\text { slight } \\
& E R 1=\text { no limitation } \\
& N=\text { not rated }
\end{aligned}
$$

